ALABgE CENTRAL BANK BALANCE

2018 SHEET? FLOOR VS CORRIDOR SYSTEMS IN A NEW KEYNESIAN ENVIRONIMENT

o scar Arce Galo Nunno, Dominik thaler and cartos Thomas

Documentos de Trabajo. N. 1851

\title{
BANCODEESPAÑA
}

Eurosistema. 
A LARGE CENTRAL BANK BALANCE SHEET? FLOOR VS CORRIDOR

SYSTEMS IN A NEW KEYNESIAN ENVIRONMENT 


\section{A LARGE CENTRAL BANK BALANCE SHEET? FLOOR VS CORRIDOR SYSTEMS IN A NEW KEYNESIAN ENVIRONMENT ${ }^{*}$}

Óscar Arce, Galo Nuño, Dominik Thaler ${ }^{(*)}$ and Carlos Thomas

BANCO DE ESPAÑA

$\left.{ }^{\star}{ }^{\star}\right)$ The views expressed in this manuscript are those of the authors and do not necessarily represent the views of the European Central Bank or Banco de España. We would like to thank Stéphane Dupraz, Jordi Galí, Morten Ravn, Ricardo Reis and the participants at the 2018 EUl-Banque de France Conference, the 2018 Meeting of the Verein fuer Socialpolitik, the Banque de France Workshop «Monetary Policy and Asset Prices: Lessons from the Crisis and New Tools", the 2017 Econometric Society European Winter Meeting, the 3rd Banco de EspañaCEMFI Workshop, the De Nederlandsche Bank 2017 Annual Research Conference, the 3rd EUI Alumni Conference, the 2017 Workshop of the ECB's MPC Task Force on the Operational Framework, and seminars at CREST-Polytechnique, the Bank of England, the Banco de España and BBVA. All remaining errors are ours. Declarations of interest: none.

$\left.{ }^{(*}\right)$ Corresponding author: dominik.thaler@bde.es. 
The Working Paper Series seeks to disseminate original research in economics and finance. All papers have been anonymously refereed. By publishing these papers, the Banco de España aims to contribute to economic analysis and, in particular, to knowledge of the Spanish economy and its international environment.

The opinions and analyses in the Working Paper Series are the responsibility of the authors and, therefore, do not necessarily coincide with those of the Banco de España or the Eurosystem.

The Banco de España disseminates its main reports and most of its publications via the Internet at the following website: http://www.bde.es.

Reproduction for educational and non-commercial purposes is permitted provided that the source is acknowledged.

C BANCO DE ESPAÑA, Madrid, 2018

ISSN: 1579-8666 (on line) 


\section{Abstract}

The quantitative easing (QE) policies implemented in recent years by central banks have had a profound impact on the working of money markets, giving rise to large excess reserves and pushing down key interbank rates against their floor - the interest rate on reserves. With macroeconomic fundamentals improving, central banks now face the dilemma as to whether to maintain this large balance sheet/floor system, or else to reduce their balance sheet size towards pre-crisis trends and operate traditional corridor systems. We address this issue using a New Keynesian model featuring heterogeneous banks that trade funds in an interbank market characterized by matching frictions. In this environment, balance sheet expansions push market rates towards their floor by slackening the interbank market. A large balance sheet regime is found to deliver ampler "policy space" by widening the steady-state distance between the interest on reserves and its effective lower bound (ELB). Nonetheless, a lean-balance-sheet regime that resorts to temporary but prompt QE in response to recessions severe enough for the ELB to bind achieves similar stabilization and welfare outcomes as a large-balance-sheet regime in which interest-rate policy is the primary adjustment margin thanks to the larger policy space.

Keywords: central bank balance sheet, interbank market, search and matching frictions, reserves, zero lower bound.

JEL classification: E42, E44, E52, G21. 


\section{Resumen}

Las políticas de compra de activos (QE, por sus siglas en inglés) implementadas en los últimos años por los bancos centrales han tenido un impacto profundo en el funcionamiento de los mercados monetarios, dando lugar a un gran exceso de reservas bancarias y presionando los tipos de interés interbancarios contra su suelo: el tipo de interés de las reservas. Con la mejora de los fundamentos macroeconómicos, los bancos centrales ahora se enfrentan al dilema sobre si mantener este «sistema suelo» con un balance grande, o bien reducir el tamaño de su balance a niveles previos a la crisis y operar así un sistema de pasillo de tipos de interés. Abordamos este problema utilizando un modelo neokeynesiano con bancos heterogéneos que se prestan fondos en un mercado interbancario caracterizado por fricciones de emparejamiento. En este entorno, las expansiones del balance del banco central empujan los tipos de mercado a su suelo al aumentar la liquidez en el mercado interbancario. Demostramos que un régimen de balance grande ofrece más «espacio para tipos» al ampliar la distancia entre el tipo de interés de las reservas y su límite inferior ("cota inferior efectiva" o ELB, por sus siglas en inglés). No obstante, un régimen de balance pequeño que recurre a QE temporal pero rápido en casos de recesiones severas logra resultados similares de estabilización y bienestar a un régimen de balance grande en el que los tipos de interés oficiales son el margen de ajuste principal gracias al mayor «espacio para tipos».

Palabras clave: balance del banco central, mercado interbancario, fricciones de búsqueda y emparejamiento, reservas, cota inferior de los tipos de interés.

Códigos JEL: E42, E44, E52, G21. 


\section{Introduction}

The financial crisis and the ensuing Great Recession forced central banks across the industrialized world to put in place quantitative easing (QE) policies that led to a massive increase in the size of their balance sheets. On the liabilities side, balance sheet expansion has taken the form of an unprecedented increase in aggregate excess reserves. In turn, such an increase in excess liquidity has put downward pressure on overnight interbank market rates, to the point that they have been pushed towards their floor - the interest paid on excess reserves by the respective central banks, which has thus become basically the sole determinant of such interbank rates in recent years. This 'large balance sheet regime' or 'floor system' represents a change in paradigm as regards the conduct of monetary policy vis-à-vis the one prevailing before the crisis, characterized by relatively small central bank balance sheets, near-zero aggregate excess reserves, and interbank rates in between the interest rates paid and charged by central banks on excess reserves and on their marginal lending, respectively ('lean balance sheet regime', or 'corridor system').

Figure 1 illustrates these developments for the case of the euro area. Before the crisis, the EONIA - the main index of interest rates on overnight loans in the euro area interbank market remained very close to the middle of the corridor formed by the interest rates of the ECB's deposit and marginal lending facilities. Also, reserves in excess of regulatory requirements were negligible. Following the first large-scale liquidity injections put in place in the context of the recent crisis, the EONIA shifted towards the lower bound of the interest rate corridor, i.e. the deposit facility rate, as excess reserves scaled up to historical highs at that time. The launch of the large-scale asset purchase program in February 2015 consolidated the new large-balance-sheet/floor regime.

As macroeconomic fundamentals slowly but steadily improve across many advanced economies, monetary policy-makers now face the dilemma as to whether to reduce the size of their balance sheets towards pre-crisis trends and return to the corridor system, or else whether to continue operating under the current floor system. This issue has drawn much attention in recent times both in academia and policy circles. ${ }^{1}$ However, formal analyses in the context of well-suited theoretical models are relatively scarce.

In this paper, we propose a relatively simple general equilibrium model designed to compare the stabilization and welfare properties of (a) the pre-crisis lean balance sheet regime and (b) the post-crisis floor system with a large balance sheet. Our framework departs from the standard New Keynesian DSGE model in two key dimensions. First, in order to motivate the existence of an interbank market, we introduce banks that collect deposits from households and have the possibility of lending to nonfinancial firms. Banks receive idiosyncratic shocks to the return that they can expect from the latter investment. As a result, some banks endogenously choose to borrow

\footnotetext{
${ }^{1}$ See e.g. Bernanke (2016) and Bullard (2017).
} 

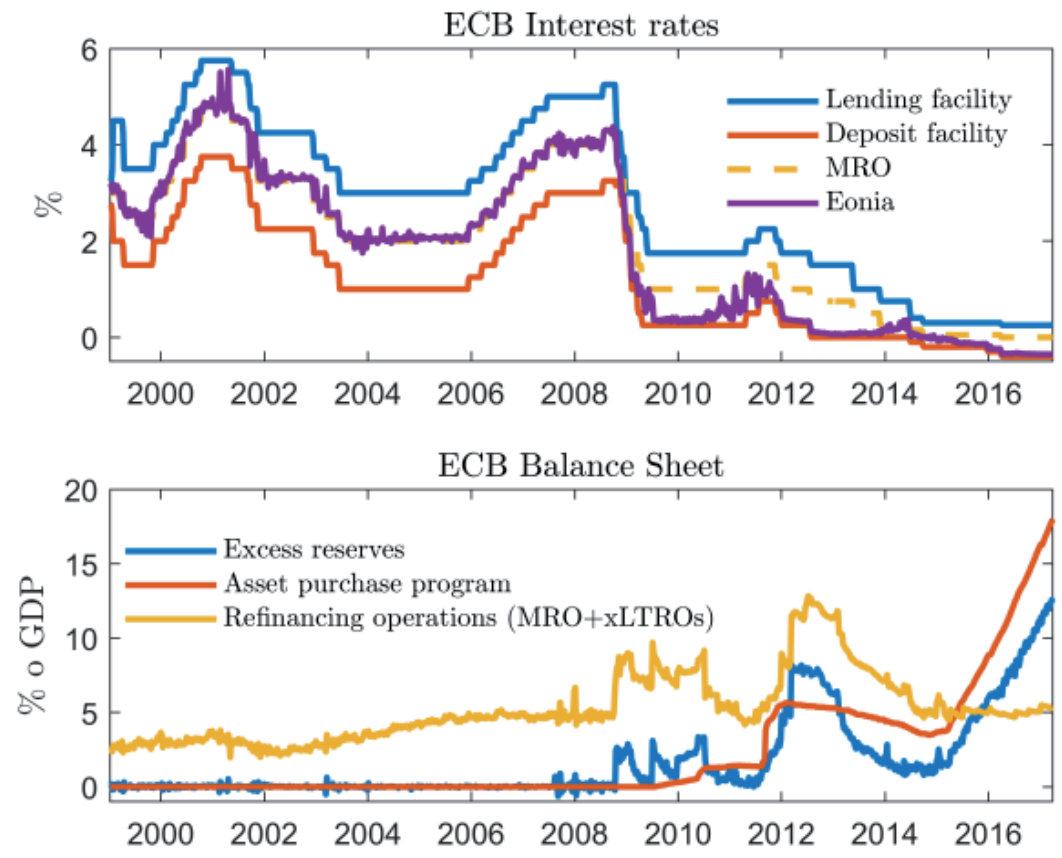

Figure 1: This figure shows the ECB interest rates and its balance sheet since the introduction of the Euro. Excess reserves are both excess reserves in current accounts as well as deposits at the deposit facility.

in the interbank market so as to finance their lending to firms, and some others will choose to lend in the same market or to hold government bonds. ${ }^{2}$ Second, following a recent literature, we capture the bilateral trading nature of the interbank market by assuming that the latter is characterized by search and matching frictions. ${ }^{3}$ Every period, lending and borrowing banks search for each other and, upon matching, trade interbank loans, with the central bank's deposit and lending facilities as the outside option for lending and borrowing banks, respectively. As a result, the equilibrium interbank rate falls inside the interest rate corridor formed by the deposit and lending facility rates. Crucially, its actual position within this corridor is determined by the tightness of the interbank market, i.e. the ratio between demand and supply of interbank funds. In this setup, bank reserves are therefore the residual funds that lending banks are not able to place in the interbank market.

On the analytical front, we show that the size of the central bank's balance sheet plays a key role in determining outcomes in the interbank market. On the assets side, the central bank purchases long-term government bonds and, through its lending facility, provides funding to borrowing banks

\footnotetext{
${ }^{2}$ In particular, our modelling of banks shares many features with Buera and Moll's (2015) modelling of entrepreneurs in a real framework, where the latter receive iid idiosyncratic shocks to the future return on their investments and can borrow from other entrepreneurs subject to an exogenous leverage constraint.

${ }^{3}$ See e.g. Afonso and Lagos (2015), Armenter and Lester (2017), Atkeson, Eisfeldt and Weill (2015), Bech and Monnet (2016), and Bianchi and Bigio (2017).
} 
that fail to find lenders in the interbank market. Its liabilities are banks' reserves at the deposit facility. An expansion of the central bank balance sheet through bond purchases produces ceteris paribus a symmetric fall in banks' bond holdings and a corresponding increase of the amount of funds available for lending to other banks. The resulting slackening in the interbank market improves the market position of borrowing banks and compresses the spread between the interbank rate and the deposit facility rate. We refer to this novel mechanism as the 'interbank transmission channel' of balance-sheet expansions. The interbank market slackening also makes it harder for lending banks to find suitable trading partners, thus forcing them to keep a larger proportion of their excess funds at the deposit facility. Therefore, asset purchases produce both an increase in reserves and a reduction in the gap between interbank rates and the interest on reserves.

We also show analytically that, compared to the lean balance sheet/corridor regime, the large balance sheet/floor regime delivers a steady-state deposit facility rate that is higher and therefore further away from its effective lower bound (ELB). In other words, the floor system allows for ampler 'policy space' for conventional monetary policy in the face of economic downturns. The reason is as follows. In the steady state of our model, real market interest rates are independent of the central bank's balance sheet size - as are nominal market rates, for given inflation target. ${ }^{4}$ As a result, the shrinkage of the spread between the latter rates and the interest on reserves that comes with a floor regime is reflected, not in lower market rates, but in a higher interest on reserves.

On the numerical front, we calibrate our model to the euro area, showing that it replicates well the observed relationship between excess reserves and the spread between the interbank and deposit facility rates since 1999, including both the pre-crisis period - with basically zero excess reserves and a stable spread around $1 \%$, i.e. half of the pre-crisis corridor width - and the recent period characterized by large excess reserves and a near-zero spread.

As mentioned before, our main interest is to compare the stabilization and welfare properties of both monetary policy regimes. We first perform a comparative statics exercise in which we vary the permanent size of the central bank's balance sheet, and show that a larger balance sheet increases steady-state welfare monotonically. This is despite the fact that neither central bank asset purchases per se nor the reserves resulting from these purchases fulfill any socially useful role. The reason is that an expansion of excess reserves and the ensuing slackness in the interbank market raises borrowers' matching probability to the point of essentially eliminating their recourse to the central bank's lending facility. This in turn reduces the central bank's seigniorage, which

\footnotetext{
${ }^{4} \mathrm{As}$ in standard DSGE models, in the steady state of our model the real interest rate that determines the representative household's consumption and saving decisions - here, the real interest earned on its deposits equals its rate of time preference. Under certain conditions, the steady-state interbank rate is exactly equal to the household deposit rate, and is hence independent of the size of the central bank's balance-sheet. More generally, in more complex models (e.g. OLG-models) the steady-state market interest rates may also depend on structural factors other than the rate of time preference. What matters for our argument though is that the steady-state market real rate is independent of monetary policy, as is typically the case in such models.
} 
acts as a distortionary tax on the banking sector as a whole. Nonetheless, quantitatively the welfare gains from moving from a lean- to a large-balance-sheet steady state are negligible, because in the former steady state seigniorage is very limited to begin with.

Turning to stabilization properties, we next analyze the usefulness of different central bank balance sheet regimes under severe recessions in which interest-rate policy is constrained by the ELB, as has been the case across many advanced economies during and after the Great Recession. For this purpose, we consider a crisis scenario driven by an exogenous time preference shock. The shock drives the central bank's deposit facility rate against its ELB, thus preventing further (conventional) monetary accommodation for some time. Against the backdrop of this crisis scenario, and starting from a lean balance sheet, we show that a temporary asset purchase program can reduce the severity of the recession through the above-explained interbank transmission channel: Central bank bond purchases reduce the amount of funds that inactive banks can invest in bonds and hence increases their supply of funds to the interbank market. This slackening of the interbank market in turn pushes rates down, all the way to their floor. Since interbank rates are a key determinant of effective lending and borrowing rates for the real economy, both aggregate economic activity and welfare improve relative to the baseline scenario without asset purchases.

How do these outcomes change in a floor system? As mentioned before, the latter system features higher steady-state interest on reserve and hence more space to cut it before hitting the ELB. We show that in such a regime, a reduction in policy rates in response to the crisis is enough to achieve stabilization outcomes very similar to those of the lean-balance-sheet regime with temporary QE. An important qualification of this result is that, for the latter regime to perform as well as the large-balance-sheet one in the face of a severe shock, the QE measures must be implemented as soon as the ELB would bind in the absence of QE. Indeed, we show that a corridor scenario with delayed QE loses much effectiveness relative to the floor system. Our analysis thus suggests that, in contexts in which the central bank may not be capable of/willing to implement QE policies in a prompt and decisive manner (e.g. due to implementation lags or institutional constraints) when conventional monetary policy exhausts its room for manoeuvre, a floor regime may achieve better stabilization outcomes thanks to the enlarged space for interest-rate policy.

Finally, our baseline analysis assumes for simplicity that balance-sheet policies take the form of bond purchases on the assets side. In the context of a model extension where the central bank can also engage in large-scale credit operations with banks, we show that the expansionary effects of balance sheet policies are essentially the same regardless of whether the central bank provides liquidity by purchasing bonds or through credit operations. ${ }^{5}$ While we do not believe that in

\footnotetext{
${ }^{5}$ Unlike bond purchases, which as explained before free up resources in lending banks' balance sheets and hence increase the supply of interbank funds, central bank credit operations instead reduce borrowing banks' funding needs and hence the demand of interbank funds. But their effect on interbank market tightness is essentially the same, hence the similarity of their effects.
} 
practice both policies are necessarily equally effective or operate through the same channels, we do stress the notion that, insofar as they have similar implications for the liabilities side of the central bank balance sheet, their effects through the specific interbank channel we analyze here should also be similar.

Literature review. Our paper contributes to several strands of literature within the realm of DSGE models of monetary policy transmission. In analyzing the central bank's balance sheet as an instrument of monetary policy, we contribute to a by now large literature, of which Gertler and Kiyotaki (2010, GK10), Gertler and Karadi (2011, GK11 and 2013, GK13), Cúrdia and Woodford (2011, CW) and Chen, Cúrdia and Ferrero (2012, CCF) are some prominent examples. We depart from these important contributions both in terms of modelling and in focus. As regards modelling, unlike in the latter papers (except GK10) we explicitly model the interbank market, which is a key ingredient in our analysis. Unlike in GK10, the interbank market in our framework emerges endogenously as a result of idiosyncratic shocks to the prospective return on banks' investments projects. More importantly for our purposes, our interbank market is characterized by matching frictions, which, as explained before, allows balance sheet policies to endogenously affect the position of interbank (and other) market rates inside the policy rate corridor. In terms of focus, none of the above papers compares the pre-crisis corridor system with the current floor system in a macroeconomic model with both deposit and lending central bank facilities. Furthermore, the mechanism through which balance sheet policies have effects is fundamentally different. In GK11 and GK13, central bank asset purchases reduce excess returns on the acquired assets by relaxing banks' leverage constraints. In CCF, transaction costs and segmented markets allow purchases of long-term government bonds to be effective by compressing term premia. In CW, asset purchases reduce credit spreads both by lowering banks' intermediation costs and by creating reserves which further reduce intermediation costs. ${ }^{6}$ In our setup, by contrast, such policies are effective because, by raising the relative supply of funds in the (frictional) interbank market, they compress the spread between short-term market interest rates and the floor of the interest rate corridor.

In analyzing the transmission of balance-sheet policies in a dynamic model with an endogenous market for interbank loans characterized by matching frictions, our analysis is also related to Bianchi and Bigio (2017, BB). An important difference is how we motivate the existence of the interbank market. As mentioned before, in our framework the interbank market emerges as a result of heterogeneous investment opportunities across banks. In BB, banks instead receive idiosyncratic withdrawal shocks which, coupled with mandatory reserve requirements, lead those banks with excess reserves to lend federal funds to those other banks with liquidity shortfalls. Also, we place our interbank market substructure into an otherwise standard New Keynesian DSGE model, which

\footnotetext{
${ }^{6}$ Ireland (2014) proposes a New Keynesian model where banks' demand for reserves arises due to their role as an input in the production of banking services.
} 
allows us to analyze the extent to which balance sheet policies complement conventional interest rate policies in binding-ELB situations. Finally, our paper largely differs in focus. Bianchi and Bigio (2017) use their framework to study the determinants of the decline in bank lending during the recent financial crisis. By contrast, we focus on the comparison between the lean-balancesheet/corridor system that prevailed before the crisis and the current large-balance-sheet/floor regime (still) prevailing in the largest industrialized economies. ${ }^{7}$

Finally our theory relates to the empirical literature on the effects of balance sheet policies. Most of this literature finds that asset purchases, which go hand in hand with reserve creation, are effective as a monetary policy tool. We do not aim here at summarizing this large and increasing literature. Within the latter, however, we note that the evidence in Christensen and Krogstrup (2018) speaks directly in favour of the transmission channel we model here. They document that even those balance sheet policies which do not withdraw long term assets from the market, but increase the stock of reserves by either reducing the supply of other central bank debt or by purchasing other short term assets, have an impact on market interest rates. ${ }^{8}$ Also related are the empirical findings in Reis (2016), according to which the first QE program in the US was effective at raising expected inflation but subsequent QE rounds were not. As we show in the last section, our model offers a result in a similar vein: a given balance sheet expansion is less effective at stimulating the macroeconomy the higher the starting balance-sheet size is.

\section{Model}

Time is discrete. The economy is composed of households, nonfinancial firms (intermediate-good firms, final-good producers and retailers), banks, the central bank and the government.

\subsection{Households}

The representative household's utility is

$$
\mathbb{E}_{0} \sum_{t=0}^{\infty} \beta^{t}\left[u\left(C_{t}\right)-v\left(L_{t}\right)\right],
$$

\footnotetext{
${ }^{7}$ Armenter and Lester (2017) analyze the current configuration of the US money market setup, with both a reserve facility for banks and a reverse-repo facility for nonbanks, in a two-period, partial equilibrium model with matching frictions. While being very different in modelling and scope, we follow them in assuming competitive search in the money (interbank) market, which allows us to characterize the dependence of the interbank market rate on its tightness in extremely simple terms.

${ }^{8}$ Christensen and Krogstrup (2017) build a simple partial equilibrium model of portfolio balance channels that can account for the reserves-induced effects of QE documented in their empirical work.
} 
where $C_{t}$ is consumption, $L_{t}$ is labor supply and $\beta$ is the household's discount factor. In addition to consuming and supplying labor, households save in the form of bank deposits, the real value of which is denoted by $D_{t}$. They also build new capital goods $K_{t}$ using the technology

$$
K_{t}=\left[1-S\left(\frac{I_{t}}{I_{t-1}}\right)\right] I_{t}+(1-\delta) \Omega_{t-1} K_{t-1},
$$

where $I_{t}$ are final goods used for investment purposes, and $(1-\delta) \Omega_{t-1} K_{t-1}$ is depreciated effective capital repurchased from firms after production in period $t$; in the latter term, $\delta$ is the depreciation rate and $\Omega_{t-1}$ is an effective capital index, to be defined below, which the household takes as given. The function $S$ satisfies $S(1)=S^{\prime}(1)=0$ and $S^{\prime \prime}(1) \equiv \zeta>0$. The budget constraint is

$$
C_{t}+I_{t}+D_{t}=W_{t} L_{t}+\frac{R_{t-1}^{D}}{P_{t} / P_{t-1}} D_{t-1}+Q_{t}^{K}\left[1-S\left(\frac{I_{t}}{I_{t-1}}\right)\right] I_{t}+\sum_{s=R, B} \Pi_{t}^{s}-T_{t}
$$

where $P_{t}$ is the aggregate price level, $R_{t-1}^{D}$ is the riskless gross deposit rate, $W_{t}$ is the real wage, $Q_{t}^{K}$ is the real price of capital goods, $\left\{\Pi_{t}^{s}\right\}_{s=R, B}$ are lump-sum real dividend payments from the household's ownership of retailers $(s=R)$ and banks $(s=B)$, and $T_{t}$ are lump-sum taxes. The first order conditions are standard,

$$
\begin{gathered}
1=\mathbb{E}_{t} \Lambda_{t, t+1} \frac{R_{t}^{D}}{1+\pi_{t+1}}, \quad W_{t}=\frac{v^{\prime}\left(L_{t}\right)}{u^{\prime}\left(C_{t}\right)}, \\
1=Q_{t}^{K}\left[1-S\left(\frac{I_{t}}{I_{t-1}}\right)-S^{\prime}\left(\frac{I_{t}}{I_{t-1}}\right) \frac{I_{t}}{I_{t-1}}\right]+\mathbb{E}_{t} \Lambda_{t, t+1} Q_{t+1}^{K} S^{\prime}\left(\frac{I_{t+1}}{I_{t}}\right)\left(\frac{I_{t+1}}{I_{t}}\right)^{2},
\end{gathered}
$$

where $\Lambda_{t, t+1}=\beta \frac{u^{\prime}\left(C_{t+1}\right)}{u^{\prime}\left(C_{t}\right)}$ is the stochastic discount factor and $\pi_{t} \equiv P_{t} / P_{t-1}-1$ is the inflation rate.

We assume that all private agents in the economy (households, banks, and firms) can save in a non-modelled technology ('mattress' or 'vault') at a net nominal rate $-\kappa$, where $\kappa \geq 0$. Therefore there is an effective lower bound (ELB) on all gross nominal interest rates, given by $1-\kappa$.

\section{$2.2 \quad$ Intermediate good firms}

We assume that intermediate good firms (and banks) are segmented across a continuum of 'islands', indexed by $j \in[0,1]$. The representative firm on island $j$ is perfectly competitive and produces units of the intermediate good, $Y_{t}^{j}$, according to a Cobb-Douglas technology,

$$
Y_{t}^{j}=Z_{t}\left(\omega_{t-1}^{j} K_{t-1}^{j}\right)^{\alpha}\left(L_{t}^{j}\right)^{1-\alpha},
$$


where $Z_{t}$ is an exogenous aggregate total factor productivity (TFP) process, $L_{t}^{j}$ is labor, $K_{t-1}^{j}$ is the pre-determined stock of installed capital, and $\omega_{t-1}^{j}$ is an island-specific shock to effective capital.

The timing is as follows: At the end of period $t-1$ each firm $j$ learns the realization of the shock to next period's effective capital, $\omega_{t-1}^{j}$. These shocks are iid over time and across islands, and have cumulative distribution function $F(\omega)$. At this point each firm needs to install capital on its island, which it buys from the household at unit price $Q_{t-1}^{K}$. In order to finance this purchase, the firm must obtain funding from its local bank. As in Gertler and Kiyotaki (2010) and Gertler and Karadi (2011), we assume that the firm sells to the bank one unit of equity $A_{t-1}^{j}$ per unit of capital acquired: $A_{t-1}^{j}=K_{t-1}^{j}$. Equity is a perfectly state-contingent claim on the future return from one unit of capital and is traded at price $Q_{t-1}^{A, j}$. By perfect competition, the price of the capital good and of equity coincide $\left(Q_{t-1}^{K}=Q_{t-1}^{A, j}\right)$, and therefore $Q_{t-1}^{K} K_{t-1}^{j}=Q_{t-1}^{K} A_{t-1}^{j}$. Finally, at the beginning of period $t$, the firm hires labor and produces.

Each firm $j$ chooses labor in order to maximize operating profits, $P_{t}^{Y} Y_{t}^{j}-P_{t} W_{t} L_{t}^{j}$, subject to (2), where $P_{t}^{Y}$ is the price of the intermediate good. The first order condition with respect to labor implies that the effective capital-labor ratio is equalized across islands,

$$
\frac{\omega_{t-1}^{j} K_{t-1}^{j}}{L_{t}^{j}}=\left(\frac{W_{t}}{M C_{t}(1-\alpha) Z_{t}}\right)^{1 / \alpha},
$$

for all $j$, where $M C_{t} \equiv P_{t}^{Y} / P_{t}$ is the inverse of the average gross markup of final goods prices over the intermediate good price, as explained below. The firm's nominal profits then equal $P_{t}^{Y} Y_{t}^{j}-P_{t} W_{t} L_{t}^{j}=P_{t} R_{t}^{k} \omega_{t-1}^{j} K_{t-1}^{j}$, where

$$
R_{t}^{k} \equiv \alpha M C_{t} Z_{t}\left[\frac{(1-\alpha) M C_{t} Z_{t}}{W_{t}}\right]^{(1-\alpha) / \alpha}
$$

is the common real return on effective capital. After production, the firm sells the depreciated effective capital $(1-\delta) \omega_{t-1}^{j} K_{t-1}^{j}$ to households at unit price $Q_{t}^{K}$. The total real cash flow from the firm's investment project equals the sum of operating profits and proceeds from the sale of depreciated capital,

$$
R_{t}^{k} \omega_{t-1}^{j} K_{t-1}^{j}+(1-\delta) Q_{t}^{K} \omega_{t-1}^{j} K_{t-1}^{j}
$$

Since capital is financed entirely by equity, the cash flow in (4) is paid off entirely to the lending bank. 


\subsection{Banks}

On each island there exists a representative bank. Only the bank on island $j$ has the technology to obtain perfect information about firms on that island, monitor them, and enforce their contractual obligations. ${ }^{9}$ This effectively precludes firms from obtaining funding from other sources, including households or other banks. As indicated before, banks finance firms' investment in the form of perfectly state-contingent debt, $A_{t}^{j}$. After production in period $t+1$, island $j$ 's firm pays the bank the entire cash flow from the investment project,

$$
\left[R_{t+1}^{k}+(1-\delta) Q_{t+1}^{K}\right] \omega_{t}^{j} A_{t}^{j}=\frac{R_{t+1}^{k}+(1-\delta) Q_{t+1}^{K}}{Q_{t}^{K}} \omega_{t}^{j} Q_{t}^{K} A_{t}^{j}
$$

The gross return on the bank's investment in real assets $\left(Q_{t}^{K} A_{t}^{j}\right)$ is thus the product of an aggregate component,

$$
R_{t+1}^{A} \equiv \frac{R_{t+1}^{k}+(1-\delta) Q_{t+1}^{K}}{Q_{t}^{K}},
$$

and an island-specific component, $\omega_{t}^{j}$. Besides investing in the local firm, the bank may borrow or lend funds in the interbank market by means of one-period nominal loans. Let $B_{t}^{+, j}$ and $B_{t}^{-, j}$ denote the real amount borrowed and lent at time $t$, respectively, with $B_{t}^{+, j}, B_{t}^{-, j} \geq 0$. For each unit lent in the interbank market at $t$ the bank receives a noncontingent gross nominal return $R_{t}^{L}$ at period $t+1$, whereas each unit borrowed costs the bank the noncontingent gross nominal rate $R_{t}^{B}$ at $t+1$. Both rates are taken as given by the bank. Later we will see how they are determined. ${ }^{10}$ As of now it suffices to know that in equilibrium $R_{t}^{B} \geq R_{t}^{L}$.

The bank can also purchase nominal long-term Treasury bonds. In particular, we assume that a new bond issued at time $t$ pays $\zeta(1-\zeta)^{s}$ units of currency $s+1$ periods later, for $s \geq 0 .{ }^{11}$ A convenient feature of this specification is that a bond issued $s$ periods ago is equivalent to $(1-\zeta)^{s}$ new bonds, so in each period we need only keep track of the price of one bond cohort. Let $Q_{t}^{G}$ denote the nominal price of a bond issued at time $t$. Hence, the nominal return at the beginning of period $t+1$ on the bank's portfolio of government bonds is

$$
R_{t+1}^{G} \equiv \frac{\zeta+(1-\zeta) Q_{t+1}^{G}}{Q_{t}^{G}}
$$

We denote by $b_{t}^{j, G}$ the real market value of the bank's government bond portfolio at the end of period $t$. Finally, the bank takes a real amount $D_{t}^{j}$ of deposits from the household, which as

\footnotetext{
${ }^{9}$ The costs of these activities for the bank are assumed to be negligible.

${ }^{10}$ In particular, they will both be a function of the monetary policy rates and the actual interbank market rate.

${ }^{11}$ Ever since Woodford (2001), this form of bond with geometrically decaying coupons has become a standard way of modelling long-term nominal government debt in a tractable manner.
} 
mentioned before pay a gross nominal return $R_{t}^{D}$. Combining all these elements, the bank's real net earnings at the start of the following period, denoted by $E_{t+1}^{j}$, will be given by

$$
E_{t+1}^{j}=R_{t+1}^{A} \omega_{t}^{j} Q_{t}^{K} A_{t}^{j}+\frac{R_{t}^{L}}{1+\pi_{t+1}} B_{t}^{-, j}+\frac{R_{t+1}^{G}}{1+\pi_{t+1}} b_{t}^{j, G}-\frac{R_{t}^{D}}{1+\pi_{t+1}} D_{t}^{j}-\frac{R_{t}^{B}}{1+\pi_{t+1}} B_{t}^{+, j} .
$$

In each period $t$ the sequence of events is as follows. The bank starts the period with net earnings $E_{t}^{j}$. We assume that the bank pays a fraction $1-\varsigma \in(0,1)$ of its earnings to households as dividends. The remaining fraction $\varsigma$ is retained as post-dividend equity, denoted by $N_{t}^{j}=\varsigma E_{t}^{j}$. ${ }^{12}$ Following the dividend payment, but before learning the shock to the local firm's capital productivity in the next period $\left(\omega_{t}^{j}\right)$, the bank takes deposits $D_{t}^{j}$ from households. The deposits market then closes, after which the island-specific shock $\omega_{t}^{j}$ is realized. Upon observing it, the bank then chooses how much to invest in the local firm $\left(Q_{t}^{K} A_{t}^{j}\right)$ and in government bonds $\left(b_{t}^{j, G}\right)$, and how much to borrow or lend in the interbank market $\left(B_{t}^{+, j}, B_{t}^{-, j}\right)$, subject to its balance sheet constraint,

$$
Q_{t}^{K} A_{t}^{j}+B_{t}^{-, j}+b_{t}^{j, G}=N_{t}^{j}+D_{t}^{j}+B_{t}^{+, j}
$$

Finally, banks face an exogenous leverage constraint,

$$
Q_{t}^{K} A_{t}^{j} \leq \phi N_{t}^{j}
$$

with $\phi>1 ;^{13}$ and they can not shortsell assets $\left(A_{t}^{j}, B_{t}^{+, j}, b_{t}^{j, G} \geq 0\right)$ or lend negative amounts $\left(B_{t}^{-, j} \geq 0\right)$.

The bank maximizes the expected discounted stream of dividends, $\mathbb{E}_{t} \sum_{t=1}^{\infty} \Lambda_{t, t+s}(1-\varsigma) E_{t+s}^{j}$. The problem can be expressed recursively as a two-stage problem within each period, whereby the bank first chooses deposits and then, after the realization of the idiosyncratic shock, chooses the remaining balance-sheet items,

$$
\begin{gathered}
V_{t}\left(N_{t}^{j}\right)=\max _{D_{t}^{j} \geq 0} \int \bar{V}_{t}\left(N_{t}^{j}, D_{t}^{j}, \omega\right) d F(\omega), \\
\bar{V}_{t}\left(N_{t}^{j}, D_{t}^{j}, \omega_{t}^{j}\right)=\max _{A_{t}^{j} \geq 0, b_{t}^{j, G} \geq 0, B_{t}^{+, j} \geq 0, B_{t}^{-, j} \geq 0} \mathbb{E}_{t} \Lambda_{t+1}\left[(1-\varsigma) E_{t+1}^{j}+V_{t+1}\left(\varsigma E_{t+1}^{j}\right)\right],
\end{gathered}
$$

subject to equations (6), (7) and (8).

\footnotetext{
${ }^{12}$ In equilibrium, this specification is equivalent to assuming that banks do not pay dividends but each period a constant fraction $1-\varsigma$ of randomly selected banks close for exogenous reasons and pay their accumulated net worth to the household as dividends. For models using specifications similar to the latter, see e.g. Gertler and Karadi (2011) and Nuño and Thomas (2017).

${ }^{13}$ We are assuming that government bonds or interbank lending do not enter the leverage constraint in equation (8). This is completely inconsequential. As we show below, in equilibrium the banks for which the leverage constraint binds choose not to invest in bonds or interbank loans. Conversely, the leverage constraint is slack for those banks which choose to invest in bonds or interbank loans.
} 
Next we assume an implicit restriction on parameters, which ensures that in equilibrium the interbank market will be active:

Assumption 1: We assume that parameters are such that the following inequality holds in equilibrium for all $t: D_{t} \leq(\phi-1) N_{t}$.

This condition simplifies the solution of the banks problem, since it avoids additional case distinctions. In our numerical exercises we make sure it is satisfied. ${ }^{14}$ Given this assumption, the solution of the bank's problem is given by the following lemma (proved in Appendix A.1):

Lemma 1 (Bank's problem) The solution to the bank's problem is given by a demand policy for the local firm's assets,

$$
A_{t}^{j}= \begin{cases}\phi N_{t}^{j} / Q_{t}^{K}, & \text { if } \omega_{t}^{j}>\omega_{t}^{B} \\ \left(N_{t}^{j}+D_{t}^{j}\right) / Q_{t}^{K}, & \text { if } \omega_{t}^{L} \leq \omega_{t}^{j} \leq \omega_{t}^{B} \\ 0, & \text { if } \omega_{t}^{j}<\omega_{t}^{L}\end{cases}
$$

and for interbank borrowing,

$$
B_{t}^{+, j}= \begin{cases}(\phi-1) N_{t}^{j}-D_{t}^{j}, & \text { if } \omega_{t}^{j}>\omega_{t}^{B} \\ 0, & \text { if } \omega_{t}^{L} \leq \omega_{t}^{j} \leq \omega_{t}^{B} \\ 0, & \text { if } \omega_{t}^{j}<\omega_{t}^{L}\end{cases}
$$

where

$$
\omega_{t}^{B} \equiv \frac{\mathbb{E}_{t}\left[\tilde{\Lambda}_{t, t+1} R_{t}^{B} /\left(1+\pi_{t+1}\right)\right]}{\mathbb{E}_{t}\left[\tilde{\Lambda}_{t, t+1} R_{t+1}^{A}\right]}, \quad \omega_{t}^{L} \equiv \frac{\mathbb{E}_{t}\left[\tilde{\Lambda}_{t, t+1} R_{t}^{L} /\left(1+\pi_{t+1}\right)\right]}{\mathbb{E}_{t}\left[\tilde{\Lambda}_{t, t+1} R_{t+1}^{A}\right]}
$$

$\tilde{\Lambda}_{t, t+1} \equiv \Lambda_{t, t+1}\left(1-\varsigma+\varsigma \lambda_{t+1}^{N}\right)$ and $\lambda_{t}^{N}$ is the marginal value of equity. Demand for government bonds and interbank lending satisfies

$$
\begin{gathered}
b_{t}^{j, G}=B_{t}^{-, j}=0, \quad \text { if } \omega_{t}^{j} \geq \omega_{t}^{L}, \\
b_{t}^{j, G}+B_{t}^{-, j}=N_{t}^{j}+D_{t}^{j}, \quad\left(b_{t}^{j, G}, B_{t}^{-, j}\right) \geq 0, \text { if } \omega_{t}^{j}<\omega_{t}^{L} .
\end{gathered}
$$

\footnotetext{
${ }^{14}$ Allowing this condition to be violated would introduce a discontinuity in the solution of the model: If the government engages in large enough asset purchases, it eventually may bring the interbank market to collaps as borrowing orders reach 0 . Additional purchases then have no more effect on the model. The solution of the banks problem for the general case is available upon request. Notwithstanding, for our calibration quantitatively it does not matter much whether or not we explicitly account for this satiation point. Even while assumption 1 holds, the marginal effect of asset purchases converges towards zero asymptotically (see Section 3 below). For our calibration this convergence is rather fast: The marginal effect of asset purchases is already very close to 0 long before assumption 1 may be violated.
} 
Banks individual deposit demand satisfies:

$$
D_{t}^{j} \in\left[0,(\phi-1) N_{t}^{j}\right]
$$

The ex-ante return on government bonds and the return on interbank lending satisfy a no-arbitrage condition,

$$
\mathbb{E}_{t}\left(\tilde{\Lambda}_{t, t+1} \frac{R_{t+1}^{G}}{1+\pi_{t+1}}\right)=\mathbb{E}_{t}\left(\tilde{\Lambda}_{t, t+1} \frac{R_{t}^{L}}{1+\pi_{t+1}}\right)
$$

Finally, the nominal deposit rate equals

$$
\begin{aligned}
R_{t}^{D}= & {\left[1-F\left(\omega_{t}^{B}\right)\right] R_{t}^{B}+F\left(\omega_{t}^{L}\right) R_{t}^{L} } \\
& +\left[F\left(\omega_{t}^{B}\right)-F\left(\omega_{t}^{L}\right)\right] \frac{\mathbb{E}\left(\omega \mid \omega_{t}^{L} \leq \omega \leq \omega_{t}^{B}\right) \mathbb{E}_{t}\left[\tilde{\Lambda}_{t, t+1} R_{t+1}^{A}\right]}{\mathbb{E}_{t}\left[\tilde{\Lambda}_{t, t+1} /\left(1+\pi_{t+1}\right)\right]}
\end{aligned}
$$

with $R_{t}^{D} \in\left[R_{t}^{L}, R_{t}^{B}\right]$

The lemma states that, according to their island-specific return realization $\omega_{t}^{j}$, banks endogenously split into the following three groups, illustrated in figure 2 :

- On islands where the local firm draws an idiosyncratic shock above the borrowing threshold $\omega_{t}^{B}$, the local bank borrows from the interbank market so as to invest in the firm up to the leverage constraint.

- Banks that draw an idiosyncratic return below the lending threshold $\omega_{t}^{L}$ lend their resources (equity and deposits) in the interbank market and to the government, with both investments offering the same ex ante return according to equation (12). ${ }^{15}$

- Finally, banks with an idiosyncratic return in between both thresholds do not borrow or lend in the interbank market and simply invest their equity and deposits in the local firm.

This implies that the leverage constraint is always binding for the more productive banks, while it is slack for the less productive ones.

Notice also that, according to equation (13), the unit cost of taking deposits at the beginning of the period - i.e. the deposit rate - equals the expected benefit across realizations of $\omega_{t}^{j}$. For high-profitability banks $\left(\omega_{t}^{j}>\omega_{t}^{B}\right)$ that are leverage-constrained, an additional unit of deposits allows them to reduce their interbank borrowing, thus saving $\frac{R_{t}^{B}}{1+\pi_{t+1}}$. For low-profitability banks

\footnotetext{
${ }^{15}$ Notice that for these banks the demand for government bonds $b_{t}^{j, G}$ versus interbank lending $B_{t}^{-, j}$ is undetermined at the individual level, as both assets are equally profitable ex ante. However, it will be determined at the aggregate level as explained later on.
} 


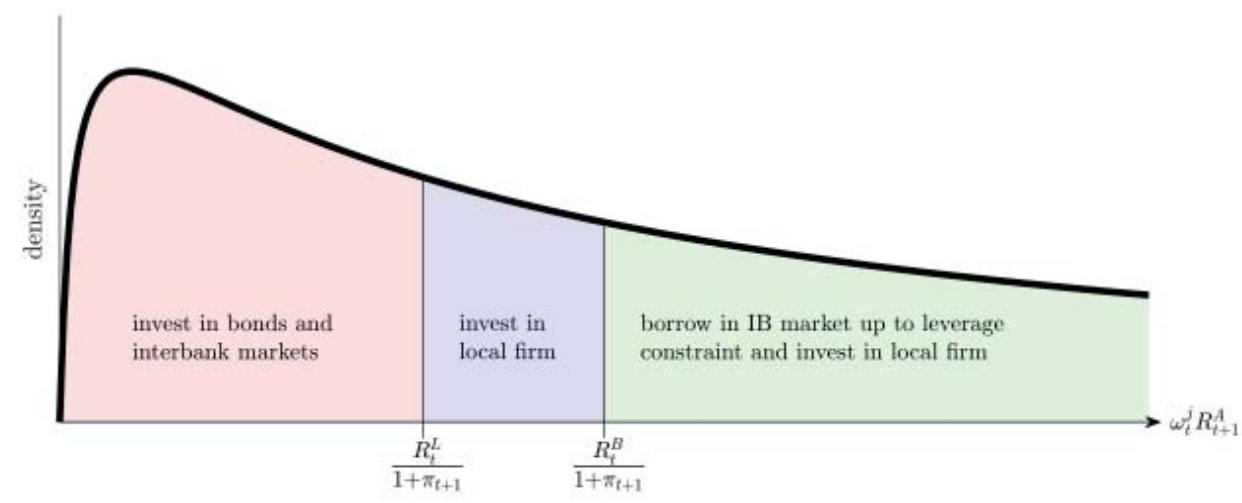

Figure 2: This figure illustrates how banks split into 3 groups according to the return on their island (x-axis). For simplicity we abstract from aggregate uncertainty in this graph.

$\left(\omega_{t}^{j}<\omega_{t}^{L}\right)$, each additional unit of deposits is invested in interbank lending or government bonds, which yields $\frac{R_{t}^{L}}{1+\pi_{t+1}}$. For intermediate-profitability banks $\left(\omega_{t}^{L} \leq \omega_{t}^{j} \leq \omega_{t}^{B}\right)$, each additional unit of deposits is invested in the local firm, with an average idiosyncratic return of $\mathbb{E}\left(\omega \mid \omega_{t}^{L} \leq \omega \leq \omega_{t}^{B}\right){ }^{16}$

\subsection{The interbank market}

The interbank market is modelled as a decentralized, over-the-counter (OTC) market, as in Afonso and Lagos (2012), Armenter and Lester (2017), or Bianchi and Bigio (2017), among many others. Banks that wish to lend place lending orders, whereas banks that wish to borrow place borrowing orders. Lending and borrowing orders are placed on a per-unit basis, as in Atkeson et al. (2012). Borrowing and lending orders then search for each other in an interbank market characterized by search and matching frictions.

We start by determining the volume of borrowing and lending orders. We know from Lemma 1 that banks with $\omega_{t}^{j}>\omega_{t}^{B}$ borrow from other banks in the amount $B_{t}^{+, j}=(\phi-1) N_{t}^{j}-D_{t}^{j} \geq 0$, whereas those with $\omega_{t}^{j}<\omega_{t}^{L}$ lend to other banks in the amount $B_{t}^{-, j}=\left(N_{t}^{j}+D_{t}^{j}\right)-b_{t}^{j, G} \geq 0$. The mass of borrowing and lending orders are thus given respectively by

$$
\begin{gathered}
\Phi_{t}^{B} \equiv \int_{0}^{1} B_{t}^{+, j} d j=\int_{j: \omega_{t}^{j}>\omega_{t}^{B}}\left[(\phi-1) N_{t}^{j}-D_{t}^{j}\right] d j=\left[1-F\left(\omega_{t}^{B}\right)\right]\left[(\phi-1) N_{t}-D_{t}\right] \\
\Phi_{t}^{L} \equiv \int_{0}^{1} B_{t}^{-, j} d j=\int_{j: \omega_{t}^{j}<\omega_{t}^{L}}\left[\left(N_{t}^{j}+D_{t}^{j}\right)-b_{t}^{j, G}\right] d j=F\left(\omega_{t}^{L}\right)\left(N_{t}+D_{t}\right)-b_{t}^{G},
\end{gathered}
$$

\footnotetext{
${ }^{16}$ Since the bank's problem is locally linear in deposits $D_{t}^{j}$, the banks optimality conditions do not pin down the individual amount of deposit taking but instead the equilibrium deposit rate: By equation (13) in equilibrium the bank breaks even ex ante, so it is indifferent between taking one more unit of deposits or not. The only requirement is that all banks satisfy $0 \leq D_{t}^{j} \leq(\phi-1) N_{t}^{j}$.
} 
where $N_{t} \equiv \int_{0}^{1} N_{t}^{j} d j$ is aggregate bank equity, $b_{t}^{G} \equiv \int_{j: \omega_{t}^{j}<\omega_{t}^{L}} b_{t}^{j, G} d j$ are aggregate bank holdings of government bonds, and in each equality with have used the fact that $\omega_{t}^{j}$ is distributed independently from $N_{t}^{j}$ and $D_{t}^{j}$.

Following Armenter and Lester (2017), we assume competitive search in the interbank market. ${ }^{17}$ Our motivation for assuming competitive search is that, as will become clear shortly, it delivers a natural explanation for the observed relationship between excess reserves and the spread between their return and that of short-term interbank claims. The interbank market is divided into many different 'submarkets'. Each submarket is a subset of borrowers and lenders searching for each other. Submarkets differ in the loan rate that is offered to both sides, denoted by $R_{s, t}^{I B}$ for submarket $s$. In each submarket, lending $\left(\Phi_{s, t}^{L}\right)$ and borrowing orders $\left(\Phi_{s, t}^{B}\right)$ are matched according to a common matching function, $\Upsilon\left(\Phi_{s, t}^{L}, \Phi_{s, t}^{B}\right)$. We assume that $\Upsilon$ is $\mathrm{C}^{1}$, weakly increasing and concave in both arguments, naturally satisfies $0 \leq \Upsilon(x, y) \leq \min (x, y)$ and has constant returns to scale. Given constant returns to scale, each lending order finds a borrowing order with probability

$$
\frac{\Upsilon\left(\Phi_{s, t}^{L}, \Phi_{s, t}^{B}\right)}{\Phi_{s, t}^{L}}=\Upsilon\left(1, \frac{\Phi_{s, t}^{B}}{\Phi_{s, t}^{L}}\right) \equiv \Gamma^{L}\left(\frac{\Phi_{s, t}^{B}}{\Phi_{s, t}^{L}}\right),
$$

in which case it earns the interest rate $R_{s, t}^{I B}$; otherwise the unit of funds is deposited at the central bank and earns the deposit facility rate, $R_{t}^{D F}$. Similarly, each borrowing order finds a lending order with probability

$$
\Upsilon \frac{\left(\Phi_{s, t}^{L}, \Phi_{s, t}^{B}\right)}{\Phi_{s, t}^{B}}=\Upsilon\left(\frac{1}{\Phi_{s, t}^{B} / \Phi_{s, t}^{L}}, 1\right) \equiv \Gamma^{B}\left(\frac{\Phi_{s, t}^{B}}{\Phi_{s, t}^{L}}\right),
$$

in which case it pays the interest rate $R_{s, t}^{I B}$; otherwise the unit of funds must be borrowed from the central bank at the lending facility rate, $R_{t}^{L F}$, with $R_{t}^{L F}>R_{t}^{D F}$. Let $\theta_{s, t} \equiv \Phi_{s, t}^{B} / \Phi_{s, t}^{L}$ denote the ratio of borrowing to lending orders in submarket $s$, which we henceforth refer to as interbank (sub)market tightness. Thus, the matching probability for lending (borrowing) orders $\Gamma^{L}\left(\Gamma^{B}\right)$ is increasing (decreasing) in market tightness.

Both borrowers and lenders send their respective orders to the submarkets that maximize their respective values. As shown in Appendix A.2, value maximization with respect to the choice of interbank submarket is equivalent, in the case of lending banks, to maximizing the average return on lending orders,

$$
\Gamma^{L}\left(\theta_{s, t}\right) R_{s, t}^{I B}+\left(1-\Gamma^{L}\left(\theta_{s, t}\right)\right) R_{t}^{D F} \equiv R_{s, t}^{L},
$$

In the case of borrowing banks, the same maximization is equivalent to minimizing the average cost of borrowing orders,

$$
\Gamma^{B}\left(\theta_{s, t}\right) R_{s, t}^{I B}+\left(1-\Gamma^{B}\left(\theta_{s, t}\right)\right) R_{t}^{L F} \equiv R_{s, t}^{B} .
$$

\footnotetext{
${ }^{17}$ The concept of competitive search equilibrium has a long tradition in search theory, starting with the seminal contribution of Moen (1997). See also Mortensen and Pissarides (1999).
} 
Let $R_{t}^{L}$ denote the maximum average return that a lender can obtain in equilibrium. Any submarket that attracts lenders must therefore offer them the average return $R_{t}^{L}$. In other words, the pair $\left(R_{s, t}^{I B}, \theta_{s, t}\right)$ in any submarket that is active in equilibrium must satisfy $R_{s, t}^{L}=R_{t}^{L}$, or

$$
\Gamma^{L}\left(\theta_{s, t}\right) R_{s, t}^{I B}+\left(1-\Gamma^{L}\left(\theta_{s, t}\right)\right) R_{t}^{D F}=R_{t}^{L}
$$

Therefore, in order to accept visiting a submarket that offers a lower rate $R_{s, t}^{I B}$, lenders must be compensated by a higher market tightness $\theta_{s, t}$ and therefore a higher matching probability $\Gamma^{L}\left(\theta_{s, t}\right)$. Subject to (20), borrowers choose the submarket that minimizes their borrowing cost (19) with respect to $R_{s, t}^{I B}$ and $\theta_{s, t} \cdot{ }^{18}$ As shown in Appendix A, the solution to this problem is given by the following interbank rate. ${ }^{19}$

Proposition 1 (Interbank rate) The equilibrium interbank interest rate is given by

$$
R_{t}^{I B}=\varphi\left(\theta_{t}\right) R_{t}^{D F}+\left(1-\varphi\left(\theta_{t}\right)\right) R_{t}^{L F}
$$

where

$$
\varphi\left(\theta_{t}\right) \equiv \frac{d \Gamma^{L}\left(\theta_{t}\right)}{d \theta} \frac{\theta_{t}}{\Gamma^{L}\left(\theta_{t}\right)}=\frac{\partial \Upsilon\left(\Phi_{t}^{L}, \Phi_{t}^{B}\right)}{\partial \Phi_{t}^{B}} \frac{\Phi_{t}^{B}}{\Upsilon\left(\Phi_{t}^{L}, \Phi_{t}^{B}\right)} \in(0,1)
$$

The equilibrium interest rate for matched orders is a weighted average of the respective outside return/cost: the deposit facility rate $R_{t}^{D F}$ for lenders and the lending facility rate $R_{t}^{L F}$ for borrowers, with the weight on the former given by the elasticity of the matching function with respect to the number of borrowing orders, $\varphi\left(\theta_{t}\right)$. Therefore, when the elasticity $\varphi\left(\theta_{t}\right)$ is high, the interbank rate paid by borrowers and earned by lenders is close to the floor of the interest rate corridor. In this regard, $\varphi\left(\theta_{t}\right)$ can be interpreted as the borrowers' share of the joint surplus, defined as the gap between both policy rates.

While the sign of $\varphi^{\prime}\left(\theta_{t}\right)$ depends on the assumed matching technology, it is natural to consider technologies for which $\varphi$, and hence borrowers' surplus share, decreases with the tightness of the

\footnotetext{
${ }^{18}$ As argued by Armenter and Lester (2017), the competitive search paradigm captures salient features of trading activity in interbank markets. Given the repeated interactions, lenders typically have ex ante information about which borrowers pay higher or lower interest rates; moreover, those that offer higher rates typically attract more lenders. Thus, competitive search captures the bilateral and stochastic nature of trading in interbank markets while retaining the link between interest rates and allocations.

${ }^{19}$ In equilibrium, all banks visit the same submarket, characterized by the pair $\left(R_{t}^{I B}, \theta_{t}\right)$ that satisfies equation (21) and $\theta_{t}=\Phi_{t}^{B} / \Phi_{t}^{L}$, with the aggregate amount of borrowing and lending orders, $\Phi_{t}^{B}$ and $\Phi_{t}^{L}$, being determined by equations (14) and (15). Given the equilibrium pair $\left(R_{s, t}^{I B}, \theta_{s, t}\right)=\left(R_{t}^{I B}, \theta_{t}\right)$, lenders' and borrowers' average return, $R_{t}^{L}$ and $R_{t}^{B}$, simply equal the left-hand side of equations (20) and (19), respectively.
} 
interbank market. We shall maintain this assumption from now on. Intuitively, when the ratio between borrowing and lending orders increases, it becomes harder for borrowers to find lenders, so the former must offer rates that are higher and hence closer to the lending facility rate. Conversely, in a slack interbank market with a relative abundance of lending orders, lenders must accept rates that are lower and hence closer to the deposit facility rate.

As indicated above, our assumption of competitive search is motivated by our interest in providing a natural and simple explanation for the downward-sloping relationship between excess reserves and the spread between the interbank rate and the deposit facility rate (DFR) observed in the euro area and other major advanced economies. Indeed, from equation (21) the foregone return from funds deposited at the central bank is given by

$$
R_{t}^{I B}-R_{t}^{D F}=\left(1-\varphi\left(\theta_{t}\right)\right)\left(R_{t}^{L F}-R_{t}^{D F}\right)
$$

As we prove in the next section, in our model there exists an inverse relationship between the amount of excess reserves and interbank market tightness. Thus, an economy with large excess reserves is characterized by a slack interbank market, i.e. by a low $\theta_{t}$. Provided $\varphi^{\prime}<0$, an increase in excess reserves therefore narrows the gap $R_{t}^{I B}-R_{t}^{D F}$ (for a given width of the policy rate corridor, $R_{t}^{L F}-R_{t}^{D F}$ ). In search-theoretic environments an alternative (and relatively more common) approach is to assume random search, instead of competitive search. However, standard formulations of that approach would not deliver the above endogenous relationship between the amount of reserves and the interbank-DFR spread. ${ }^{20}$

Such inverse relationship between the amount of reserves and the spread between their return and that of short-term interbank rates is common in the literature on reserves. In much of that literature, banks hold reserves in order to self-insure against liquidity shocks (as in the classic Poole, 1968, analysis or, more recently, Bianchi and Bigio, 2017) or because it constitutes an essential input to their activities (see Cúrdia and Woodford, 2011, and Ireland, 2014, for recent examples). Instead, in our model banks with relatively poor investment opportunities simply try to pass their reserves on to other banks and earn a higher return along the way; but, as in Afonso and Lagos (2012) and other studies in the search-theoretical literature, search and matching frictions in the interbank market imply that some banks nevertheless end up holding reserves at the end of the period. In reality, both explanations are likely to coexist, that is, banks may wish to hold some reserves because of the liquidity services they provide, but also because frictions in the interbank market prevent them from finding suitable borrowers.

\footnotetext{
${ }^{20}$ In a standard random search setup, each matched borrower-lender pair would negotiate the interbank loan rate à la Nash according to an exogenous bargaining power parameter, $\bar{\varphi}$. The agreed rate would be given by equation (21) with $\bar{\varphi}$ replacing $\varphi\left(\theta_{t}\right)$. The opportunity cost of reserves would then be $(1-\bar{\varphi})\left(R_{t}^{L F}-R_{t}^{D F}\right)$, which is independent of interbank market tightness for a given corridor width. Nonetheless, Bianchi and Bigio (2017) show that, by extending the standard random search setup (with a single search round) to a multiround search environment, one can arrive to similar results, albeit at the cost of additional complexity.
} 


\subsection{Final good producers}

A competitive representative final good producer aggregates a continuum of differentiated retail goods indexed by $i \in[0,1]$ using a Dixit-Stiglitz technology, $Y_{t}=\left(\int_{0}^{1} Y_{i, t}^{(\epsilon-1) / \epsilon} d i\right)^{\epsilon /(\epsilon-1)}$, where $\epsilon>1$ is the elasticity of substitution across retail goods. Cost minimization implies

$$
Y_{i, t}=\left(\frac{P_{i, t}}{P_{t}}\right)^{-\epsilon} Y_{t} \equiv Y_{t}^{d}\left(P_{i, t}\right)
$$

where $P_{t}=\left(\int_{0}^{1} P_{i, t}^{1-\epsilon} d i\right)^{1 /(1-\epsilon)}$ is a price index. Total spending in intermediate inputs then equals $\int_{0}^{1} P_{i, t} Y_{i, t} d i=P_{t} Y_{t}$. Free entry implies zero profits, such that the equilibrium price of the final good is exactly $P_{t}$.

\subsection{Retail goods producers}

We assume that the monopolistic competition occurs at the retail level. Retailers purchase units of the intermediate good firms, transform them one-for-one into retail good varieties, and sell these to final good producers. Each retailer $i$ sets a price $P_{i, t}$ as in the sticky price model of Calvo (1983) taking as given the demand curve $Y_{t}^{d}\left(P_{i, t}\right)$ and the price of the intermediate good, $P_{t}^{y}$. Specifically, during each period a fraction of firms $(1-\theta)$ are allowed to change prices, whereas the other fraction, $\theta$, do not change. Retailers that are able to change prices in period $t$ choose a new optimal price in order to maximize its expected discounted stream of profits,

$$
\max _{P_{i, t}} \sum_{k=0}^{\infty} \theta^{k} \mathbb{E}_{t}\left[\Lambda_{t, t+k}\left(\frac{P_{i, t}}{P_{t+k}}-M C_{t+k}\right)\left(\frac{P_{i, t}}{P_{t+k}}\right)^{-\epsilon} Y_{t+k}\right]
$$

The first-order condition is standard, with all time- $t$ price-setters choosing a common price $P_{t}^{*}$; see Appendix B. The price level $P_{t}$ evolves according to $P_{t}^{1-\epsilon}=\theta P_{t-1}^{1-\epsilon}+(1-\theta)\left(P_{t}^{*}\right)^{1-\epsilon}$.

\subsection{Central Bank}

Interest rate policy. The central bank sets two nominal policy rates: the (gross) deposit facility rate $R_{t}^{D F}$ and the (gross) lending facility rate $R_{t}^{L F}$. We assume that the policy rates are set such that: (i) a constant corridor of width $\chi>0$ is maintained, i.e.

$$
R_{t}^{L F}=R_{t}^{D F}+\chi
$$


and (ii) the central bank's operational target, which we assume to be the interbank rate, achieves a certain target level. ${ }^{21}$ This target level is described by a conventional Taylor rule,

$$
R_{t}^{I B, *}=\rho R_{t-1}^{I B}+(1-\rho)\left(\bar{R}_{s s}+v \pi_{t}\right)
$$

where $\bar{R}_{s s}$ is the steady-state nominal interbank rate, $\rho \in(0,1)$ is the persistence parameter, and $v>1$ determines the response to deviations in net inflation from target (assumed to be zero). Combining equation (21) and (25), we obtain the following relationship between the operational target and the deposit facility rate: $R_{t}^{I B}=R_{t}^{D F}+\left(1-\varphi_{t}\right) \chi$, where $\varphi_{t} \equiv \varphi\left(\theta_{t}\right)$. Using this and the Taylor rule (26), we can then find the deposit facility rate that implements the desired level for the operational target,

$$
R_{t}^{D F, *}=\rho\left[R_{t-1}^{D F}+\left(1-\varphi_{t-1}\right) \chi\right]+(1-\rho)\left(\bar{R}+v \pi_{t}\right)-\left(1-\varphi_{t}\right) \chi
$$

As mentioned before, all gross nominal rates have an ELB given by $1-\kappa \leq 1$. Thus, if $R_{t}^{D F, *}$ is above such ELB, then $R_{t}^{D F}=R_{t}^{D F, *}$ and $R_{t}^{I B}=R_{t}^{I B^{*}}$. But if $R_{t}^{D F, *}$ falls below the ELB, then $R_{t}^{D F}=1-\kappa$ and the central bank must accept a positive deviation of the interbank rate from its target. Therefore, the deposit facility rate equals

$$
R_{t}^{D F}=\max \left\{R_{t}^{D F, *}, 1-\kappa\right\}
$$

with given by (27).

Market rates and the interest rate corridor. It is worthwhile to pause for a moment to take stock of the different market interest rates in our model and where they lie relative to each other inside the interest rate corridor formed by the two policy rates. According to (21), the interbank rate $R_{t}^{I B}$ is a weighted average of the two policy rates $\left(R_{t}^{D F}, R_{t}^{L F}\right)$, being closer to the floor the higher the borrowers' surplus share $\varphi\left(\theta_{t}\right)$. The effective returns on interbank lending and borrowing are given, respectively, by

$$
\begin{aligned}
& R_{t}^{L}=\Gamma^{L}\left(\theta_{t}\right) R_{t}^{I B}+\left(1-\Gamma^{L}\left(\theta_{t}\right)\right) R_{t}^{D F}, \\
& R_{t}^{B}=\Gamma^{B}\left(\theta_{t}\right) R_{t}^{I B}+\left(1-\Gamma^{B}\left(\theta_{t}\right)\right) R_{t}^{L F}
\end{aligned}
$$

i.e. they are weighted averages of the interbank rate and the respective outside-option return $\left(R_{t}^{D F}, R_{t}^{L F}\right)$, with weights that depend on the respective matching probabilities, $\Gamma^{L}\left(\theta_{t}\right) \equiv \Gamma_{t}^{L}$ and

\footnotetext{
${ }^{21}$ Targeting an index of interbank market rates is common among major central banks - e.g. the Federal Funds Rate in the US. We could have alternatively chosen the household discount rate $R_{t}^{D}$ as the central bank's operating target. Our results would have been very similar, because in equilibrium both rates are very close to each other, regardless of the size of the central bank's balance sheet.
} 
$\Gamma^{B}\left(\theta_{t}\right) \equiv \Gamma_{t}^{B}$. Finally, from Lemma 1 the deposit rate lies in between the effective interbank lending and borrowing rates, $R_{t}^{D} \in\left[R_{t}^{L}, R_{t}^{B}\right]$; its position relative to $R_{t}^{I B}$ is in principle ambiguous. Taking all this together, we have the following equilibrium ordering:

Lemma 2 Market $\left(R_{t}^{L}, R_{t}^{I B}, R_{t}^{D}, R_{t}^{B}\right)$ and policy $\left(R_{t}^{D F}, R_{t}^{L F}\right)$ nominal rates satisfy

$$
R_{t}^{D F} \leq R_{t}^{L} \leq R_{t}^{I B}, R_{t}^{D} \leq R_{t}^{B} \leq R_{t}^{L F}
$$

Much of our theoretical analysis in the next sections will be devoted to analyzing how market rates move inside the interest rate corridor $\left(R_{t}^{D F}, R_{t}^{L F}\right)$ as the size of the central bank's balance sheet changes. We turn next precisely to balance-sheet policy.

Balance sheet policy. The central bank also chooses the real market value of its government bond holdings, $b_{t}^{G, C B}$. We assume the latter is determined by the following rule,

$$
b_{t}^{G, C B}=(1-\zeta) b_{t-1}^{G, C B}+\zeta \bar{b}^{G, C B}+n p_{t}+\zeta\left(b_{t-1}^{G, C B}-\bar{b}^{G, C B}\right) r i_{t},
$$

where $n p_{t}$ and $r i_{t} \in\{0,1\}$ are extraordinary real net purchases and extraordinary real reinvestment, which are generally zero. This rule says that, in the absence of extraordinary measures, the central bank keeps the real market value of its bond portfolio fixed at $\bar{b}^{G, C B}$. The real net purchases give the central bank a tool to increase the balance sheet size in extraordinary times, while reinvestment allows the central bank to keep the balanced sheet size fixed for a while after net purchases have been phased out.

The central bank's assets are government bonds, $b_{t}^{G, C B}$, and loans to banks extended by its lending facility, i.e. the mass of borrowing orders that did not find matches in the interbank market: $\Phi_{t}^{B}\left(1-\Gamma_{t}^{B}\right)$. Its liabilities are banks' reserves at its deposit facility, i.e. the mass of interbank lending orders that did not find a match: $\Phi_{t}^{L}\left(1-\Gamma_{t}^{L}\right) \cdot{ }^{22}$ We assume that the central bank accumulates no equity and pays all profits to the government. ${ }^{23}$ The central bank's balance sheet, expressed in real terms, is therefore

$$
b_{t}^{G, C B}+\Phi_{t}^{B}\left(1-\Gamma_{t}^{B}\right)=\Phi_{t}^{L}\left(1-\Gamma_{t}^{L}\right)
$$

Finally, the central bank's real profits are

$$
\Pi_{t}^{C B}=\frac{R_{t}^{G}}{1+\pi_{t}} b_{t-1}^{G, C B}+\frac{R_{t-1}^{L F}}{1+\pi_{t}} \Phi_{t-1}^{B}\left(1-\Gamma_{t-1}^{B}\right)-\frac{R_{t-1}^{D F}}{1+\pi_{t}} \Phi_{t-1}^{L}\left(1-\Gamma_{t-1}^{L}\right) .
$$

\footnotetext{
${ }^{22}$ The monetary base is therefore the nominal amount of reserves at the central bank, $P_{t} \Phi_{t}^{L}\left(1-\Gamma_{t}^{L}\right)$. For convenience, we abstract from cash holdings by banks and households, although nothing of substance for our key insights would change if we allowed for such holdings.

${ }^{23}$ In case of central bank losses, these are assumed to be covered by the Treasury.
} 


\subsection{Government}

The budget constraint of the government expressed in real terms is given by

$$
\bar{b}_{t-1} \frac{R_{t}^{G}}{1+\pi_{t}}=\bar{b}_{t}+T_{t}+\Pi_{t}^{C B}
$$

where $\bar{b}_{t}$ is the real market value of government debt. ${ }^{24}$ Without loss of generality, the latter is assumed to be held constant at a certain level: $\bar{b}_{t}=\bar{b}$.

\subsection{Aggregation, market clearing and equilibrium}

Market clearing for capital requires that total supply by households, $K_{t}$, equals total demand by intermediate firms, $\int_{0}^{1} K_{t}^{j} d j$. Since $K_{t}^{j}=A_{t}^{j}$ on each island $j$ the capital stock $K_{t}$ equals total demand of firms' assets by banks, $\int_{0}^{1} A_{t}^{j} d j$. To calculate the latter, we use Lemma 1, obtaining

$K_{t}=\int_{j: \omega_{t}^{j}>\omega_{t}^{B}} \frac{\phi N_{t}^{j}}{Q_{t}^{K}} d j+\int_{j: \omega_{t}^{j} \in\left[\omega_{t}^{L}, \omega_{t}^{B}\right]} \frac{N_{t}^{j}+D_{t}^{j}}{Q_{t}^{K}} d j=\frac{\phi\left[1-F\left(\omega_{t}^{B}\right)\right] N_{t}+\left[F\left(\omega_{t}^{B}\right)-F\left(\omega_{t}^{L}\right)\right]\left(N_{t}+D_{t}\right)}{Q_{t}^{K}}$,

where in the second equality we have used the fact that $\omega_{t}^{j}$ is independently distributed from $N_{t}^{j}$ and $D_{t}^{j}$.

Labor market clearing requires that household's labor supply $L_{t}$ equals firms' total labor demand, $\int_{0}^{1} L_{t}^{j} d j$. To calculate the latter, we start by using (3) to solve for individual labor demand $L_{t}^{j}$ and we then aggregate across firms: $\int_{0}^{1} L_{t}^{j} d j=\left(\frac{(1-\alpha) Z_{t} M C_{t}}{W_{t}}\right)^{1 / \alpha} \int_{0}^{1} \omega_{t-1}^{j} K_{t-1}^{j} d j$. To solve for $\int_{0}^{1} \omega_{t-1}^{j} K_{t-1}^{j} d j$, we use again Lemma 1 and $K_{t}^{j}=A_{t}^{j}$ to obtain

$$
\begin{aligned}
\int_{0}^{1} \omega_{t}^{j} K_{t}^{j} d j & =\frac{\phi N_{t}}{Q_{t}^{K}} \int_{\omega_{t}^{B}} \omega d F(\omega)+\frac{N_{t}+D_{t}}{Q_{t}^{K}} \int_{\omega_{t}^{L}}^{\omega_{t}^{B}} \omega d F(\omega) \\
& =\frac{\phi N_{t}}{Q_{t}^{K}}\left[1-F\left(\omega_{t}^{B}\right)\right] \mathbb{E}\left(\omega \mid \omega \geq \omega_{t}^{B}\right)+\frac{N_{t}+D_{t}}{Q_{t}^{K}}\left[F\left(\omega_{t}^{B}\right)-F\left(\omega_{t}^{L}\right)\right] \mathbb{E}\left(\omega \mid \omega_{t}^{L} \leq \omega<\omega_{t}^{B}\right)
\end{aligned}
$$

where we have used again the fact that $\omega_{t}^{j}$ is independently distributed from $N_{t}^{j}, D_{t}^{j}$. Using (32), we can express the above equation more compactly as

$$
\int_{0}^{1} \omega_{t}^{j} K_{t}^{j} d j=\Omega_{t} K_{t}
$$

\footnotetext{
${ }^{24}$ The government's real budget constraint can be derived from the nominal budget constraint: $\zeta \bar{B}_{t-1}=$ $\bar{B}_{t}^{\text {new }} Q_{t}^{G}+P_{t}\left(T_{t}+\Pi_{t}^{C B}\right)$, where $\bar{B}_{t}^{\text {new }}=\bar{B}_{t}-(1-\zeta) \bar{B}_{t-1}$ is gross new bond issuance, using also the definition of $R_{t}^{G}$ (equation 5) and $\bar{b}_{t} \equiv \bar{B}_{t} Q_{t}^{G} / P_{t}$.
} 
where

$$
\Omega_{t} \equiv \frac{\phi\left[1-F\left(\omega_{t}^{B}\right)\right] \mathbb{E}\left(\omega \mid \omega \geq \omega_{t}^{B}\right)}{\phi\left[1-F\left(\omega_{t}^{B}\right)\right]+\frac{N_{t}+D_{t}}{N_{t}}\left[F\left(\omega_{t}^{B}\right)-F\left(\omega_{t}^{L}\right)\right]}+\frac{\frac{N_{t}+D_{t}}{N_{t}}\left[F\left(\omega_{t}^{B}\right)-F\left(\omega_{t}^{L}\right)\right] \mathbb{E}\left(\omega \mid \omega_{t}^{L} \leq \omega<\omega_{t}^{B}\right)}{\phi\left[1-F\left(\omega_{t}^{B}\right)\right]+\frac{N_{t}+D_{t}}{N_{t}}\left[F\left(\omega_{t}^{B}\right)-F\left(\omega_{t}^{L}\right)\right]}
$$

is an index of capital efficiency. ${ }^{25}$ Labor market clearing then requires

$$
L_{t}=\left(\frac{(1-\alpha) Z_{t} M C_{t}}{W_{t}}\right)^{1 / \alpha} \Omega_{t-1} K_{t-1}
$$

Aggregate supply of the intermediate good equals $\int_{0}^{1} Y_{t}^{j} d j$. Equations (3) and (35) imply that the effective capital-labor ratio $\omega_{t-1}^{j} K_{t-1}^{j} / L_{t}^{j}$ equals $\Omega_{t-1} K_{t-1} / L_{t}$ for all firms. From equation (2), we then have

$$
\int_{0}^{1} Y_{t}^{j} d j=Z_{t}\left(\frac{L_{t}}{\Omega_{t-1} K_{t-1}}\right)^{1-\alpha} \int_{0}^{1} \omega_{t-1}^{j} K_{t-1}^{j} d j=Z_{t} L_{t}^{1-\alpha}\left(\Omega_{t-1} K_{t-1}\right)^{\alpha}
$$

where in the second equality we have used (33). Using (23), aggregate demand of the intermediate good equals $\int_{0}^{1} Y_{i, t} d i=Y_{t} \int_{0}^{1}\left(\frac{P_{i, t}}{P_{t}}\right)^{-\epsilon} d i=Y_{t} \Delta_{t}$, where $\Delta_{t} \equiv \int_{0}^{1}\left(P_{i, t} / P_{t}\right)^{-\epsilon} d i$ is an index of relative price dispersion. Market clearing for the intermediate good therefore requires

$$
Y_{t}=\frac{Z_{t}}{\Delta_{t}} L_{t}^{1-\alpha}\left(\Omega_{t-1} K_{t-1}\right)^{\alpha}
$$

Aggregate supply of the final good must equal consumption and investment demand by households,

$$
Y_{t}=C_{t}+I_{t}
$$

Market clearing for government bonds requires supply to equal demand by private banks and the central bank, ${ }^{26}$

$$
\bar{b}_{t}=b_{t}^{G}+b_{t}^{G, C B}
$$

Finally, we can aggregate equation (6) across banks and use $N_{t}^{i}=\varsigma E_{t}^{j}$ to find an expression for aggregate bank equity,

$$
\frac{N_{t}}{\varsigma}=R_{t}^{A} \Omega_{t-1} Q_{t-1}^{K} K_{t-1}+\frac{R_{t-1}^{L}}{1+\pi_{t}} \Phi_{t-1}^{L}+\frac{R_{t}^{G}}{1+\pi_{t}} b_{t-1}^{G}-\frac{R_{t-1}^{D}}{1+\pi_{t}} D_{t-1}-\frac{R_{t-1}^{B}}{1+\pi_{t}} \Phi_{t-1}^{B}
$$

where we have used (33) and $A_{t-1}^{j}=K_{t-1}^{j}$ to substitute for $\int_{0}^{1} \omega_{t-1}^{j} A_{t-1}^{j} d j\left(=\Omega_{t-1} K_{t-1}\right)$.

\footnotetext{
${ }^{25}$ In the limiting case in which $\omega_{t-1}^{B}=\omega_{t-1}^{L} \equiv \bar{\omega}_{t-1}, \Omega_{t}$ collapses to $\mathbb{E}\left(\omega \mid \omega \geq \bar{\omega}_{t-1}\right)$.

${ }^{26}$ Notice that we have implicitly assumed that the household cannot hold government bonds. This assumption is innocuous, since in equilibrium the household will always prefer deposits over bonds.
} 
This concludes the set-up of the model. We define an equilibrium in this model as a set of state-contingent functions for prices and quantities such that all agents' optimization problems are solved and markets clear. Appendix B.1 lists the conditions that have to hold in equilibrium for aggregate variables.

\section{The interbank transmission channel of bond purchases}

Having set up the model, we now discuss the mechanism through which the central bank's balance sheet policy affects interest rates and, through these, the rest of the economy. We focus our discussion here on asset purchases; however the last section of the paper shows that our arguments apply to credit operations with banks as well.

For this and for the next section it is useful to define two further properties that the matching function may fulfill:

Definition 1 (Match-efficient interbank market) The interbank market is match-efficient if $\Upsilon(x, x)=x$. If $\Upsilon(x, x)<x$, then it is match-inefficient. The interbank market is asymptotically match-efficient if $\lim _{x \rightarrow \infty} \Upsilon(x, y)=\lim _{x \rightarrow \infty} \Upsilon(y, x)=y$.

This definition states that the interbank market is match-efficient if, whenever the number of lending and borrowing orders is the same, all orders find a match (since then both matching probabilities equal $\Upsilon(x, x) / x=1)$. If in such situations some orders do not find a match, then the interbank market is said to be match-inefficient. Asymptotic match-efficiency means that, if the volume of orders on one of the two sides of the market is arbitrarily large, then the number of matches equals the volume of orders on the short side. Notice that, as the matching function is increasing, match efficiency necessarily implies asymptotic match efficiency.

The (capped) Cobb-Douglas function, $\Upsilon(x, y)=\min \left\{\lambda_{2} x^{\lambda_{1}} y^{1-\lambda_{1}}, x, y\right\}$, with $\lambda_{2} \in(0,1)$ and $\lambda_{1} \in(0,1),{ }^{27}$ is match-inefficient, although it is still asymptotically match-efficient. ${ }^{28}$ Similarly, the functional form proposed by Den Haan et al. (2000), $\Upsilon(x, y)=x y\left(x^{\lambda}+y^{\lambda}\right)^{-1 / \lambda}$ is matchinefficient but asymptotically match-efficient. In the limit $\lambda \rightarrow \infty$, this function becomes equivalent to the Leontieff function $\Upsilon(x, y)=\min \{x, y\}$, which is the only continuous and weakly increasing matching technology that satisfies match-efficiency. ${ }^{29}$

\footnotetext{
${ }^{27}$ In discrete time environments, matching functions need to respect the requirement that matching probabilities do not exceed unity - i.e. there cannot be more matches than searchers on either side. The Cobb-Douglas specification generally does not satisfy this requirement, hence its capping. If $\lambda_{2} \geq 1$ the capped Cobb-Douglas function is equal to the Leontieff function.

${ }^{28}$ For $\lambda_{2}<1, \Upsilon(x, x)=\min \left\{\lambda_{2} x, x, x\right\}=\lambda_{2} x<x$, hence the match-inefficiency. However, $\lim _{x \rightarrow \infty} \Upsilon(x, y)=$ $\min \{\infty, \infty, y\}=y$, hence the asymptotic match-efficiency.

${ }^{29}$ Proof available upon request. However, in violation of our assumption that $\Upsilon$ is $\mathrm{C}^{1}$, this function is not continuously differentiable. Therefore, in the following whenever we speak of a match-efficient technology we refer to the following limiting case: $\lim _{\lambda \rightarrow \bar{\lambda}} \Upsilon(x, y ; \lambda)$, where $\Upsilon(x, y ; \lambda)$ is a continuous non-match-efficient matching function parametrized by $\lambda$ satisfying $\lim _{\lambda \rightarrow \bar{\lambda}} \Upsilon(x, y ; \lambda)=\min \{x, y\} \forall x, y$.
} 
Having defined these concepts, we now analyze the transmission of asset purchases. Combining the balance sheet constraint (31) and the interbank market clearing condition $\Gamma_{t}^{B} \Phi_{t}^{B}=\Gamma_{t}^{L} \Phi_{t}^{L}$ yields

$$
\Phi_{t}^{L}-\Phi_{t}^{B}=b_{t}^{G, C B}
$$

That is, the difference between lending and borrowing orders in the interbank market equals the market value of bonds held by the central bank. Dividing by $\Phi_{t}^{B}$, rearranging, and using the definition of interbank market tightness, $\theta_{t}=\Phi_{t}^{B} / \Phi_{t}^{L}$, we obtain

$$
\theta_{t}^{-1}=\widetilde{b}_{t}^{G, C B}+1
$$

where $\widetilde{b}_{t}^{G, C B} \equiv b_{t}^{G, C B} / \Phi_{t}^{B}$ denotes central bank bond holdings normalized by the value of interbank borrowing orders. Therefore, by increasing its bond holdings, the central bank can (for given $\Phi_{t}^{B}$ ) reduce the tightness in the interbank market. ${ }^{30}$ This in turn affects borrowers' surplus share $\varphi\left(\theta_{t}\right)$, the matching probabilities $\left(\Gamma^{x}\left(\theta_{t}\right), x=L, B\right)$, and ultimately, through equations $(21),(28)$ and (29), the position of market rates inside the corridor. The following proposition characterizes how asset purchases affect market interest rates:

Proposition 2 (Effect of central bank bond purchases) (i) Government bond purchases by the central bank $\widetilde{b}_{t}^{G, C B}$ push the interbank rate $R_{t}^{I B}$ and with it the effective borrowing and lending rates $R_{t}^{B}$ and $R_{t}^{L}$ towards the bottom of the corridor:

$$
\frac{\partial R_{t}^{I B}-R_{t}^{D F}}{\partial \widetilde{b}_{t}^{G, C B}}, \frac{\partial R_{t}^{B}-R_{t}^{D F}}{\partial \widetilde{b}_{t}^{G, C B}}, \frac{\partial R_{t}^{L}-R_{t}^{D F}}{\partial \widetilde{b}_{t}^{G, C B}}<0 .
$$

(ii) Bond purchases feature a weak form of decreasing returns to scale of bond purchases, defined as follows. Let $\Theta_{t}\left(\widetilde{b}_{t}^{G, C B}\right) \equiv\left(R_{t}^{I B}(0)-R_{t}^{D F}(0)\right)-\left(R_{t}^{I B}\left(\widetilde{b}_{t}^{G, C B}\right)-R_{t}^{D F}\left(\widetilde{b}_{t}^{G, C B}\right)\right)$ be the reduction in the interbank rate due to bond purchases, relative to the case of no bond purchases. Then

$$
\Theta_{t}\left(x \widetilde{b}_{t}^{G, C B}\right)<\Theta_{t}\left(\widetilde{b}_{t}^{G, C B}\right) x \forall x>\widetilde{x} \text {, for some } \widetilde{x} \geq 1
$$

\footnotetext{
${ }^{30}$ The central bank controls the ratio $\widetilde{b}_{t}^{G, C B} \equiv b_{t}^{G, C B} / \Phi_{t}^{B}$ indirectly, by directly choosing the nominal value of bonds held $b_{t}^{G, C B} P_{t}$. To be able to exercise this control, it must be (i) that prices do not simply adjust such that the real holdings $b_{t}^{G, C B}$ stay constant and (ii) that the volume of borrowing orders does not adjust such that the ratio $b_{t}^{G, C B} / \Phi_{t}^{B}$ stays constant. The former is guaranteed by price stickiness - in a model without nominal rigidities by contrast, there exists an equilibrium where the central bank's nominal asset holdings have no influence on real variables. Whether the latter holds true is determined in general equilibrium. Figure 9 in Appendix 3 shows a numerical example how nominal purchases translate into changes of $b_{t}^{G, C B} / \Phi_{t}^{B}$ almost proportionally, since neither $P_{t}$ nor $\Phi_{t}^{B}$ respond significantly.
} 

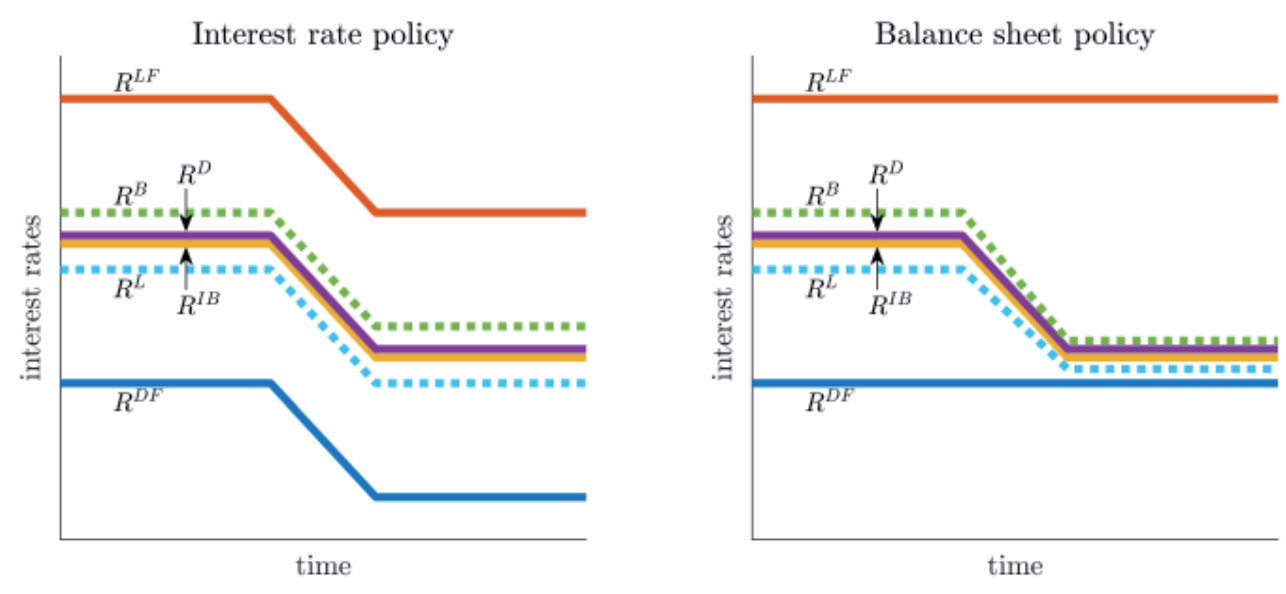

Figure 3: This figure schematically represents the transmission of monetary policy to market rates. It shows how the rates respond to a parallel shift in the policy rates (panel 1) or an expansion of the balance sheet (panel 2). Note that the model predicts no particular ordering of $R^{D}$ and $R^{I B}$. The case depicted here with $R^{D}>R^{I B}$ is purely illustrative.

The proof can be found in Appendix A. According to part (i), bond purchases monotonically reduce the spread between the actual interbank rate (as well as the effective interbank borrowing and lending rates) and the deposit facility rate. The previously derived negative effect of bond purchases on interbank market tightness, together with of our assumption that $\varphi^{\prime}\left(\theta_{t}\right)<0$, are key in driving this result.

Another way to understand this result is as follows. Given a fixed supply of government bonds, larger holdings by the central bank imply smaller holdings by commercial banks, $b_{t}^{G}$. From equation (15), ceteris paribus this increases the amount of funds that banks with relatively poor investment opportunities try to place in the interbank market. This increase in lending orders $\Phi_{t}^{L}$ reduces the tightness in the interbank market ( $\theta_{t}$ falls) for a given volume of borrowing orders $\Phi_{t}^{B}$. Under competitive search - and the assumption that $\varphi^{\prime}\left(\theta_{t}\right)<0$ - this implies a higher surplus share for borrowers and, from equation (21), a lower interbank market rate for given policy rates. In addition, the fall in interbank market tightness makes it harder for lenders to find borrowers and easier for borrowers to find lenders ( $\Gamma_{t}^{L}$ decreases, $\Gamma_{t}^{B}$ increases). From equations $(28,29)$, it follows that $R_{t}^{L}$ and $R_{t}^{B}$ fall too. Panel 2 in Figure 3 illustrates these effects.

The effect of balance sheet policies on $R_{t}^{L}$ and $R_{t}^{B}$ is passed through to the household deposit rate according to equation (13). Since $R_{t}^{D}$ depends also on other variables that are determined in general equilibrium, Proposition 2 cannot generally be extended to $R_{t}^{D}$. However, as we will see in our numerical analysis, for our calibration $R_{t}^{D}$ is always indistinguishable from $R_{t}^{I B}$ and hence moves essentially one for one with the latter. The reduction in the nominal deposit rate 
in turn triggers a general equilibrium response similar to that triggered by a policy rate cut in the standard New Keynesian model: Since prices are sticky, real rates fall and households bring forward consumption, which stimulates the economy. ${ }^{31}$

Part (ii) of the proposition follows from (38) and the fact that by Lemma $2 R_{t}^{I B} \geq R_{t}^{D F} \cdot 32$ Since bond purchases monotonically reduce the interbank-DFR spread but the latter is always non-negative, for a given bond purchase program of size $\tilde{b}_{t}^{G, C B}$ (starting from zero holdings) there exists a minimum scaling factor $\widetilde{x} \geq 1$ such that a proportional increase in the size of the program by any factor $x \geq \widetilde{x}$ reduces the above spread by a less than proportional amount.

In addition to market interest rates, asset purchases also have implications for the quantity of reserves. The larger volume of interbank lending orders $\Phi_{t}^{L}$ and the lower lender matching probability $\Gamma_{t}^{L}$ imply that more lending orders fail to find a match and hence end up at the central banks reserve facility: $\left(1-\Gamma_{t}^{L}\right) \Phi_{t}^{L}$ increases. Our model therefore delivers an inverse relationship between the interbank-reserves interest rate spread and the amount of excess reserves. How much of the bond purchases actually translates into an increase in reserves depends on what happens with the other asset in the central bank's balance sheet: lending facility credit, $\left(1-\Gamma_{t}^{B}\right) \Phi_{t}^{B}$. In the special case of match-efficiency, since borrowing orders are the 'short side' of the interbank, they all are matched $\left(\Gamma_{t}^{B}=1\right)$. Therefore, there is no lending facility activity and bond purchases translates one for one into reserves creation. In the more general case of match-inefficiency, some borrowing orders fail to be matched $\left(\Gamma_{t}^{B}<1\right)$ and hence there is always some lending facility credit. In this case, bond purchases and the resulting interbank market slackening raise borrowers' matching probability and $\left(1-\Gamma_{t}^{B}\right) \Phi_{t}^{B}$ falls (for given borrowing orders $\Phi_{t}^{B}$ ), such that bond purchases crowd out some facility lending. As long as the interbank market is approximately match-efficient, however, $\Gamma_{t}^{B}$ is always close to one and the latter effect is negligible, so bond purchases increase reserves almost one for one. ${ }^{33}$

Finally, we highlight that our model can also be used to understand the asymmetric corridor system that the US Federal Reserve (the "Fed") operated until 2008 (as did many other central banks). Back then, the Fed paid no interest on excess reserves: $R_{t}^{D F}=1$ for all $t$. It also offered

\footnotetext{
${ }^{31}$ Our model features additional transmission channels of monetary policy that are not present in the standard New Keynesian model. First, a change in interbank market tightness also affects the average capital efficiency $\Omega_{t}$ defined in equation (34). Second, nominal contracts imply redistributionary effects between households and banks, which in turn affect the average capital efficiency as well. We abstract however from further discussion of these additional effects here for convenience and because they turn out to be small for plausible calibrations.

${ }^{32}$ Note that decreasing returns to scale are conventionally defined as in the proposition but with $\widetilde{x}=1$.

${ }^{33}$ The timing adds some subtle details to these mechanisms. The central bank purchases assets before the interbank market closes from banks that are on islands that had low productivity in the previous period, i.e. those with $\omega_{t-1}^{j}<\omega_{t-1}^{L}$. It pays in reserves. These banks instantaneously use these reserves to finance their portfolio choices. After the interbank market closes, these reserves end up with the banks on islands that have low productivity in the current period, i.e. those with $\omega_{t}^{j}<\omega_{t}^{L}$. Imagine for example: A particular bank $j$ 's draw $\omega_{t}^{j}$ is below $\omega_{t}^{L}$ both yesterday and today. Yesterday it bought bonds worth one unit today. Today it sells them to the central bank in exchange for reserves before the interbank market closes. It uses these funds to lend them in the interbank market. When the interbank market closes, $\Gamma_{t}^{L}$ units of reserves have been lent to other banks and $\left(1-\Gamma_{t}^{L}\right)$ remain on bank j's balance sheet.
} 
discount window loans at a discount rate $\left(R_{t}^{L F}\right.$ in our model) which was set 1ppt above the Fed funds target $\left(R_{t}^{I B}\right)$. Instead of steering the latter by moving both the upper and lower bound of the corridor as in a standard corridor system, the Fed did so by moving only the discount rate and fine-tuning its government bond holdings through open market operations. For example, to lower the Fed funds rate the Fed would buy bonds and lower the discount rate. This is consistent with our model. Lowering $R_{t}^{L F}$ alone reduces $R_{t}^{I B}$, however less than one for one since the relative position of $R_{t}^{I B}$ within the corridor remains constant (for given tightness). An increase of government bond holdings is hence necessary to lower $R_{t}^{I B}$ further, up until it falls one-for-one with $R_{t}^{L F}{ }^{34}$

\section{Large vs lean balance sheet}

In this section we compare the properties of a "lean" central bank balance sheet regime, in which the central bank holds no bonds, with those of a "large" balance sheet regime, in which the central bank has permanently expanded its balance sheet size through an asset purchasing program.

\subsection{Lean balance sheet}

By lean balance sheet we refer to a scenario in which central bank asset holdings are arbitrarily small. In particular, we consider for illustration the limiting case in which the central bank does not hold any government bonds: $b_{t}^{G, C B}=0$. In this case the central banks balance sheet has only one item on each side: lending facility lending is the only asset and deposit facility borrowing (reserves) the only liability. From equation (36), the volume of borrowing and lending orders must then be the same, such that interbank market tightness equals $\theta_{t}=\Phi_{t}^{B} / \Phi_{t}^{L}=1$. The match finding probabilities of borrowers and lenders hence equal

$$
\Gamma_{t}^{L}=\Gamma_{t}^{B}=\Upsilon(1,1)
$$

If in addition one assumes a match-efficient interbank market, in which the number of matches always equals the 'short side' of the market, both matching probabilities are one: $\Gamma_{t}^{L}=\Gamma_{t}^{B}=$ $\Upsilon(1,1)=1$. Hence neither lending nor borrowing banks need to access the central bank's deposit or lending facilities, so reserves and facility lending are both zero: $\Phi_{t}^{L}\left(1-\Gamma_{t}^{L}\right)=\Phi_{t}^{B}\left(1-\Gamma_{t}^{B}\right)=0$. Therefore, under match-efficiency, a 'lean' balance sheet is in fact a zero-sized balance sheet.

Combining (39) with equations (13), (21), (25), (28) and (29) allows us to characterize the relative position of equilibrium rates within the corridor formed by the policy rates:

\footnotetext{
${ }^{34}$ Two further details (unmodelled here) distinguish the US from the Euro Area. (i) Prior to 2002 the discount rate was below the Fed funds rate. Banks did nevertheless not use the discount window much because lending was rationed and stigmatized. (ii) Not all agents in the Fed funds market have access to the Fed's deposit facility, which is why the Fed funds rate lately traded marginally below the interest on excess reserves.
} 
Proposition 3 (Corridor system) If $b_{t}^{G, C B}=0$, then

$$
\begin{aligned}
R_{t}^{I B} & =\varphi(1) R_{t}^{D F}+(1-\varphi(1)) R_{t}^{L F} \\
R_{t}^{B} & =R_{t}^{L F}-\chi \varphi(1) \Upsilon(1,1) \\
R_{t}^{L} & =R_{t}^{D F}+\chi[1-\varphi(1)] \Upsilon(1,1)
\end{aligned}
$$

which implies $R_{t}^{D F}<R_{t}^{L}<R_{t}^{I B}<R_{t}^{B}<R_{t}^{L F}$. If the interbank market is furthermore matchefficient, then $\Upsilon(1,1)=1$ and

$$
R_{t}^{D}=R_{t}^{L}=R_{t}^{B}=R_{t}^{D}=R_{t}^{I B}=\varphi(1) R_{t}^{D F}+(1-\varphi(1)) R_{t}^{L F}
$$

The interbank rate thus equals a weighted average of the two policy rates with a constant weight of $\varphi(1)$. For instance, if the matching technology satisfies $\varphi(1)=1 / 2$, such that its elasticity with respect to borrowing or lending amounts equals one half when both quantities are symmetric, then the interbank rate always lies in middle of the corridor and the distances between the interbank $R_{t}^{I B}$ and each of the two effective rates $R_{t}^{L}$ and $R_{t}^{B}$ are equal. Furthermore, in the case of a match-efficient interbank market, all market interest rates coincide with the interbank rate. ${ }^{35}$ This is true also for the household deposit rate, by virtue of the fact that $R_{t}^{D} \in\left[R_{t}^{L}, R_{t}^{B}\right]$.

This regime resembles a corridor system like the one used by the ECB prior to 2009. The balance sheet was essentially zero (in terms of excess reserves) and the interbank rate was in the middle of the corridor.

\subsection{Large balance sheet}

We contrast the lean balance sheet system with the case in which the central bank's bond holdings (normalized by the volume of interbank borrowing orders) becomes arbitrarily large, $\widetilde{b}_{t}^{G, C B} \rightarrow \infty .^{36}$ From equation (37), the interbank market becomes arbitrarily slack in this case: $\theta_{t} \searrow 0$. This in turn implies $\Gamma_{t}^{L} \searrow 0$, i.e. lending orders are matched with a vanishingly small probability. Also, borrowers' matching probability increases relative to the lean balance sheet case, $\Gamma_{t}^{B} \geq$ $\Upsilon(1,1)$, and converges to one under asymptotic match efficiency. So the effective interbank lending and borrowing rates converge, respectively, to the interest on reserves and (under asymptotic

\footnotetext{
${ }^{35}$ An implication of $R_{t}^{L}=R_{t}^{B}$ is that $\omega_{t}^{B}=\omega_{t}^{L} \equiv \bar{\omega}_{t}$, such that there is no intermediate segment of banks that neither borrow nor lend in the interbank market. Capital efficiency (equation 34) then simplifies to $\Omega_{t}=$ $\mathbb{E}\left(\omega \mid \omega \geq \bar{\omega}_{t}\right)$.

${ }^{36} \widetilde{b}_{t}^{G, C B} \rightarrow \infty$ may require $b_{t}^{G, C B} \rightarrow \infty$ (see footnote 30 ). Naturally, the maximum size of the central bank balance sheet is limited by the total size of the bond market: $b_{t}^{G, C B} \leq \bar{b}_{t}$. Hence, formally we need to consider the limit where both the banks holdings of bond and the total stock of bonds go towards infinity: $\widetilde{b}_{t}^{G, C B} \rightarrow \infty$ and $\bar{b}_{t} \rightarrow \infty$ and $b_{t}^{G, C B} \leq \bar{b}_{t}$. To abbreviate notation we just write $\widetilde{b}_{t}^{G, C B} \rightarrow \infty$.
} 
match efficiency) to the actual interbank rate. The following result establishes that the latter rate converges to the floor, pulling all other market rates with it.

Proposition 4 (Floor system) $A s \widetilde{b}_{t}^{G, C B} \rightarrow \infty$, borrowing banks' surplus share converges to one, $\lim _{\widetilde{b}_{t}^{G, C B} \rightarrow 0} \varphi\left(\theta_{t}\right)=1$. The interbank and effective lending rates converge to the bottom of the corridor,

$$
\lim _{\widetilde{b}_{t}^{G, C B} \rightarrow 0} R_{t}^{I B}=\lim _{\widetilde{b}_{t}^{G, C B} \rightarrow 0} R_{t}^{L}=R_{t}^{D F} .
$$

If the matching technology is furthermore asymptotically match efficient, all other market rates converge too to the bottom of the corridor,

$$
\lim _{\widetilde{b}_{t}^{G, C B} \rightarrow 0} R_{t}^{B}=\lim _{\widetilde{b}_{t}^{G, C B} \rightarrow 0} R_{t}^{D}=R_{t}^{D F} .
$$

The proof can be found in Appendix A. Thus, as the central bank's bond holdings become arbitrarily large, the economy converges to a 'floor system', in which the central bank effectively sets all market rates by setting the interest on reserves. This equilibrium resembles the current situation in the euro area and other advanced economies, characterized by large excess reserves and money market indices trading very close to the deposit facility rate.

Having characterized how balance sheet policy affect market rates, we now briefly discuss how conventional interest-rate policy operates in our framework. From Propositions 3 and 4, it is straightforward to see that (parallel) changes in both policy rates transmit one-for-one to market rates under both regimes. ${ }^{37}$ Panel 1 in Figure 3 illustrates this graphically for the case of a lean balance sheet.

\subsection{Policy space with respect to the ELB}

The relative position of market rates within the policy rate corridor has important implications for monetary policy when taking into account the ELB. This section shows that the floor system provides more policy space for conventional interest rate policy compared to the corridor system. To see this most clearly, consider the case of match efficiency. From the household's Euler equation (1), our assumption of a zero net inflation target, and Propositions 3 and 4, the steady-state interbank rate in both regimes equals

$$
R_{s s}^{I B}=R_{s s}^{D}=1 / \beta
$$

\footnotetext{
${ }^{37}$ The only exception is the transmission to the household deposit rate $R_{t}^{D}$ in the lean balance sheet case. As discussed in Section 3, $R_{t}^{D}$ depends on $\left(R_{t}^{B}, R_{t}^{L}\right)$ but also on other endogenous variables that are affected in general equilibrium. As argued there too however, in our numerical implementation it is always the case that $R_{t}^{D} \approx R_{t}^{I B}$, such that policy rate changes move deposit rates almost one-for-one also under a lean balance sheet.
} 
That is, the interbank rate depends only on households' discount factor and is hence independent of monetary policy (for given inflation target). From the same propositions, one can then obtain the steady-state level of the floor rate, i.e. the deposit facility rate.

Proposition 5 (Policy space) Assume the interbank market is match-efficient. In a corridor system $\left(b_{t}^{G, C B}=0\right)$ the steady-state gross deposit facility rate is

$$
R_{s s}^{D F}=1 / \beta-[1-\varphi(1)] \chi<1 / \beta .
$$

In a floor system, the steady-state deposit facility rate is

$$
R_{s s}^{D F}=1 / \beta
$$

Therefore, a floor system implies a wider distance between the steady-state deposit facility rate and its $E L B, 1-\kappa \leq 1$.

The intuition is the following. In both regimes, the steady-state interbank rate equals the inverse of the household's discount factor. In the corridor regime, the interbank rate lies in the middle of the two policy rates, so necessarily the steady-state deposit facility rate must lie below $1 / \beta$, the more so the wider the corridor width $\chi$. By contrast, in the floor regime the steady-state deposit facility rate coincides with the steady-state interbank rate and hence is equal to $1 / \beta$. As a result, the floor system features a wider (steady-state) distance between the deposit facility rate and its ELB, thus allowing for more 'policy space' for interest rate cuts in the face of deflationary shocks. This result will play a key role in our numerical results, when we compare crisis scenarios under both the lean-balance-sheet/corridor system and the large-balance-sheet/floor one.

We finally note that our 'policy space' result can also be extended to the more general case of asymptotic match efficiency, albeit with some additional complexity. ${ }^{38}$

\section{Quantitative analysis}

\subsection{Calibration}

We assume standard preferences: $u\left(C_{t}\right)-v\left(L_{t}\right)=C_{t}^{1-\gamma} /(1-\gamma)-L_{t}^{1+\psi} /(1+\psi)$. We also use a standard quadratic specification for investment adjustment costs: $S(x)=\frac{\iota}{2}(x-1)^{2}$, where $\iota$ is a

\footnotetext{
${ }^{38}$ In particular, the expression for $R_{s s}^{D F}$ in the corridor regime is slightly more complicated than equation (40), as it is to prove that it lies below $1 / \beta$. This proof is available upon request.
} 


\begin{tabular}{llll}
\hline Parameter & Value & Target \\
\hline \hline$\alpha$ & Capital share & 0.33 & \\
$\delta$ & Depreciation & 0.025 & \\
$\beta$ & Discount factor & 0.995 & \\
$\gamma$ & Risk aversion & 1 & \\
$\psi$ & Inverse Frisch elasticity & 0.276 & \\
$\theta$ & Calvo parameter & 0.779 & Gertler and Karadi (2013) \\
$\epsilon$ & Markup & 4.167 & \\
$\iota$ & Investment adjustment & 1.728 & \\
$v$ & Taylor rule inflation & 1.5 & \\
$\rho$ & Taylor rule persistence & 0.8 & \\
\hline$\kappa$ & Effective lower bound & 0 & ZLB \\
$\phi$ & Leverage constraint & 18.8 & Steady-state leverage ratio \\
$\zeta$ & Bond maturity & 0.05 & 5 years average maturity \\
$\bar{B} / \bar{Y}$ & Government debt & 1.34 & Banks' steady-state bond holdings \\
$\bar{B} G, C B$ & Government debt held by CB & 0 & No QE pre crisis \\
$\chi$ & Corridor width & $0.5 \%$ & Pre-crisis corridor width \\
$\varsigma$ & Dividend ratio & 0.975 & RoE of banks \\
$\mu$ & Mean of idiosyncratic shocks & -0.023 & Normalize $\bar{\Omega}=1$ \\
$\sigma$ & Std of idiosyncratic shocks & 0.0028 & Ratio of redistr. to productive assets \\
$\lambda$ & Matching function & 225 & Ratio of interbank to CB lending \\
\hline
\end{tabular}

Table 1: Calibrated parameter values

scale parameter. Idiosyncratic shocks are assumed to be log-normally distributed with parameters $\mu$ and $\sigma$. The matching function is as in Den Haan et al. (2000),

$$
\Upsilon\left(\Phi_{t}^{L}, \Phi_{t}^{B}\right)=\frac{\Phi_{t}^{L} \Phi_{t}^{B}}{\left(\left(\Phi_{t}^{L}\right)^{\lambda}+\left(\Phi_{t}^{B}\right)^{\lambda}\right)^{1 / \lambda}} .
$$

In calibrating the standard parameters, i.e. those of the production function $(\alpha, \delta)$, the utility function $(\beta, \gamma, \psi)$ and the New Keynesian elements $(\theta, \epsilon, \iota, v, \rho)$, we follow Gertler and Karadi (2013), who use the values of Primiceri et al. (2006).

Most of the remaining parameters are non-standard and relate to the banking sector. We set $\kappa$ to 0, that is we assume the ELB is zero. For the remaining parameters, we target moments from pre-crisis euro area data (1999-2007). ${ }^{39}$ The parameter defining the corridor width $\chi$ is set to $0.5 \%$ per quarter, which implies an annualized corridor width of 2 percentage points, as used by the ECB before the crisis. The central bank is assumed to not hold any QE asset in the (corridor-system) steady state, $\bar{b}^{G, C B}=0$, as was the case prior to the crisis. Banks' dividend ratio $\varsigma$ is chosen to match the historical average real return on bank equity of $10 \%$. The parameter defining the maturity of government debt $\zeta$ is set to 0.05 , which yields an average maturity of 5 years. The mean of the iid shocks to island specific capital efficiency $\mu$ is set such that the steady state capital efficiency $\Omega_{s s}$ is normalized to 1 .

\footnotetext{
${ }^{39}$ We calibrate the model in line with the European institutional set up. In the US the corridor system was only implemented in 2008. At the same time the Fed flooded the market with liquidity, which drove the fed funds rate close to the interest-on-excess-reserves floor.
} 


\begin{tabular}{lr|rr}
\hline \hline Assets & & & Liabilities \\
\hline Claims on private nonfin. & $62.8 \%$ & $6.8 \%$ & Equity \\
Claims on government & $10.4 \%$ & $66.3 \%$ & Deposits \\
Interbank claims & $26.9 \%$ & $26.9 \%$ & Interbank liabilities \\
\hline
\end{tabular}

Table 2: Aggregate bank balance sheet

We choose the parameters $\bar{b}, \phi$ and $\sigma$ to match the average structure of the aggregate balance sheet of the monetary financial institutions (MFIs) in the euro area over the years 1999-2007 according to ECB data. Table 2 reports the targeted balance sheet. ${ }^{40}$ The government debt level we obtain $(b)$ hence reflects only the debt held by the banks. Appendix D describes in detail how we aggregated the data to arrive to this stylized aggregate balance sheet.

The matching function parameter $\lambda$ is set such that the model reproduces the empirical relationship between excess reserves over GDP and the interbank-deposit facility rate spread during the entire euro period (1999-2017). ${ }^{41}$ In particular, we choose $\lambda$ to minimize the weighted mean absolute error between the data and the model prediction. ${ }^{42}$ As shown in Figure 4, our calibrated model replicates the relationship between excess reserves and the interbank-DFR spread fairly well, both for the pre-crisis corridor system in which this spread fluctuated around 1\% (i.e. one half of the corridor width) and for the current floor system in which it is essentially zero. ${ }^{43}$ The resulting value for $\lambda$ is very high, implying almost exact match-efficiency. As a result, in the absence of central bank bond holdings only $0.08 \%$ of banks' assets are excess reserves, a negligible number albeit an order of magnitude larger than in the pre-crisis data $(0.006 \%)$. Furthermore our calibration yields a ratio of total bank assets to GDP of 3.1, which is close to its data counterpart of 2.6 .

\footnotetext{
${ }^{40}$ The balance sheet structure in the table defines 3 targets: 2 ratios between the three asset categories and the ratio of equity to deposits. Since we have 3 parameters, we match the targeted structure perfectly.

${ }^{41}$ To determine this relationship numerically for the model, we compute the steady state spread and the excess reserves to GDP ratio for different values of $\bar{b}^{G, C B}$. As an alternative more consistent with the time series nature of our data, we also determined this relationship using a dynamic perfect foresight simulation. In this simulation the economy starts at the steady state with 0 bond holdings. Then the balance sheet is gradually expanded. No shocks occur. The numerical results are virtually identical.

Notice also that, as empirical proxy for the model's interbank rate, we take the EUREPO rate. The latter, contrary e.g. to EONIA, is based on secured interbank transactions and is hence a closer counterpart to $R_{t}^{I B}$, which carries no default risk.

${ }^{42}$ We use weekly observations from 1999-2017. We weight the observations by the probability density function of the data, which we approximate by a histogram of 30 equal spaced bins. This allows us to get a good overall fit of the relationship despite having many more observations close to zero than for higher values of excess reserves. Finally notice that in the data the corridor was changed over time while we abstract from this policy in the model. Normalization by division through the corridor width yields similar results.

${ }^{43}$ Figure 10 in Appendix $\mathrm{C}$ shows that similar relationships between the amount of excess reserves and the interbank-reserves interest rate spread hold for other major currency areas, such as the US, Japan and the UK.
} 


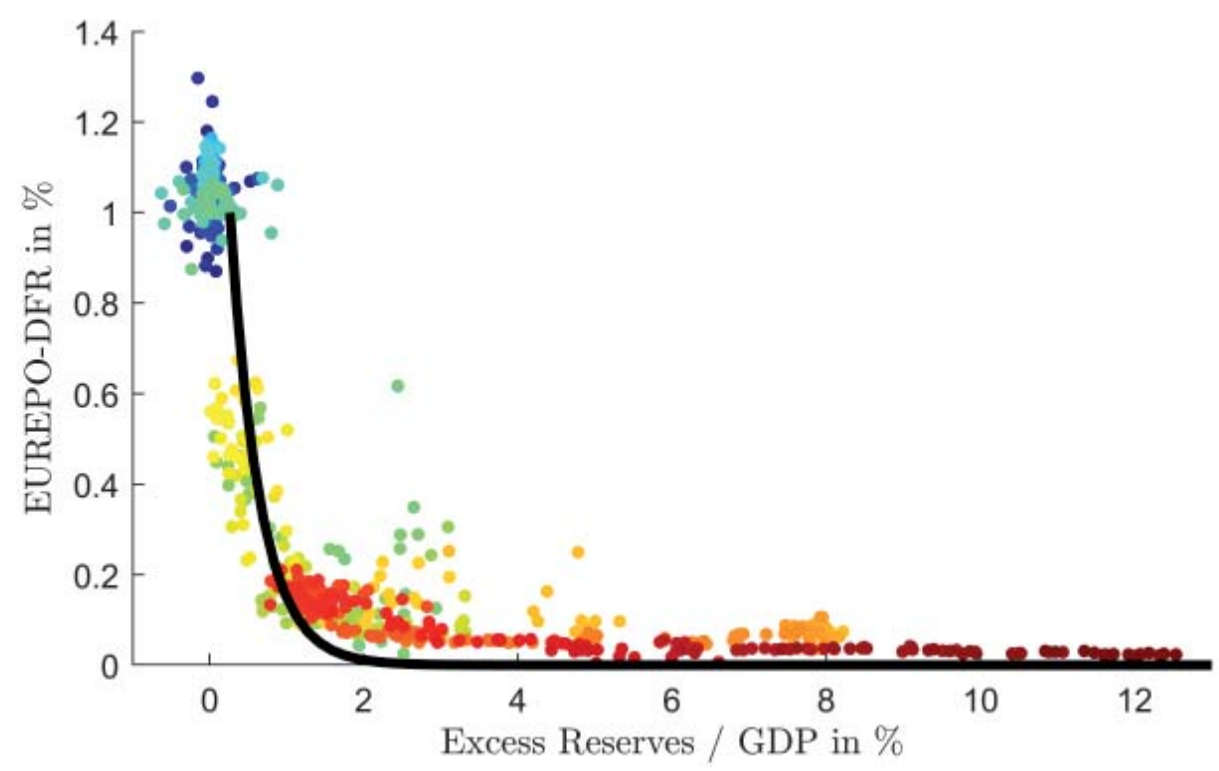

Figure 4: This figure shows the realtionship between the EUREPO-DF spread and the excess reserves in the steady state of the model and in weekly EMA data (colours indicate time from 1999 (blue) to 2017 (red)). Since the shortest available maturity for the EUREPO is 4 weeks, we approximated the expected DFR over the next 4 weeks by the materialized DFR.

\subsection{Comparative statics: the role of the central bank balance-sheet size}

We start our numerical analysis by investigating the effect of the balance-sheet size on the steady state equilibrium. Figure 5 plots the relationship between the steady-state value of a number of endogenous variables and the endogenous excess reserves/GDP ratio, as we vary the steady-state real market value of central bank's bond holdings $\bar{b}^{G, C B}$ (starting from zero). ${ }^{44}$ As the ratio of reserves increases, the interest rates on deposits $R_{s s}^{D}$ and interbank loans $R_{s s}^{I B}$ both converge to each other and all rates converge to the bottom of the corridor, $R_{s s}^{D F}$. This means that the interbankDFR spread also converges to zero (as shown already in Figure 4), consistently with Proposition 2 .

The top panels show that both steady state GDP and welfare (the latter in consumptionequivalent units) increase in the ratio of excess reserves. This is the result of the reduction in central bank seigniorage. These profits result from the difference in the remuneration on the central bank's assets and liabilities. In particular,

$$
\Pi_{s s}^{C B}=R_{s s}^{G} \bar{b}^{G, C B}+R_{s s}^{L F}\left(1-\Gamma_{s s}^{B}\right) \Phi_{s s}^{B}-R_{s s}^{D F}\left(1-\Gamma_{s s}^{L}\right) \Phi_{s s}^{L}
$$

\footnotetext{
${ }^{44}$ Since our calibrated matching function implies approximate match-efficiency, by the arguments of Section 3 the increase in the central bank's bond holdings translates almost one-for-one into an increase in reserves. Thus, using bond holdings over GDP as the x-axis variable in Figure 5 would make basically no difference (other than the fact that the reserves ratio is very small but not exactly zero for $b_{s s}^{G, C B}=0$.
} 

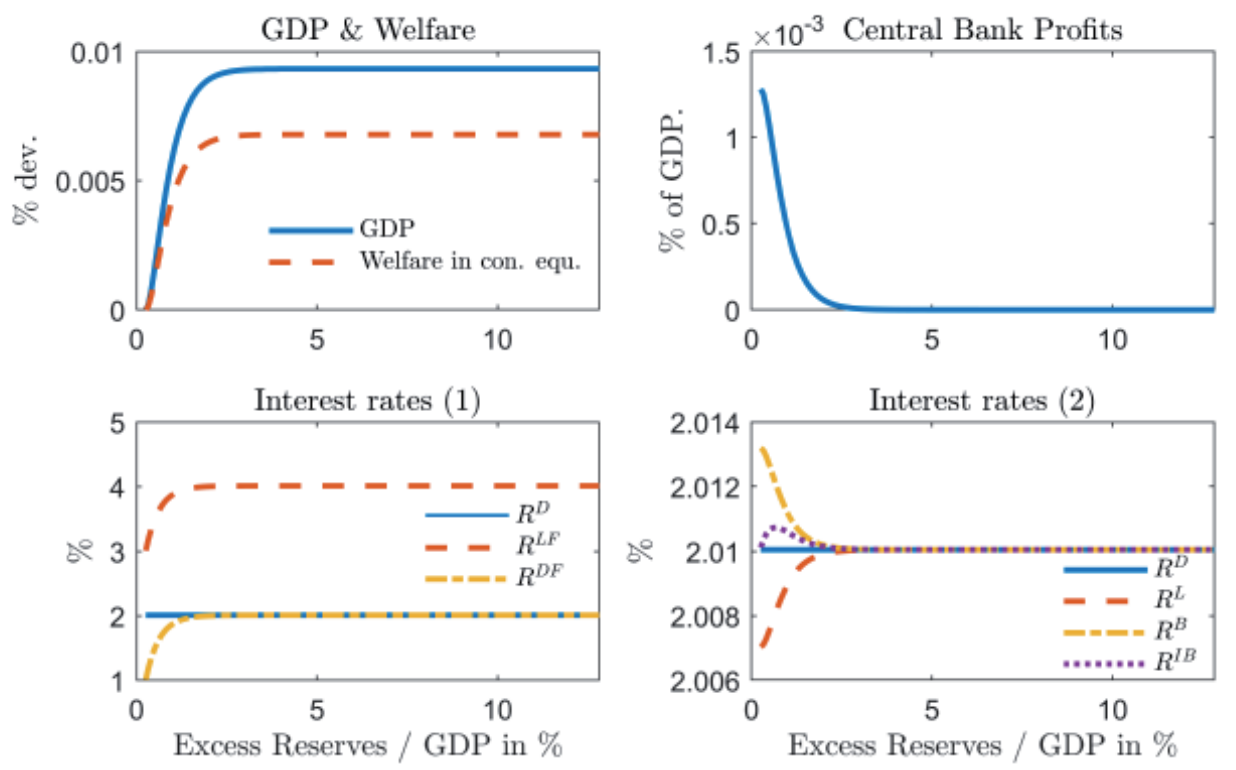

Figure 5: This figure illustrates the effect of the central bank's balance sheet size in steady state. The upper left panel displays deviations from the steady state associated with a balance sheet size of 0 . The welfare difference is measured in current consumption equivalents. The upper right panel displays central banks profits as \% of GDP.

where $R_{s s}^{L F}=R_{s s}^{D F}+\chi$ and $R_{s s}^{G}=R_{s s}^{L}>R_{s s}^{D F}$. As the size of the balance sheet increases, the per unit margin goes down faster such that total profits drop. Since the profits raised by the central bank act like a tax on banks and hence on capital returns, they distort the household's savings decision. Therefore, lower profits imply higher welfare. ${ }^{45}$ However, as the upper two panels demonstrate, these effects are quantitatively rather negligible.

\subsection{Balance sheet policies at the ELB}

Next we consider the dynamic implications of different balance sheet policies when the economy is driven to the ELB. To bring the economy there, we consider a time-varying household discount factor and simulate a temporary shock to it. We consider four different scenarios, which differ only in the central bank's balance sheet policy:

(i) A lean initial balance sheet with no unconventional policy response to the crisis: $b_{t}^{G, C B}=0 \forall t$.

(ii) A large initial balance sheet but no unconventional policy response to the crisis: $b_{t}^{G, C B}=$ $\bar{b}^{G, C B}>0 \forall t$.

\footnotetext{
${ }^{45}$ Since our model features multiple distortions, it is not a priori clear that an increase in one distortion must decrease welfare. Nevertheless, this numerical finding is intuitive since central bank profits act like a tax on capital (hence causing underinvestment) and none of the other frictions leads to overinvestment.
} 
(iii) Starting from the same lean balance sheet as in scenario (i), the central bank implements a temporary bond purchase program.

(iv) Starting from the same lean balance sheet as in scenario (i), the central bank implements the same temporary bond purchase program as in scenario (iii), but with a 1 year delay.

In all four cases the interest rate policy follows the same Taylor rule, and the economy is assumed to rest at the corresponding steady state before the shock (assumed to take place at time $t=1$ ). At $t=1$, the discount factor $\beta$ increases, and then it gradually converges back to its steady state value following an $\mathrm{AR}(1)$ process; once the shock arrives, its future path is perfectly foreseen thereafter. ${ }^{46}$ We choose the size of the shock - common to all scenarios - such that the ELB constraint binds for 10 quarters under scenario (i). In scenario (ii) we consider an initial balance sheet size of $5 \%$ of GDP, a level high enough that $R_{s s}^{I B} \simeq R_{s s}^{D F}$ and hence the economy effectively rests in a floor regime. ${ }^{47}$ In scenario (iii), we assume the central bank purchases bonds for 2 periods at a speed of $1 \%$ of steady state GDP per quarter, reinvests for one period, and then lets its bond portfolio mature, ${ }^{48}$ this path for bond holdings is announced contemporaneously to the crisis shock. Finally, in scenario 4, we assume the central bank implements the same bond purchase program, but with a 4 quarter lag.

The blue lines Figure 6 display the economy's response in scenario (i), i.e. under a lean balance sheet and no QE. As households become more patient, they postpone consumption, driving down aggregate demand and inflation. The central bank responds to the fall in inflation by lowering its two policy rates - holding the corridor width constant -, but the deposit facility rate hits the ELB, preventing further (conventional) monetary accommodation for some periods.

The red lines show the responses in scenario (ii), where the central bank permanently operates a large balance sheet, i.e. a floor system. In this case the response of output and inflation is more muted and welfare is higher relative to scenario (i). This results from the fact that, in a floor system, the central bank has more policy space for conventional interest-rate policy, since the associated steady-state level of the DFR is higher than under a lean balance sheet (Proposition 5).

\footnotetext{
${ }^{46}$ We solve for the paths of the endogenous variables using the Newton-based perfect foresight solver for the non-linear model implemented in DYNARE. Notice that the future path of the exogenous variables ( $\beta$ and the unconventional policy response, if any) is revealed on the impact period.

Computing the nonlinear solution has two advantages: It allows us to consider the ELB and to capture the highly nonlinear relationship between the central bank balance sheet size and the real variables.

${ }^{47}$ As shown in Figure 4, in the euro area for excess reserve ratios above $5 \%$ the spread between the interbank rate and the DFR is stabilized at near-zero levels.

${ }^{48}$ In terms of the rule in equation (30) for central bank's bond holdings, we thus assume $n p_{t}=0.01 \times Y^{\text {annual }}$ for $t=1,2$ and $r i_{t}=1$ for $t=1,2,3$.
} 

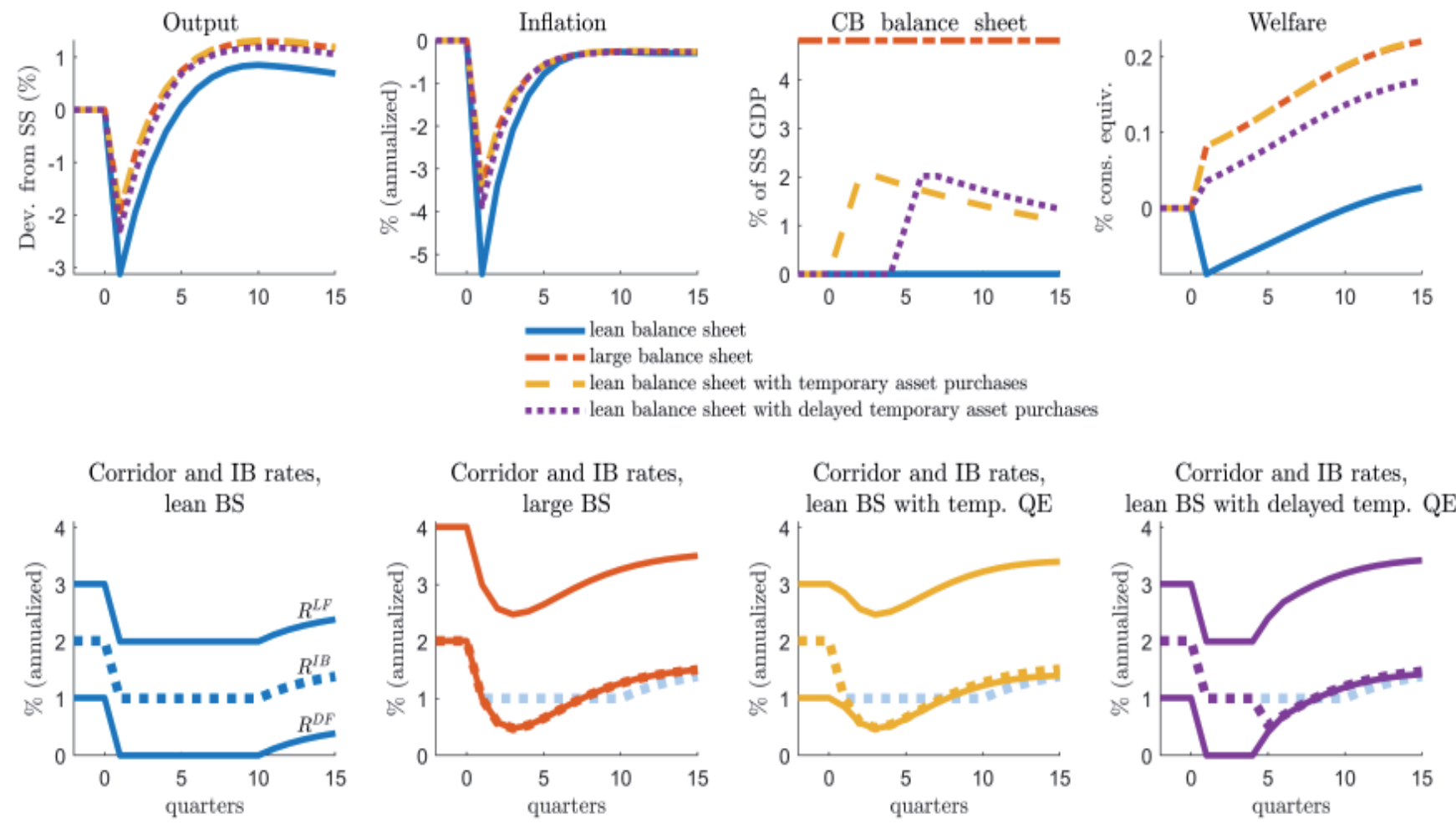

Figure 6: This figure shows the responses of key variables to the shock under the different assumptions about unconventional monetary policy. The top row compares 3 variables across different scenarios. Each of the panels in the bottom row shows the corridor rates and the interbank rate in one of the 3 scenarios. The interbank rate under the first scenario is reproduced in all panels for comparison. The deposit rate is not plotted, however it is virtually identical to the interbank rate. Figure 9 in Appendix $\mathrm{C}$ shows further varibles for the same simulations.

For our calibration, the additional stimulus afforded by the larger policy rate cut is actually enough to prevent the ELB from binding. This results in higher output, inflation and welfare. As shown in Table 3, the percentage drop on impact in output and (annualized) inflation is, respectively, 1.2 and 2.1 percentage points smaller than in scenario (i).

The yellow lines in Figure 6 display responses in scenario (iii), where the economy starts from the same lean balance sheet as in scenario (i), but the central bank engages in temporary asset purchases. This scenario illustrates in general equilibrium our 'interbank transmission channel' of temporary QE policies. As the central bank purchases bonds, the supply of funds to the interbank market increases, lowering its tightness and hence the interbank interest rate (for given interest on reserves). The lower interbank rate is passed through to households' deposit rate, thus stimulating their consumption. A temporary QE program thus allows the central bank to add further stimulus during a binding-ELB episode by pushing interbank interest rates, and all other market rates across the economy, towards the bottom of the interest rate corridor. In fact, under our calibration the 


\begin{tabular}{lrr}
\hline lean balance sheet (i) vs ... & Output & Inflation \\
\hline \hline large balance sheet (ii) & $1.2 \mathrm{ppt}$ & $2.1 \mathrm{ppt}$ \\
lean balance sheet with temporary asset purchases (iii) & $1.2 \mathrm{ppt}$ & $2.1 \mathrm{ppt}$ \\
lean balance sheet with delayed temporary asset purchases (iv) & $0.8 \mathrm{ppt}$ & $1.6 \mathrm{ppt}$ \\
\hline
\end{tabular}

Table 3: Differences between the lean balance sheet and the other three scenarios (on impact)

expansionary effect is strong enough that the DFR stays above the ELB. ${ }^{49}$ As shown in Table 3, the stabilization gains from this temporary QE are the same (up to the first decimal) as those of the floor regime.

Finally, scenario (iv) deviates from scenario (iii) in that the balance sheet expansion starts with an (anticipated) delay of 4 quarters relative to the crisis shock. While the central bank's intervention is successful in lifting the economy from the ELB once it eventually comes into force, the economy stays at the ELB for the first 4 quarters. Output, inflation and welfare are hence higher than under the lean balance sheet scenario (i) but lower than under scenarios (ii) and (iii). Indeed, these differences are significant as table 3 highlights: On impact, the delay causes additional drops of output and inflation of 0.4 and 0.5 ppt. ${ }^{50}$

Comparing the latter three scenarios highlights an important result of our model: temporary $\mathrm{QE}$ - i.e. temporary excess liquidity provision - and a permanently large balance sheet - i.e. permanent excess liquidity provision - are close substitutes, provided the former is implemented in a timely manner. In that case, both regimes are able to compress the spread between market rates and the DFR when it is most needed, i.e. during a ELB episode, or at least (as in our simulations) at times when the ELB would otherwise bind. If however QE is not implemented promptly enough (e.g. because of operational complexities or institutional constraints), then the lean-balance-sheet regime underperforms compared to the case of a permanently large balance sheet.

\section{Further analysis}

\subsection{On the marginal effectiveness of balance sheet expansions}

In section 3 we showed analytically that bond purchases are subject to (a weak form of) decreasing marginal effects on market rates. In this subsection we analyze numerically the marginal effectiveness of balance sheet policies, not only on market rates but also on macroeconomic outcomes. To this end we compare the response of the economy in scenario (iii) above with three alternative

\footnotetext{
${ }^{49}$ Notice that QE is only really effective at the ELB, when conventional monetary policy looses control over the interbank rate $R^{I B}$. During normal times conventional monetary policy (as described by the taylor rule) undoes the effect of quantitative measures.

${ }^{50} \mathrm{In}$ scenario (iv) the delayed QE is announced and anticipated in the impact quarter $(t=1)$. The paths for output, inflation and welfare would be even lower if the QE program were to come as a surprise in $t=5$.
} 

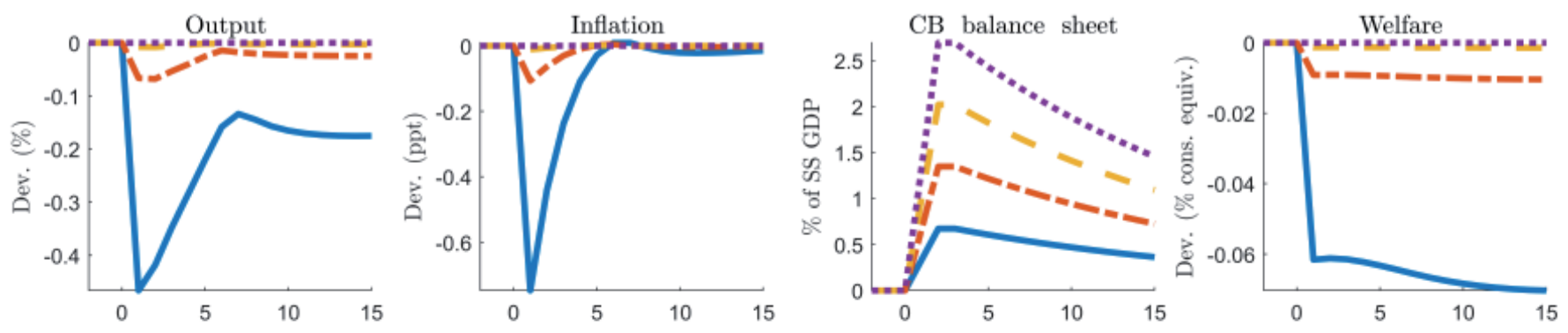

- lean balance sheet with temporary bond purchases (small)

- lean balance sheet with temporary bond purchases (benchmark

..... . lean balance sheet with temporary loans to banks (large)
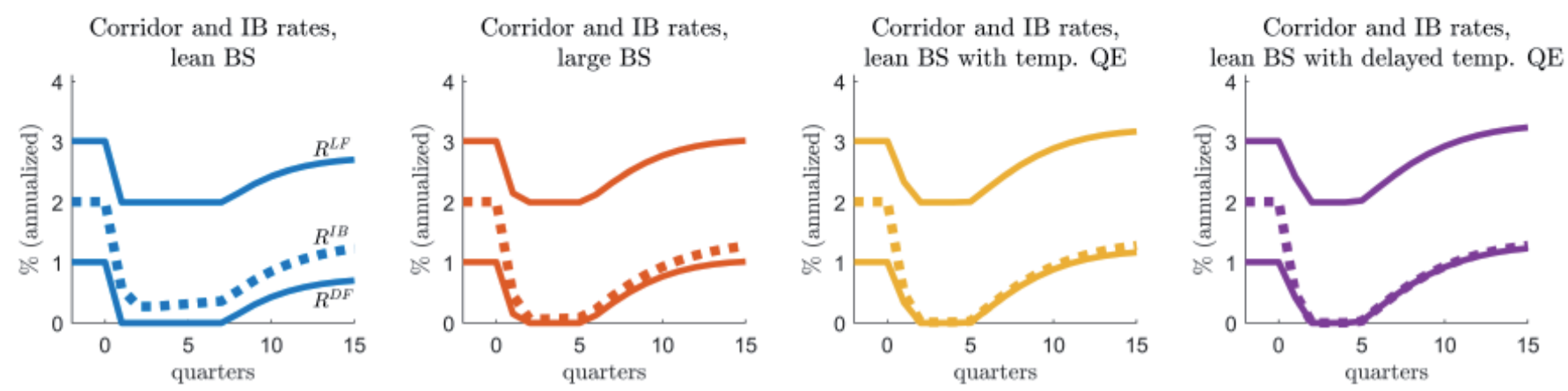

Figure 7: The panels in the first row of this figure compare the responses of key variables to a time preference shock under different assumptions about unconventional monetary policy. Output, inflation and welfare are expressed in deviations from the respective paths under the most aggresive balance sheet expansion. Each panel in the second row shows the evolution of the corridor and the interbank rates for one of the 4 scenarios.

scenarios where the path of bond purchases is as in the former scenario but scaled up or down. In particular, these scenarios feature bond purchases worth $1 / 3 \%, 2 / 3 \%, 1 \%$ and $4 / 3 \%$ of steady-state GDP for 2 quarters. ${ }^{51}$ Figure 7 compares the responses of key variables. The variables in the first row are expressed in percent deviations from the path of the corresponding variable in the fourth scenario, i.e. the one that features the largest balance sheet expansion.

Comparing the four scenarios we observe how the marginal effect of the central banks balance sheet expansion declines as the balance sheet increases. While extending purchases from $1 / 3 \%$ of GDP to $2 / 3 \%$ of GDP increases GDP by $0.4 \%$ at the peak, expending purchases to $1 \%$ of GDP only results in an additional increase of roughly 0.05\%. Any further expansion is essentially irrelevant for output. A similar pattern holds for inflation. This numerical general equilibrium result complements proposition 2, which showed that the marginal effect of QE on the interbank rate exhibits decreasing returns to scale and converges towards 0 as the balance sheet size is expanded.

\footnotetext{
${ }^{51}$ Unlike in the previous section, we now simulate a larger crisis shock, so that none of the four scenarios avoids hitting the ELB.
} 
This feature of the model is consistent with the empirical finding by Reis (2016) that only the first QE announcement in the US had a significant effect on inflation expectations, while for later QE announcements, when the Fed's balance sheet was already large, little to no effect can be found in the data.

\subsection{Central bank asset composition}

So far we have assumed that balance sheet policies take the exclusive form of bond purchases. In reality, central banks have also implemented programs aimed at providing large amounts of credit to the banking sector under more favorable conditions (in terms e.g. of pricing) than those of their lending facilities. In this section, we extend the model to allow the central bank to engage in this kind of program. We show that all our previous results go through: What matters in our model is how much excess liquidity is created through balance-sheet policies, not which assets are financed with it.

Assume in particular that, once banks draw their idiosyncratic shock $\omega_{t}^{j}$, they can obtain credit $B_{t}^{j, C B}$ from the central bank at the administered rate $R_{t}^{C F}{ }^{52}$ This rate is lies within the corridor, but it is lower than the lending facility rate, $R_{t}^{L F}$, so it is effectively subsidized. In equilibrium the effective borrowing rate equates this credit rate $R_{t}^{C F}=R_{t}^{B}{ }^{53}$ It is trivial to show that the demand and supply for interbank loans in Lemma 1 now becomes

$$
B_{t}^{+, j}= \begin{cases}(\phi-1) N_{t}^{j}-D_{t}^{j}-B_{t}^{j, C B}, & \text { if } \omega_{t}^{j}>\omega_{t}^{B}, \\ 0, & \text { if } \omega_{t}^{j}<\omega_{t}^{B},\end{cases}
$$

Defining $B_{t}^{C B} \equiv \int_{0}^{1} B_{t}^{j, C B} d j$ the aggregate amount of such credit operations, aggregate interbank borrowing orders are now given by

$$
\Phi_{t}^{B}=\left[(\phi-1) N_{t}-D_{t}\right]\left[1-F\left(\omega_{t}^{B}\right)\right]-B_{t}^{C B} .
$$

The central bank's balance sheet constraint now includes the new asset class,

$$
B_{t}^{C B}+b_{t}^{G, C B}+\Phi_{t}^{B}\left(1-\Gamma_{t}^{B}\right)=\Phi_{t}^{L}\left(1-\Gamma_{t}^{L}\right)
$$

\footnotetext{
${ }^{52}$ Central banks' large-scale credit operations typically took place only at certain dates and hence lacked the standing nature of lending facilities. To capture the latter feature in our model, we assume that, after each period's interbank trading round, those borrowing orders that have failed to find a lending bank can no longer be funded with central bank subsidized credit.

${ }^{53}$ We focus here on equilibria where the constraint $B_{t}^{j, C B} \geq 0$ is slack. In any such equilibria borrowing banks must be indifferent between going to the interbank market or directly to this credit facility.
} 
Banks equity now evolves as

$$
\frac{N_{t}}{\varsigma}=R_{t}^{A} \Omega_{t-1} Q_{t-1}^{K} K_{t-1}+\frac{R_{t-1}^{L}}{1+\pi_{t}} \Phi_{t-1}^{L}+\frac{R_{t}^{G}}{1+\pi_{t}} b_{t-1}^{G}-\frac{R_{t-1}^{D}}{1+\pi_{t}} D_{t-1}-\frac{R_{t-1}^{B}}{1+\pi_{t}} \Phi_{t-1}^{B}-\frac{R_{t-1}^{B}}{1+\pi_{t}} B_{t-1}^{C B} .
$$

All other equilibrium conditions remain unchanged.

In our model, the main difference between central bank's bond purchases and subsidized credit operations is that, ceteris paribus, the former increases the supply of funds to the interbank market, $\Phi_{t}^{L}$, whereas the latter reduces the demand for interbank funds, $\Phi_{t}^{B} \cdot{ }^{54}$ As it turns out, any equilibrium allocation that can be sustained with bond purchases can also alternatively be sustained with subsidized credit operations, as the following result establishes:

Proposition 6 (Equivalence of loan and bond programs) Assuming perfect foresight, let $X$ be the set of equilibrium sequences for all $t$ (prices, quantities and exogenous processes). Consider a particular sequence $\left\{x_{t}^{*}\right\}_{t=0}^{\infty} \in X$ which satisfies the following conditions:

1. The central bank holds some government bonds: $b_{t}^{G, C B *}>0$ for some $t$.

2. The central bank never extends any subsidized loans to banks: $B_{t}^{C B *}=0, \forall t \geq 0$.

Then there exists another sequence $\left\{x_{t}^{+}\right\}_{t=0}^{\infty} \in X$ with identical initial conditions $x_{0}^{+}=x_{0}^{*}$, which satisfies:

1. The central bank purchases no bonds: $b_{t}^{G, C B+}=0, \forall t \geq 1$.

2. At each $t$ at which the central bank holds bonds in $x_{t}^{*}$, it extends a positive but smaller amount of subsidized loans to banks in $x_{t}^{+}$. In particular

$$
B_{t}^{C B+}=b_{t}^{G, C B *} \Gamma_{t}^{L *} \leq b_{t}^{G, C B *}, \forall t \geq 1
$$

3. The sequences of all equilibrium variables besides $B_{t}^{C B+}, b_{t}^{G, C B+}, \Phi_{t}^{B+}, b_{t}^{G+}$ and $\Phi_{t}^{L+}$ are equal in both sequences.

The proof can be found in Appendix A. This proposition states that it is essentially irrelevant which of the two instruments the central bank uses to affect the liquidity conditions in the interbank market. The intuition is that, by purchasing bonds, the central bank increases the supply of funds to the interbank market, while by providing loans to banks it reduces the demand of interbank

\footnotetext{
${ }^{54} \mathrm{~A}$ second, comparatively minor difference is that the maximum size of the lending program is given by borrowing banks' total demand for funds, $\left[(\phi-1) N_{t}-D_{t}\right]\left[1-F\left(\omega_{t}^{B}\right)\right]$, whereas bond purchases are limited by the size of the bond market, $\bar{b}_{t}$.
} 


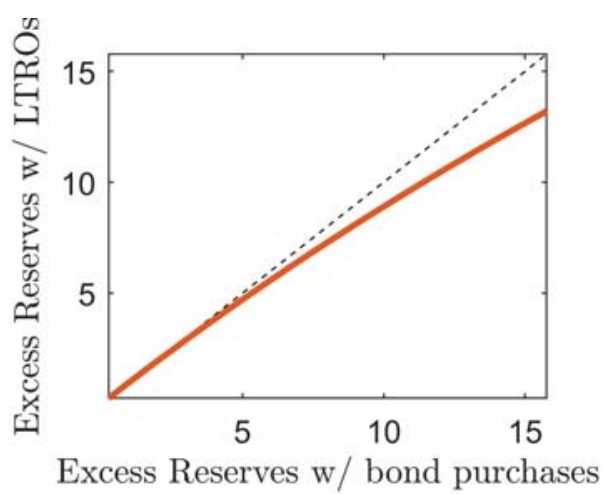

Figure 8: This figure shows by how much the central bank needs to expand its balance sheet by issuing bonds in order to obtain the allocation associated with the amount of governemnet bond purchases on the $\mathrm{x}$ axis. On both axis, the excess reserves are expressed as fraction of steady state GDP. The dashed line is the 45 degree line.

funds. Both interventions can equally increase the ratio of interbank borrowing over lending orders, which in turn affects each side's matching probabilities and surplus share. ${ }^{55}$ Importantly, this proposition implies that all previous propositions, relative to the effect of bond purchases, have counterparts relative to the effects of credit operations.

The proposition entails an interesting detail. The central bank can obtain the allocation associated with a certain level of public bond purchases by alternatively issuing a smaller level of credit operations $\left(B_{t}^{C B+} \leq b_{t}^{G, C B *}\right)$. Figure 8 shows this relationship in steady state for the calibrated model. As the figure shows, the larger the balance sheet is, the larger is the difference between the amounts required in the two cases. For instance, to obtain the same steady state allocation associated to a balance sheet size of $15 \%$ of GDP achieved by expanding bonds holdings, the central bank would alternatively need to expand credit operations until achieving a balance sheet size of about $13 \%$ of GDP.

We have also repeated the dynamic simulations in the previous section assuming that, instead of purchasing bonds, the central bank implements credit operations in the same amounts. We find the differences to be quantitatively negligible. ${ }^{56}$ This is in line with the fact that the empirical relationship between volume and return spread of excess reserves seen in Figure 4 seems not to be affected by the fact that the ECB's balance sheet policies went through two differentiated phases, with credit operations dominating until 2015 and asset purchases largely taking over from there on (see again Figure 1).

\footnotetext{
${ }^{55}$ Due to the different (long-term) government bonds and (one-period) credit operations, our equivalence result holds only under perfect foresight. With aggregate uncertainty, interest rate risk would matter and the result would hold exactly only if government bonds had the same maturity as credit operations; the result would still holds up to a first order approximation in the first period of the implementation of either program.

${ }^{56}$ These simulations are not shown here for brevity but are available upon request.
} 


\section{Conclusion}

The quantitative easing (QE) policies implemented by central banks across many advanced economies in order to combat the effect of the recent crisis has given rise to an unprecedented increase in the size of their balance sheets and the volume of excess reserves, which in parallel has pushed interbank and other money market rates towards their floor: the interest on excess reserves ('floor system'). With macroeconomic fundamentals gradually improving, such central banks now face the dilemma as to whether to keep this large balance sheet/floor regime, or else to return to the relatively small pre-crisis balance sheets with low levels of excess reserves and interbank rates trading in the middle of the corridor formed by central banks' lending and deposit facility rates ('corridor system'). This paper has proposed a New Keynesian model with a banking sector and an interbank market characterized by search and matching friction with the aim of comparing the stabilization and welfare properties of the floor and corridor regimes.

Our analysis has first uncovered a novel mechanism through which QE can be effective, overturning the famous irrelevance result of Wallace (1981) and Eggertsson and Woodford (2003). Because of matching frictions in the interbank market, the position of the equilibrium interbank rate - and of other market rates relevant for private spending - inside the corridor depends on the relative volumes of lending and borrowing orders, i.e. on interbank market tightness. By purchasing government bonds or run credit operations with banks, the central bank can make the interbank market more slack and thus push the interbank rate down towards the bottom of the corridor, thus stimulating economic activity. Our model replicates well the observed relationship between the quantity of excess reserves and the spread between money market rates and the deposit facility rate in the euro area. It also speaks to empirical evidence in studies such as Reis (2016) - where the first QE program in the US is found to be more effective than subsequent ones - and Christensen and Krogstrup (2018) - where the reserves expansion produced by QE affects the economy through banks' portfolios, regardless of the type of assets being purchased.

Comparing lean vs. large balance sheet regimes, we find that the latter provides the central bank with more policy space for conventional interest rate policy vis-à-vis the effective lower bound (ELB). At the same time, we show that a regime that combines a lean balance sheet with temporary but quick balance sheet expansions at the ZLB provides a very similar degree of policy accommodation. In practice, though, such quick adjustments of the central bank balance sheet might be difficult for operational or institutional reasons. In those cases, our model provides a rationale for choosing a floor over a corridor system, even for normal times. Such a floor system requires the central bank to hold an amount of assets large enough to drive the spread between the interbank and the deposit facility rate to (close to) zero.

Some caveats are in order. Our model ignores a number of factors that are potentially relevant for the design of central banks' balance sheet size (and composition), such as the potential for operating losses and the resulting implications for their intertemporal insolvency and - ultimately 
- their independence from fiscal authorities (see e.g. Hall and Reis 2015 and Del Negro and Sims 2015), as well as financial stability concerns (Greenwood et al. 2016). Hence, our analysis should be viewed as suggesting an additional, complementary argument to be considered in this debate.

Finally, our results depend on the central bank charging a positive spread between its deposit and lending facility rates. This policy has a centuries old tradition going back to Bagehot, is ubiquitous until today, and the size of the spread is typically non-negligible. However, we did not explicitly model a reason for why such a spread exists. Instead, we assumed the existence of an interest rate corridor (with an exogenous width) and then assessed the implications of our framework for the stabilization properties of small- and large-balance-sheet regimes. In fact, the modern academic literature is largely silent on the question as to why and how to set such a spread. Understanding this issue better, and especially integrating the resulting insights into DSGE environments like the one proposed here, is an important task that we leave for future research. 


\section{References}

[1] Afonso, Gara and Lagos, Ricardo (2015). "Trade Dynamics in the Market for Federal Funds," Econometrica, 83 (1), 263-313.

[2] Armenter, Roc and Lester, Benjamin (2017). "Excess Reserves and Monetary Policy Implementation," Review of Economic Dynamics, 23, 212-235.

[3] Atkeson, Andrew, Eisfeldt, Andrea L. and Weill, Pierre-Olivier (2015). "Entry and Exit in OTC Derivatives Markets", Econometrica, 83 (6), 2231-2292.

[4] Bech, Morten and Monnet, Cyril (2016). "A search-based model of the interbank money market and monetary policy implementation," Journal of Economic Theory, 164(C), 32-67.

[5] Bernanke, Ben (2016). "Should the Fed keep its balance sheet large?", September 2, Blog entry.

[6] Bianchi, Javier and Bigio, Saki (2017). "Banks, Liquidity Management, and Monetary Policy," Working paper.

[7] Christensen, Jens and Krogstrup, Signe (2017). "A Portfolio Model of Quantitative Easing" Federal Reserve Bank of San Francisco Working Paper 2016-12.

[8] Christensen, Jens and Krogstrup, Signe (2018). "Transmission of Quantitative Easing: The Role of Central Bank Reserves", Economic Journal, forthcoming.

[9] Buera, Francisco and Moll, Benjamin (2015). Aggregate Implications of a Credit Crunch: The Importance of Heterogeneity, American Economic Journal: Macroeconomics, 7(3), 1-42.

[10] Bullard, James (2017). "The Role of the Fed's Balance Sheet for the U.S. Monetary Policy Outlook in 2017", GWU Alumni Lecture in Economics, George Washington University, February 28. Link: https://www.stlouisfed.org/ /media/Files/PDFs/Bullard/remarks/2017/Bullard_GWU_. Alumni_Lect

[11] Chen, Han, Cúrdia, Vasco and Ferrero, Andrea (2012). "The Macroeconomic Effects of Largescale Asset Purchase Programmes", The Economic Journal, 122, 289-315.

[12] Cúrdia, Vasco and Woodford, Michael (2011). "The central-bank balance sheet as an instrument of monetarypolicy", Journal of Monetary Economics, Elsevier, 58(1), 54-79.

[13] Calvo, Guillermo, (1983). "Staggered prices in a utility-maximizing framework", Journal of Monetary Economics, 12(3), 383-398. 
[14] Del Negro, Marco and Sims, Christopher (2015). "When does a central bank's balance sheet require fiscal support?," Journal of Monetary Economics, 73(C), 1-19.

[15] Eggertsson, Gauti and Woodford, Michael (2003). "The Zero Bound on Interest Rates and Optimal Monetary Policy." Brookings Papers on Economic Activity, 2003(1), 139-211.

[16] den Haan, Wouter, Ramey, Garey and Watson, Joel (2000). "Job Destruction and Propagation of Shocks," American Economic Review, 90(3), 482-498.

[17] Gertler, Mark and Karadi, Peter (2011). "A model of unconventional monetary policy," Journal of Monetary Economics, 58(1), 17-34.

[18] Gertler, Mark and Karadi, Peter (2013). "QE 1 vs. 2 vs. 3. . . : A Framework for Analyzing Large-Scale Asset Purchases as a Monetary Policy Tool," International Journal of Central Banking, 9(1), 5-53.

[19] Gertler, Mark and Kiyotaki, Nobuhiro (2010). "Financial Intermediation and Credit Policy in Business Cycle Analysis," Handbook of Monetary Economics, in: Benjamin M. Friedman \& Michael Woodford (ed.), Handbook of Monetary Economics, edition 1, volume 3, chapter 11, pages 547-599.

[20] Greenwood, Robin, Hanson, Samuel and Stein, Jeremy (2016). "The Federal Reserve's Balance Sheet as a Financial-Stability Tool." 2016 Economic Policy Symposium Proceedings. Jackson Hole: Federal Reserve Bank of Kansas City.

[21] Hall, Robert and Reis, Ricardo (2015). "Maintaining Central-Bank Financial Stability under New-Style Central Banking," NBER Working Papers 21173, National Bureau of Economic Research.

[22] Ireland, Peter (2014). "The Macroeconomic Effects Of Interest On Reserves," Macroeconomic Dynamics, 18(6), 1271-1312.

[23] Moen, Espen (1997). "Competitive Search Equilibrium", Journal of Political Economy, 105(2), 385-411.

[24] Mortensen, Dale and Pissarides, Christopher (1999). "Job reallocation, employment fluctuations and unemployment," Handbook of Macroeconomics,in: J. B. Taylor \& M. Woodford (ed.), Handbook of Macroeconomics, edition 1, volume 1, chapter 18, pages 1171-1228 Elsevier.

[25] Nuño, Galo, and Thomas, Carlos (2017). "Bank Leverage Cycles." American Economic Journal: Macroeconomics, 9(2), 32-72. 
[26] Poole, William. (1968). "Commercial bank reserve management in a stochastic model: implications for monetary policy", The Journal of Finance, 23, 769-791.

[27] Primiceri, Giorio, Schaumburg, Ernst and Tambalotti, Andrea (2006). "Intertemporal disturbances", NBER WP12243.

[28] Reis, Ricardo (2016). "Funding Quantitative Easing to Target Inflation," in: Designing Resilient Monetary Policy Frameworks for the Future, Jackson Hole Economic Policy Symposium: Federal Reserve Bank of Kansas City.

[29] Wallace, Neil (1981). "A Modigliani-Miller Theorem for Open-Market Operations," The American Economic Review, 71(3), 267-74

[30] Woodford, Michael (2001). "Fiscal Requirements for Price Stability," Journal of Money, Credit and Banking, 33(3), 669-728. 


\section{Appendix}

\section{A Proofs}

\section{A.1 Proof of Lemma 1 (Bank's problem)}

Bank $j$ 's problem at the beginning of period $t$ is the following,

$$
\begin{gathered}
V_{t}\left(N_{t}^{j}\right)=\max _{D_{t}^{j}} \int \bar{V}_{t}\left(N_{t}^{j}, D_{t}^{j}, \omega\right) d F(\omega), \\
\bar{V}_{t}\left(N_{t}^{j}, D_{t}^{j}, \omega_{t}^{j}\right)=\max _{A_{t}^{j} \geq 0, b_{t}^{G, j} \geq 0, B_{t}^{+, j} \geq 0, B_{t}^{-, j} \geq 0} \mathbb{E}_{t} \Lambda_{t, t+1}\left[(1-\varsigma) E_{t+1}^{j}+V_{t+1}\left(\varsigma E_{t+1}^{j}\right)\right],
\end{gathered}
$$

subject to

$$
\begin{gathered}
Q_{t}^{K} A_{t}^{j}+b_{t}^{G, j}+B_{t}^{-, j}=N_{t}^{j}+B_{t}^{+, j}+D_{t}^{j}, \\
Q_{t}^{K} A_{t}^{j} \leq \phi N_{t}^{j}
\end{gathered}
$$

where

$$
E_{t+1}^{j}=R_{t+1}^{A} \omega_{t}^{j} Q_{t}^{K} A_{t}^{j}+\frac{R_{t+1}^{G} b_{t}^{j, G}+R_{t}^{L} B_{t}^{-, j}}{1+\pi_{t+1}}-\frac{R_{t}^{D} D_{t}^{j}+R_{t}^{B} B_{t}^{+, j}}{1+\pi_{t+1}}
$$

We use (42) to substitute for $B_{t}^{j,+}$ in the above problem. Let $\lambda_{A t}^{j}, \lambda_{G t}^{j}, \lambda_{B t}^{+, j}, \lambda_{B t}^{-, j}, \lambda_{\phi t}^{j}$ denote the Lagrange multipliers associated to $A_{t}^{j} \geq 0, b_{t}^{G, j} \geq 0, B_{t}^{+, j} \geq 0, B_{t}^{-, j} \geq 0$ and the leverage constraint (43), respectively. A solution to the banks problem must satisfy both the FOC with respect to $D_{t}^{j}, A_{t}^{j}, b_{t}^{G, j}, B_{t}^{-, j}$, given respectively by

$$
\begin{aligned}
\int \frac{\partial \bar{V}_{t}}{\partial D_{t}^{j}}\left(N_{t}^{j}, D_{t}^{j}, \omega\right) d F(\omega) & =0, \\
\mathbb{E}_{t} \Lambda_{t, t+1}\left[1-\varsigma+\varsigma V_{t+1}^{\prime}\left(N_{t+1}^{j}\right)\right]\left(R_{t+1}^{A} \omega_{t}^{j}-\frac{R_{t}^{B}}{1+\pi_{t+1}}\right)+\frac{\lambda_{A t}^{j}}{Q_{t}^{K}}+\lambda_{B t}^{+, j}-\lambda_{\phi t}^{j} & =0, \\
\mathbb{E}_{t} \Lambda_{t, t+1}\left[1-\varsigma+\varsigma V_{t+1}^{\prime}\left(N_{t+1}^{j}\right)\right]\left(\frac{R_{t+1}^{G}-R_{t}^{B}}{1+\pi_{t+1}}\right)+\lambda_{G t}^{j}+\lambda_{B t}^{+, j} & =0, \\
\mathbb{E}_{t} \Lambda_{t, t+1}\left[1-\varsigma+\varsigma V_{t+1}^{\prime}\left(N_{t+1}^{j}\right)\right]\left(\frac{R_{t}^{L}-R_{t}^{B}}{1+\pi_{t+1}}\right)+\lambda_{B t}^{-, j}+\lambda_{B t}^{+, j} & =0
\end{aligned}
$$

and the Kuhn Tucker conditions 


$$
\begin{aligned}
\min \left(A_{t}^{j}, \lambda_{A t}^{j}\right) & =0 \\
\min \left(b_{t}^{G, j}, \lambda_{G t}^{j}\right) & =0, \\
\min \left(B_{t}^{-, j}, \lambda_{B t}^{+, j}\right) & =0 \text { where } B_{t}^{-, j}=Q_{t}^{K} A_{t}^{j}+b_{t}^{G, j}+B_{t}^{-, j}-N_{t}^{j}-D_{t}^{j}, \\
\min \left(B_{t}^{-, j}, \lambda_{B t}^{-, j}\right) & =0, \\
\min \left(\phi N_{t}^{j}-Q_{t}^{K} A_{t}^{j}, \lambda_{\phi t}^{j}\right) & =0 .
\end{aligned}
$$

Using the envelope condition

$$
\frac{\partial \bar{V}_{t}}{\partial D_{t}^{j}}\left(N_{t}^{j}, D_{t}^{j}, \omega_{t}^{j}\right)=\mathbb{E}_{t} \Lambda_{t, t+1}\left[1-\varsigma+\varsigma V_{t+1}^{\prime}\left(N_{t+1}^{j}\right)\right]\left(\frac{R_{t}^{B}-R_{t}^{D}}{1+\pi_{t+1}}\right)-\lambda_{B t}^{+, j}
$$

using $N_{t+1}^{j}=\varsigma E_{t+1}^{j}$ we can express the FOC with respect to deposits (45) $\operatorname{as}^{57}$

$$
\int \mathbb{E}_{t} \Lambda_{t, t+1}\left[1-\varsigma+\varsigma V_{t+1}^{\prime}\left(N_{t+1}^{j}\right)\right]\left(\frac{R_{t}^{B}-R_{t}^{D}}{1+\pi_{t+1}}\right) d F(\omega)-\int \lambda_{B t}^{+, j} d F(\omega)=0 .
$$

The marginal value of equity is given by the envelope condition

$$
V_{t}^{\prime}\left(N_{t}^{j}\right)=\int \frac{\partial \bar{V}_{t}}{\partial N_{t}^{j}}\left(N_{t}^{j}, D_{t}^{j}, \omega\right) d F(\omega)
$$

where

$$
\frac{\partial \bar{V}_{t}}{\partial N_{t}^{j}}\left(N_{t}^{j}, D_{t}^{j}, \omega_{t}^{j}\right)=\mathbb{E}_{t} \Lambda_{t, t+1}\left[1-\varsigma+\varsigma V_{t+1}^{\prime}\left(N_{t+1}^{j}\right)\right] \frac{R_{t}^{B}}{1+\pi_{t+1}}-\lambda_{B t}^{+, j}+\lambda_{\phi t}^{j} \phi .
$$

We guess that in equilibrium $V_{t}^{\prime}\left(N_{t}^{j}\right) \equiv \lambda_{t}^{N}$ is equalized across banks. Let $\tilde{\Lambda}_{t, t+1} \equiv \Lambda_{t, t+1}\left(1-\varsigma+\varsigma \lambda_{t+1}^{N}\right)$. We also make use of the fact that in equilibrium $R_{t}^{B} \geq R_{t}^{L}$, as shown in Section 2.7 in the main text.

Conjectured solution. We conjecture the following solution for the bank's problem. For some thresholds $\omega_{t}^{B}, \omega_{t}^{L}$ to be derived below:

- Banks with $\omega_{t}^{j}>\omega_{t}^{B}$ borrow in the interbank market up to the leverage constraint,

$$
\begin{gathered}
A_{t}^{j}=\phi N_{t}^{j} / Q_{t}^{K}, \\
B_{t}^{+, j}=(\phi-1) N_{t}^{j}-D_{t}^{j}, \\
b_{t}^{G, j}=B_{t}^{-, j}=0,
\end{gathered}
$$

together with $\lambda_{A t}^{j}=\lambda_{B t}^{+, j}=0<\lambda_{\phi t}^{j}$, and $\lambda_{G t}^{j}, \lambda_{B t}^{-, j} \geq 0$;

\footnotetext{
${ }^{57}$ Notice that the first integrand in equation (55) depends on $\omega_{t}^{j}$ through the term $N_{t+1}^{j}=\varsigma E_{t+1}^{j}$, where in turn $E_{t+1}^{j}$ is given by equation (44).
} 
- Banks with $\omega_{t}^{j} \in\left[\omega_{t}^{L}, \omega_{t}^{B}\right]$ invest their equity and deposits in real assets,

$$
\begin{gathered}
A_{t}^{j}=\left(N_{t}^{j}+D_{t}^{j}\right) / Q_{t}^{K} \leq \phi N_{t}^{j} / Q_{t}^{K}, \\
b_{t}^{G, j}=B_{t}^{-, j}=B_{t}^{+, j}=0,
\end{gathered}
$$

together with $\lambda_{A t}^{j}=\lambda_{\phi t}^{j}=0 \leq \lambda_{B t}^{-, j}, \lambda_{G t}^{j}, \lambda_{B t}^{+, j}$, the latter with strict inequality if $\omega_{t}^{j} \in\left(\omega_{t}^{L}, \omega_{t}^{B}\right)$;

- Banks with $\omega_{t}^{j}<\omega_{t}^{L}$ invest their equity and deposits in the interbank and government bond markets,

$$
\begin{gathered}
A_{t}^{j}=B_{t}^{+, j}=0, \\
b_{t}^{G, j}+B_{t}^{-, j}=N_{t}^{j}+D_{t}^{j},
\end{gathered}
$$

together with $\lambda_{G t}^{j}=\lambda_{B t}^{-, j}=\lambda_{\phi t}^{j}=0<\lambda_{A t}^{j}$ and $\lambda_{B t}^{+, j} \geq 0$.

Also, each bank's deposits $D_{t}^{j}$ are not determined but are only required to be in the range $\left[0,(\phi-1) N_{t}^{j}\right]$.

Verifying the conjecture. We now use our conjectured solution to evaluate the FOCs conditional on $\omega_{t}^{j}$ :

- FOC with respect to $A_{t}^{j}$ :

- Case $\omega_{t}^{j}>\omega_{t}^{B}$ :

$$
\lambda_{\phi t}^{j}=\mathbb{E}_{t}\left[\tilde{\Lambda}_{t, t+1}\left(R_{t+1}^{A} \omega_{t}^{j}-\frac{R_{t}^{B}}{1+\pi_{t+1}}\right)\right]>0 \Leftrightarrow \omega_{t}^{j}>\frac{\mathbb{E}_{t}\left[\tilde{\Lambda}_{t, t+1} \frac{R_{t}^{B}}{1+\pi_{t+1}}\right]}{\mathbb{E}_{t}\left[\tilde{\Lambda}_{t, t+1} R_{t+1}^{A}\right]} \equiv \omega_{t}^{B} .
$$

- Case $\omega_{t}^{L} \leq \omega_{t}^{j} \leq \omega_{t}^{B}:$

$$
\lambda_{B t}^{+, j}=\mathbb{E}_{t}\left[\tilde{\Lambda}_{t, t+1}\left(\frac{R_{t}^{B}}{1+\pi_{t+1}}-R_{t+1}^{A} \omega_{t}^{j}\right)\right] \geq \mathbb{E}_{t}\left[\tilde{\Lambda}_{t, t+1}\left(\frac{R_{t}^{B}}{1+\pi_{t+1}}-R_{t+1}^{A} \omega_{t}^{B}\right)\right]=0
$$

- Case $\omega_{t}^{j}<\omega_{t}^{L}$ :

$$
\mathbb{E}_{t}\left[\tilde{\Lambda}_{t, t+1}\left(R_{t+1}^{A} \omega_{t}^{j}-\frac{R_{t}^{B}}{1+\pi_{t+1}}\right)\right]+\frac{\lambda_{A t}^{j}}{Q_{t}^{K}}+\lambda_{B t}^{+, j}=0 .
$$


- FOC with respect to $b_{t}^{G, j}$ :

- Case $\omega_{t}^{j}>\omega_{t}^{B}$ :

$$
\lambda_{G t}^{j}=\mathbb{E}_{t}\left[\tilde{\Lambda}_{t, t+1} \frac{R_{t}^{B}-R_{t+1}^{G}}{1+\pi_{t+1}}\right] \geq 0
$$

- Case $\omega_{t}^{L} \leq \omega_{t}^{j} \leq \omega_{t}^{B}$ :

$$
\mathbb{E}_{t}\left[\tilde{\Lambda}_{t, t+1} \frac{R_{t+1}^{G}-R_{t}^{B}}{1+\pi_{t+1}}\right]+\lambda_{G t}^{j}+\lambda_{B t}^{+, j}=0
$$

- Case $\omega_{t}^{j}<\omega_{t}^{L}$ :

$$
\lambda_{B t}^{+, j}=\mathbb{E}_{t}\left[\tilde{\Lambda}_{t, t+1} \frac{R_{t}^{B}-R_{t+1}^{G}}{1+\pi_{t+1}}\right] \geq 0,
$$

where in (61) and (63) we conjecture (and verify below) that

$$
\mathbb{E}_{t}\left[\tilde{\Lambda}_{t, t+1} \frac{R_{t}^{B}}{1+\pi_{t+1}}\right] \geq \mathbb{E}_{t}\left[\tilde{\Lambda}_{t, t+1} \frac{R_{t+1}^{G}}{1+\pi_{t+1}}\right] .
$$

- FOC with respect to $B_{t}^{-, j}$ :

- Case $\omega_{t}^{j}>\omega_{t}^{B}$ :

$$
\lambda_{B t}^{-, j}=\mathbb{E}_{t}\left[\tilde{\Lambda}_{t, t+1} \frac{R_{t}^{B}-R_{t}^{L}}{1+\pi_{t+1}}\right] \geq 0,
$$

- Case $\omega_{t}^{L} \leq \omega_{t}^{j} \leq \omega_{t}^{B}$ :

$$
\mathbb{E}_{t}\left[\tilde{\Lambda}_{t, t+1} \frac{R_{t}^{L}-R_{t}^{B}}{1+\pi_{t+1}}\right]+\lambda_{B t}^{-, j}+\lambda_{B t}^{+, j}=0
$$

- Case $\omega_{t}^{j}<\omega_{t}^{L}$ :

$$
\lambda_{B t}^{+, j}=\mathbb{E}_{t}\left[\tilde{\Lambda}_{t, t+1} \frac{R_{t}^{B}-R_{t}^{L}}{1+\pi_{t+1}}\right] \geq 0 .
$$

- The Kuhn Tucker conditions (49), (50), (52), (53) are obviously satisfied as well. 51 obviously holds for $\omega_{t}^{j} \leq \omega_{t}^{B}$. For $\omega_{t}^{j}>\omega_{t}^{B}$ this condition holds since we conjectured $B_{t}^{-, j}=(\phi-1) N_{t}^{j}-$ $D_{t}^{j}$ and $D_{t}^{j} \in\left[0,(\phi-1) N_{t}^{j}\right]$.

Equations (63) and (66) imply

$$
\mathbb{E}_{t}\left[\tilde{\Lambda}_{t, t+1} \frac{R_{t}^{L}}{1+\pi_{t+1}}\right]=\mathbb{E}_{t}\left[\tilde{\Lambda}_{t, t+1} \frac{R_{t+1}^{G}}{1+\pi_{t+1}}\right]
$$


i.e. the (expected risk-adjusted real) return on government bonds equals the (expected riskadjusted real) effective lending rate $R_{t}^{L}$. The latter condition, together with the equilibrium relationship $R_{t}^{B} \geq R_{t}^{L}$, verifies our conjecture that $\mathbb{E}_{t}\left[\tilde{\Lambda}_{t, t+1} \frac{R_{t}^{B}}{1+\pi_{t+1}}\right] \geq \mathbb{E}_{t}\left[\tilde{\Lambda}_{t, t+1} \frac{R_{t+1}^{G}}{1+\pi_{t+1}}\right]$. Using (66) to substitute for $\lambda_{B t}^{+, j}$ in (60) yields

$$
\frac{\lambda_{A t}^{j}}{Q_{t}^{K}}=\mathbb{E}_{t}\left[\tilde{\Lambda}_{t, t+1}\left(\frac{R_{t}^{L}}{1+\pi_{t+1}}-R_{t+1}^{A} \omega_{t}^{j}\right)\right]>0 \Leftrightarrow \omega_{t}^{j}<\frac{\mathbb{E}_{t}\left[\tilde{\Lambda}_{t, t+1} \frac{R_{t}^{L}}{1+\pi_{t+1}}\right]}{\mathbb{E}_{t}\left[\tilde{\Lambda}_{t, t+1} R_{t+1}^{A}\right]} \equiv \omega_{t}^{L}
$$

Thus, the threshold definitions (58) and (67), together with the equilibrium relationship $R_{t}^{B} \geq R_{t}^{L}$, imply

$$
\omega_{t}^{L} \geq \omega_{t}^{B}
$$

Using (59) to substitute for $\lambda_{B t}^{+, j}$ in (65) and (62) yields, respectively,

$$
\begin{aligned}
& \lambda_{B t}^{-, j}=\mathbb{E}_{t}\left[\tilde{\Lambda}_{t, t+1}\left(R_{t+1}^{A} \omega_{t}^{j}-\frac{R_{t}^{L}}{1+\pi_{t+1}}\right)\right] \geq \mathbb{E}_{t}\left[\tilde{\Lambda}_{t, t+1}\left(R_{t+1}^{A} \omega_{t}^{L}-\frac{R_{t}^{L}}{1+\pi_{t+1}}\right)\right]=0, \\
& \lambda_{G t}^{j}=\mathbb{E}_{t}\left[\tilde{\Lambda}_{t, t+1}\left(R_{t+1}^{A} \omega_{t}^{j}-\frac{R_{t+1}^{G}}{1+\pi_{t+1}}\right)\right]=\mathbb{E}_{t}\left[\tilde{\Lambda}_{t, t+1}\left(R_{t+1}^{A} \omega_{t}^{j}-\frac{R_{t}^{L}}{1+\pi_{t+1}}\right)\right] \geq 0 .
\end{aligned}
$$

Equilibrium deposit rate. We can write (55) as

$$
\mathbb{E}_{t}\left[\frac{\tilde{\Lambda}_{t, t+1} R_{t}^{D}}{1+\pi_{t+1}}\right]=\mathbb{E}_{t}\left[\frac{\tilde{\Lambda}_{t, t+1} R_{t}^{B}}{1+\pi_{t+1}}\right]-\int \lambda_{B t}^{+, j} d F(\omega)
$$

Using the equilibrium values of $\lambda_{B t}^{+, j}$ in equations (59) for $\omega_{t}^{j} \in\left[\omega_{t}^{L}, \omega_{t}^{B}\right]$ and (66) for $\omega_{t}^{j}<\omega_{t}^{L}$, as well as the fact that $\lambda_{B t}^{+, j}=0$ for $\omega_{t}^{j}>\omega_{t}^{B}$, we finally obtain

$$
\begin{aligned}
\mathbb{E}_{t} \frac{\tilde{\Lambda}_{t, t+1} R_{t}^{D}}{1+\pi_{t+1}}= & \mathbb{E}_{t} \frac{\tilde{\Lambda}_{t, t+1} R_{t}^{B}}{1+\pi_{t+1}}-\mathbb{E}_{t} \frac{\tilde{\Lambda}_{t, t+1}\left(R_{t}^{B}-R_{t}^{L}\right)}{1+\pi_{t+1}} F\left(\omega_{t}^{L}\right)-\int_{\omega_{t}^{L}}^{\omega_{t}^{B}} \mathbb{E}_{t} \tilde{\Lambda}_{t, t+1}\left(\frac{R_{t}^{B}}{1+\pi_{t+1}}-R_{t+1}^{A} \omega_{t}^{j}\right) d F(\omega) \\
= & {\left[1-F\left(\omega_{t}^{B}\right)\right] \mathbb{E}_{t}\left[\frac{\tilde{\Lambda}_{t, t+1} R_{t}^{B}}{1+\pi_{t+1}}\right]+F\left(\omega_{t}^{L}\right) \mathbb{E}_{t}\left[\frac{\tilde{\Lambda}_{t, t+1} R_{t}^{L}}{1+\pi_{t+1}}\right] } \\
& +\left[F\left(\omega_{t}^{B}\right)-F\left(\omega_{t}^{L}\right)\right] \mathbb{E}\left(\omega \mid \omega_{t}^{L} \leq \omega \leq \omega_{t}^{B}\right) \mathbb{E}_{t}\left[\tilde{\Lambda}_{t, t+1} R_{t+1}^{A}\right]
\end{aligned}
$$

where $\mathbb{E}\left(\omega \mid \omega_{t}^{L} \leq \omega \leq \omega_{t}^{B}\right) \equiv\left[F\left(\omega_{t}^{B}\right)-F\left(\omega_{t}^{L}\right)\right]^{-1} \int_{\omega_{t}^{L}}^{\omega_{t}^{B}} \omega d F(\omega)$. Therefore, the (expected riskadjusted real) marginal cost of deposits, $R_{t}^{D} \mathbb{E}_{t}\left[\frac{\tilde{\Lambda}_{t, t+1}}{1+\pi_{t+1}}\right]$, must equal the (expected risk-adjusted real) marginal benefit across realizations of $\omega_{t}^{j}$ after the closing of the deposits market. Conditional on being a high-profitability bank that is leveraged up to the maximum $\left(\omega_{t}^{j} \geq \omega_{t}^{B}\right)$, an 
additional unit of deposits will allow it to reduce its interbank funding needs by one unit, thus saving $R_{t}^{B} \mathbb{E}_{t}\left[\frac{\tilde{\Lambda}_{t, t+1}}{1+\pi_{t+1}}\right]$ in expected real risk-adjusted terms. Conditional on being a low-profitability bank $\left(\omega_{t}^{j} \leq \omega_{t}^{L}\right)$, each additional unit of deposits will be invested in interbank lending or government bonds, which yields $R_{t}^{L} \mathbb{E}_{t}\left[\frac{\tilde{\Lambda}_{t, t+1}}{1+\pi_{t+1}}\right]\left(=\mathbb{E}_{t}\left[\frac{\tilde{\Lambda}_{t, t+1}}{1+\pi_{t+1}} R_{t+1}^{G}\right]\right)$. For intermediate-profitability banks $\left(\omega_{t}^{L} \leq \omega_{t}^{j} \leq \omega_{t}^{B}\right)$, each additional unit of deposits will be invested in real firm assets, which yields $\mathbb{E}_{t}\left[\tilde{\Lambda}_{t, t+1} R_{t+1}^{A}\right] \mathbb{E}\left(\omega \mid \omega_{t}^{L} \leq \omega \leq \omega_{t}^{B}\right)$ on average.

To prove that $R_{t}^{D} \in\left[R_{t}^{L}, R_{t}^{B}\right]$, notice that, using the definition of the borrowing threshold $\omega_{t}^{B}$ (see eq. 58), we can express (68) as

$$
\begin{aligned}
R_{t}^{D} & =\left[1-F\left(\omega_{t}^{B}\right)\right] R_{t}^{B}+F\left(\omega_{t}^{L}\right) R_{t}^{L}+\left[F\left(\omega_{t}^{B}\right)-F\left(\omega_{t}^{L}\right)\right] \frac{\mathbb{E}\left(\omega \mid \omega_{t}^{L} \leq \omega \leq \omega_{t}^{B}\right)}{\omega_{t}^{B}} R_{t}^{B} \\
& \leq\left[1-F\left(\omega_{t}^{B}\right)\right] R_{t}^{B}+F\left(\omega_{t}^{L}\right) R_{t}^{B}+\left[F\left(\omega_{t}^{B}\right)-F\left(\omega_{t}^{L}\right)\right] R_{t}^{B}=R_{t}^{B},
\end{aligned}
$$

where the inequality uses both $\mathbb{E}\left(\omega \mid \omega_{t}^{L} \leq \omega \leq \omega_{t}^{B}\right) \leq \omega_{t}^{B}$ and the fact that in equilibrium $R_{t}^{L} \leq$ $R_{t}^{B}$. Using instead in equation (68) the definition of the lending threshold $\omega_{t}^{L}$ (eq. 58) and the fact that $\mathbb{E}\left(\omega \mid \omega_{t}^{L} \leq \omega \leq \omega_{t}^{B}\right) \geq \omega_{t}^{L}$, one can analogously show that $R_{t}^{D} \geq R_{t}^{L}$. Therefore, $R_{t}^{L} \leq R_{t}^{D} \leq R_{t}^{B}$

Value of net worth. From (54) and (57), we learn that

$$
\frac{\partial \bar{V}_{t}}{\partial N_{t}^{j}}\left(N_{t}^{j}, D_{t}^{j}, \omega_{t}^{j}\right)=\frac{\partial \bar{V}_{t}}{\partial D_{t}^{j}}\left(N_{t}^{j}, D_{t}^{j}, \omega_{t}^{j}\right)+\mathbb{E}_{t}\left[\tilde{\Lambda}_{t, t+1} \frac{R_{t}^{D}}{1+\pi_{t+1}}\right]+\lambda_{\phi t}^{j} \phi .
$$

Averaging across realizations of $\omega_{t}^{j}$ after the closure of the deposits market, and using (56), we obtain the marginal value of real net worth,

$$
\begin{aligned}
\lambda_{t}^{N} & =\int \frac{\partial \bar{V}_{t}}{\partial D_{t}^{j}}\left(N_{t}^{j}, D_{t}^{j}, \omega_{t}^{j}\right) d F\left(\omega_{t}^{j}\right)+\mathbb{E}_{t}\left[\tilde{\Lambda}_{t, t+1} \frac{R_{t}^{D}}{1+\pi_{t+1}}\right]+\phi \int \lambda_{\phi t}^{j} d F\left(\omega_{t}^{j}\right) \\
& =\mathbb{E}_{t} \tilde{\Lambda}_{t, t+1}\left[\frac{R_{t}^{D}}{1+\pi_{t+1}}+\phi \int_{\omega_{t}^{B}}\left(R_{t+1}^{A} \omega-\frac{R_{t}^{B}}{1+\pi_{t+1}}\right) d F(\omega)\right]>0 .
\end{aligned}
$$

where in the second equality we have used (45), together with (58) and the fact $\lambda_{\phi t}^{j}=0$ for $\omega_{t}^{j} \leq \omega_{t}^{B}$. Additional equity allows all banks - regardless of their subsequent realization of $\omega_{t}^{j}-$ to economize on deposit financing, which has a unit nominal cost of $R_{t}^{D}$. Moreover, equity has an additional marginal benefit for banks that draw $\omega_{t}^{j} \geq \omega_{t}^{B}$ later in the period, because it relaxes their leverage constraint. Notice finally that, since $\omega_{t}^{j}$ is iid, $\lambda_{t}^{N}$ is indeed equalized across banks, which verifies our earlier conjecture.

Deposit allocation across banks. A final note is in order. Equation (68) implies that banks break even ex ante when taking deposits at the beginning of the period, so they are indifferent 
between taking one more units of deposits or not. Therefore, as mentioned earlier, individual deposit-taking by each bank is not pinned down ${ }^{58}$ - although it will be pinned down in the aggregate in general equilibrium by the households deposit supply. The only requirement, implicitly assumed in the above conjectured (and verified) solution, is that no bank takes more deposits than

$$
D_{t}^{j} \leq(\phi-1) N_{t}^{j}
$$

For banks that draw $\omega_{t}^{j}>\omega_{t}^{B}$ after the closure of the deposits market, the latter inequality guarantees that $B_{t}^{j+} \geq 0$, i.e. they effectively need to borrow in the interbank market so as to finance their investment in the local firm. For those that draw $\omega_{t}^{j} \in\left[\omega_{t}^{B}, \omega_{t}^{B}\right]$, it guarantees that $Q_{t}^{K} A_{t}^{j} \leq \phi N_{t}^{j}$, i.e. they do not find themselves with more funds than they can invest in the local firm while still respecting the leverage constraint. The above condition can only hold for each individual bank if it holds in aggregate:

$$
D_{t} \leq(\phi-1) N_{t}
$$

Assumption 1 makes sure parameters are such that the latter condition holds and our conjecture indeed is a solution.

\section{A.2 Proof of Proposition 1 (Interbank rate)}

Consider a bank with equity $N_{t}^{j}$, deposits $D_{t}^{j}$, and an island-specific return $\omega_{t}^{j}$ for the next period, that accesses the interbank market in period $t$ after making its optimal portfolio decision as per Lemma 1. We denote the latter portfolio by $A_{t}^{j *}, b_{t}^{G, j *}, B_{t}^{+, j *}, B_{t}^{-, j *}$. According to Lemma 1, banks that draw $\omega_{t}^{j}>\omega_{t}^{B}$ choose $b_{t}^{G, j *}=B_{t}^{-, j *}=0$ and borrow in the interbank market in the amount $B_{t}^{+, j *}=(\phi-1) N_{t}^{j}-D_{t}^{j}$. Borrowing (and lending) orders are made on a per-unit basis. Let the borrowing bank send its orders to a submarket offering a combination $\left(R_{t}^{B}, \theta_{t}\right)$ of interest rate and (sub)market tightness. ${ }^{59}$ A fraction $\Gamma^{B}\left(\theta_{t}\right)$ of orders will be matched to lending orders, in which case each of them pays the rate $R_{t}^{B}$; the remaining fraction fail to be matched and the bank must borrow instead from the lending facility at rate $R_{t}^{L F}$. The value of a borrowing bank at the time of accessing the interbank market can then be written as

$$
\begin{aligned}
\bar{V}_{t}^{B}\left(N_{t}^{j}, D_{t}^{j}, \omega_{t}^{j}\right) & =\mathbb{E}_{t} \Lambda_{t, t+1}\left[(1-\varsigma) E_{t+1}^{j}+V_{t+1}\left(\varsigma E_{t+1}^{j}\right)\right] \\
\text { where } E_{t+1}^{j} & =R_{t+1}^{A} \omega_{t}^{j} Q_{t}^{K} A_{t}^{j *}-\frac{R_{t}^{D} D_{t}^{j}}{1+\pi_{t+1}}-\frac{B_{t}^{+, j *}}{1+\pi_{t+1}}\left[\Gamma^{B}\left(\theta_{t}\right) R_{t}^{I B}+\left(1-\Gamma^{B}\left(\theta_{t}\right)\right) R_{t}^{L F}\right] .
\end{aligned}
$$

\footnotetext{
${ }^{58}$ Note that the distribution of deposits across banks is irrelevant for aggregate variables since banks are atomistic and the idiosynchratic shock $\omega_{t}^{j}$ is iid.

${ }^{59}$ For simplicity, but without loss of generality, for the purpose of this derivation we assume that each bank sends all its orders to one interbank submarket only. This is allows us to drop the subscript $s$ relative to the notation in the main text.
} 
Likewise, banks that draw $\omega_{t}^{j}<\omega_{t}^{L}$ choose $B_{t}^{+, j *}=0$ and lend in the interbank market. For a bank sending its lending orders to the submarket with interest rate-tightness pair $\left(R_{t}^{B}, \theta_{t}\right)$, a fraction $\Gamma^{L}\left(\theta_{t}\right)$ of them will be matched to borrowing orders; the remaining fraction will not and those funds will be lent to the deposit facility at rate $R_{t}^{L D}$. Their value at the time of accessing the interbank market can then be again written as

$$
\begin{aligned}
\bar{V}_{t}^{L}\left(N_{t}^{j}, D_{t}^{j}, \omega_{t}^{j}\right) & =\mathbb{E}_{t} \Lambda_{t, t+1}\left[(1-\varsigma) E_{t+1}^{j}+V_{t+1}\left(\varsigma E_{t+1}^{j}\right)\right] \\
\text { where } E_{t+1}^{j} & =R_{t+1}^{A} \omega_{t}^{j} Q_{t}^{K} A_{t}^{j *}+\frac{R_{t+1}^{G} b_{t}^{j, G *}-R_{t}^{D} D_{t}^{j}}{1+\pi_{t+1}}+\frac{B_{t}^{-, j *}}{1+\pi_{t+1}}\left[\Gamma^{L}\left(\theta_{t}\right) R_{t}^{I B}+\left(1-\Gamma^{L}\left(\theta_{t}\right)\right) R_{t}^{D F}\right] .
\end{aligned}
$$

As explained in the text, both lending and borrowing banks choose the submarket that offers them the highest value. Before solving the latter problem, we first express value functions in a more convenient way. In Appendix A.1 we showed that the (beginning-of-period) value function is linear in equity $N_{t}^{j}: V_{t+1}\left(N_{t+1}^{j}\right)=\lambda_{t+1}^{N} N_{t+1}^{j}$, where $\lambda_{t+1}^{N}$ is the common marginal value of equity at time $t+1$ across banks. Defining $\tilde{\Lambda}_{t, t+1} \equiv \Lambda_{t, t+1}\left(1-\varsigma+\varsigma \lambda_{t+1}^{N}\right)$ as in Appendix A.1, we can express (69) and (70) as

$$
\begin{gathered}
\bar{V}_{t}^{B}(\cdot)=\mathbb{E}_{t} \tilde{\Lambda}_{t, t+1}\left\{R_{t+1}^{A} \omega_{t}^{j} Q_{t}^{K} A_{t}^{j *}-\frac{R_{t}^{D} D_{t}^{j}}{1+\pi_{t+1}}-\frac{B_{t}^{+, j *}}{1+\pi_{t+1}}\left[\Gamma^{B}\left(\theta_{t}\right) R_{t}^{I B}+\left(1-\Gamma^{B}\left(\theta_{t}\right)\right) R_{t}^{L F}\right]\right\}, \\
\bar{V}_{t}^{L}(\cdot)=\mathbb{E}_{t} \tilde{\Lambda}_{t, t+1}\left\{R_{t+1}^{A} \omega_{t}^{j} Q_{t}^{K} A_{t}^{j *}+\frac{R_{t+1}^{G} b_{t}^{j, G *}-R_{t}^{D} D_{t}^{j}}{1+\pi_{t+1}}+\frac{B_{t}^{-, j *}}{1+\pi_{t+1}}\left[\Gamma^{L}\left(\theta_{t}\right) R_{t}^{I B}+\left(1-\Gamma^{L}\left(\theta_{t}\right)\right) R_{t}^{D F}\right]\right\},
\end{gathered}
$$

respectively. Since the returns to search activity in the interbank market (the terms in square brackets in equations 71 and 72) are deterministic from the point of view of period $t$, it follows that value maximization with respect to $\left(R_{t}^{B}, \theta_{t}\right)$ is equivalent to minimization of

$$
\Gamma^{B}\left(\theta_{t}\right) R_{t}^{I B}+\left(1-\Gamma^{B}\left(\theta_{t}\right)\right) R_{t}^{L F} \equiv R_{t}^{B}
$$

in the case of borrowers, and maximization of

$$
\Gamma^{L}\left(\theta_{t}\right) R_{t}^{I B}+\left(1-\Gamma^{L}\left(\theta_{t}\right)\right) R_{t}^{D F} \equiv R_{t}^{L}
$$


in the case of lenders. Let $R_{t}^{L *}$ denote the maximum average return that lenders can obtain. In order to attract lenders, any submarket must therefore offer them an average return $R_{t}^{L *}$. Subject to this, borrowers choose the combination $\left(R_{t}^{I B}, \theta_{t}\right)$ that minimizes their own average borrowing cost, i.e. they solve

$$
\begin{aligned}
& \min _{R_{t}^{I B}, \theta_{t}} \Gamma^{B}\left(\theta_{t}\right) R_{t}^{I B}+\left(1-\Gamma^{B}\left(\theta_{t}\right)\right) R_{t}^{L F} \\
& \quad \text { s.t. } \Gamma^{L}\left(\theta_{t}\right) R_{t}^{I B}+\left(1-\Gamma^{L}\left(\theta_{t}\right)\right) R_{t}^{D F}=R_{t}^{L *}
\end{aligned}
$$

The first-order conditions of this problem are

$$
\begin{gathered}
\Gamma^{B}\left(\theta_{t}\right)+\lambda_{t}^{L *} \Gamma^{L}\left(\theta_{t}\right)=0 \\
\frac{d \Gamma^{B}}{d \theta}\left(R_{t}^{I B}-R_{t}^{L F}\right)+\lambda_{t}^{L *} \frac{d \Gamma^{L}}{d \theta}\left(R_{t}^{I B}-R_{t}^{D F}\right)=0 .
\end{gathered}
$$

Combining the latter two, and using the fact that $\Gamma^{L}\left(\theta_{t}\right)=\Gamma^{B}\left(\theta_{t}\right) \theta_{t}$ and therefore $\frac{d \Gamma^{L}}{d \theta}=\frac{d \Gamma^{B}}{d \theta} \theta_{t}+$ $\Gamma^{B}$, we obtain

$$
\left(1-\frac{\frac{d \Gamma^{L}}{d \theta} \theta_{t}}{\Gamma^{L}\left(\theta_{t}\right)}\right)\left(R_{t}^{L F}-R_{t}^{I B}\right)=\frac{\frac{d \Gamma^{L}}{d \theta} \theta_{t}}{\Gamma^{L}\left(\theta_{t}\right)}\left(R_{t}^{I B}-R_{t}^{D F}\right) .
$$

Letting $\frac{d \Gamma^{L}\left(\theta_{t}\right)}{d \theta} \frac{\theta_{t}}{\Gamma^{L}\left(\theta_{t}\right)} \equiv \varphi\left(\theta_{t}\right)$ denote the elasticity of lender's matching probability with respect to tightness, we obtain

$$
R_{t}^{I B}=\varphi\left(\theta_{t}\right) R_{t}^{D F}+\left(1-\varphi\left(\theta_{t}\right)\right) R_{t}^{L F} .
$$

Finally, using $\Gamma^{L}\left(\theta_{t}\right)=\frac{\Upsilon\left(\Phi_{t}^{L}, \Phi_{t}^{B}\right)}{\Phi_{t}^{L}}=\Upsilon\left(1, \theta_{t}\right)$, we can also express $\varphi\left(\theta_{t}\right)$ as

$$
\varphi\left(\theta_{t}\right)=\frac{\partial \Upsilon}{\partial \Phi_{t}^{B}}\left(1, \theta_{t}\right) \frac{\Phi_{t}^{B} / \Phi_{t}^{L}}{\Upsilon\left(\Phi_{t}^{L}, \Phi_{t}^{B}\right) / \Phi_{t}^{L}}=\frac{\partial \Upsilon}{\partial \Phi_{t}^{B}}\left(\Phi_{t}^{L}, \Phi_{t}^{B}\right) \frac{\Phi_{t}^{B}}{\Upsilon\left(\Phi_{t}^{L}, \Phi_{t}^{B}\right)}
$$

where the second equality uses the fact that, for any function $\Upsilon(x, y)$ with constant returns to scale, $\Upsilon_{y}(x, y)=\Upsilon_{y}(1, y / x)$. Therefore, $\varphi\left(\theta_{t}\right)$ represents the elasticity of the function function with respect to borrowing orders.

It only remains to show that $\varphi\left(\theta_{t}\right) \in[0,1]$. Let $(x, y) \equiv\left(\Phi_{t}^{L}, \Phi_{t}^{B}\right)$ for ease of notation. Constant returns to scale implies $\Upsilon(x, y)=x \Upsilon(1, y / x)$. Differentiating with respect to $x$, we get

$$
\frac{\partial \Upsilon}{\partial x}(x, y)=\Upsilon\left(1, \frac{y}{x}\right)-\frac{\partial \Upsilon}{\partial y}\left(1, \frac{y}{x}\right) \frac{y}{x} .
$$

Multiplying both sides by $x$, using the fact that $\frac{\partial \Upsilon}{\partial y}\left(1, \frac{y}{x}\right)=\frac{\partial \Upsilon}{\partial y}(x, y)$, and rearranging, we obtain $\frac{\partial \Upsilon}{\partial x}(x, y) x+\frac{\partial \Upsilon}{\partial y}(x, y) y=\Upsilon(x, y)$, or equivalently

$$
\frac{\partial \Upsilon}{\partial x}(x, y) \frac{x}{\Upsilon(x, y)}+\frac{\partial \Upsilon}{\partial y}(x, y) \frac{y}{\Upsilon(x, y)}=1 .
$$


Therefore, the two elasticities with respect to each argument add up to one. Since both of them must be positive, by virtue of $\frac{\partial \Upsilon}{\partial x}, \frac{\partial \Upsilon}{\partial y}, x, y, \Upsilon \geq 0$, it follows that each of them must be less than one. In particular, $\frac{\partial \Upsilon}{\partial y}(x, y) \frac{y}{\Upsilon(x, y)} \equiv \varphi\left(\frac{y}{x}\right) \leq 1$. We thus have $\varphi\left(\frac{y}{x}\right) \in[0,1]$.

\section{A.3 Proof of Proposition 2 (Effect of central bank bond purchases)}

Since $\theta_{t}=\left(\widetilde{b}_{t}^{G, C B}+1\right)^{-1}$ we have that $\frac{\partial \theta_{t}}{\partial \widetilde{b}_{t}^{G, C B}}<0$. By assumption $\frac{\partial \varphi_{t}}{\partial \theta_{t}}<0$. Hence:

$$
\frac{\partial \varphi_{t}}{\partial \widetilde{b}_{t}^{G, C B}}=\frac{\partial \varphi_{t}}{\partial \theta_{t}} \frac{\partial \theta_{t}}{\partial \widetilde{b}_{t}^{G, C B}}>0
$$

Combining the interbank interest rate equation (21) and the definition of the corridor (25) we get

$$
R_{t}^{I B}=R_{t}^{D F}+\left(1-\varphi\left(\theta_{t}\right)\right) \chi
$$

Hence

$$
\frac{\partial R_{t}^{I B}-R_{t}^{D F}}{\partial \widetilde{b}_{t}^{G, C B}}=-\chi \frac{\partial \varphi_{t}}{\partial \widetilde{b}_{t}^{G, C B}}<0
$$

Using the definitions for the other interest rates (18), (19) and (25) we get

$$
\begin{aligned}
R_{t}^{B}-R_{t}^{D F} & =\chi-\chi \varphi_{t} \Gamma_{t}^{B}, \\
R_{t}^{L}-R_{t}^{D F} & =\left(1-\varphi_{t}\right) \Gamma_{t}^{L} \chi
\end{aligned}
$$

Using $\varphi_{t}=\frac{\partial \Upsilon\left(1, \theta_{t}\right)}{\partial \theta_{t}} \frac{\theta_{t}}{\Upsilon\left(1, \theta_{t}\right)}, \Gamma^{L}\left(\theta_{t}\right)=\Upsilon\left(1, \theta_{t}\right)$ and $\Gamma^{B}\left(\theta_{t}\right)=\Upsilon\left(1 / \theta_{t}, 1\right)$, and simplifying we get

$$
\begin{aligned}
R_{t}^{B}-R_{t}^{D F} & =\chi-\chi \frac{\partial \Upsilon\left(1, \theta_{t}\right)}{\partial \theta_{t}} \\
R_{t}^{L}-R_{t}^{D F} & =\chi\left(\Upsilon\left(1, \theta_{t}\right)-\frac{\partial \Upsilon\left(1, \theta_{t}\right)}{\partial \theta_{t}} \theta_{t}\right)
\end{aligned}
$$

Deriving wrt. $\theta_{t}$ we get

$$
\begin{aligned}
& \frac{\partial R_{t}^{B}-R_{t}^{D F}}{\partial \theta_{t}}=-\chi \frac{\partial^{2} \Upsilon\left(1, \theta_{t}\right)}{\partial \theta_{t}^{2}}>0, \\
& \frac{\partial R_{t}^{L}-R_{t}^{D F}}{\partial \theta_{t}}=-\chi \frac{\partial^{2} \Upsilon\left(1, \theta_{t}\right)}{\partial \theta_{t}^{2}} \theta_{t}>0 .
\end{aligned}
$$
0 .

Since $\frac{\partial R_{t}^{B}-R_{t}^{D F}}{\partial \widetilde{b}_{t}^{G, C B}}=\frac{\partial R_{t}^{B}-R_{t}^{D F}}{\partial \theta_{t}} \frac{\partial \theta_{t}}{\partial \widetilde{b}_{t}^{G, C B}}$ and $\frac{\partial R_{t}^{L}-R_{t}^{D F}}{\partial \widetilde{b}_{t}^{G, C B}}=\frac{\partial R_{t}^{L}-R_{t}^{D F}}{\partial \theta_{t}} \frac{\partial \theta_{t}}{\partial \widetilde{b}_{t}^{G, C B}}$ we obtain that $\frac{\partial R_{t}^{B}-R_{t}^{D F}}{\partial \widetilde{b}_{t}^{G, C B}}, \frac{\partial R_{t}^{L}-R_{t}^{D F}}{\partial \widetilde{b}_{t}^{G, C B}}<$ 
Furthermore notice that the elasticity of $\Upsilon$ is bounded below and above by 0 and 1 , by the assumption of constant returns to scale:

$$
0 \leq \varphi=\Upsilon^{\prime} \frac{\theta}{\Upsilon} \leq 1
$$

By equations (19), (21) and (18) all rates are bounded between $R^{D F}$ and $R^{L F}$

$$
R^{D F} \leq R^{L} \leq R^{I B} \leq R^{B} \leq R^{L F}
$$

Combining the negative derivative of the distance of the three endogenous rates to the DFR with the fact that they are bounded implies the last statement in the proposition.

\section{A.4 Proof of Proposition 4 (Floor system)}

Our assumptions about the matching function in Section 2.4 (continuity of $\Upsilon(\theta), \Upsilon(\theta) \leq \theta, \Upsilon(0)=$ 0) imply

$$
\lim _{\theta \rightarrow 0} \Upsilon^{\prime}(\theta) \leq 1
$$

To see this note first that $\Upsilon(\widehat{\theta})=\int_{0}^{\widehat{\theta}} \Upsilon^{\prime}(\theta) d \theta$ since $\Upsilon(\theta)$ is continous and $\Upsilon(0)=0$.

By the definition of the Rieman integral $\lim _{\widehat{\theta} \rightarrow 0} \Upsilon(\widehat{\theta})=\lim _{\widehat{\theta} \rightarrow 0} \int_{0}^{\widehat{\theta}} \Upsilon^{\prime}(\theta) d \theta=\Upsilon^{\prime}(\widehat{\theta}) \widehat{\theta}$. Hence, as $\Upsilon(\widehat{\theta}) \leq \widehat{\theta}$ for any $\widehat{\theta}$ including zero then it follows that $\lim _{\theta \rightarrow 0} \Upsilon^{\prime}(\theta) \leq 1$. Furthermore, by assumption $0 \leq \Upsilon^{\prime}(\theta)$. Therefore $\Upsilon^{\prime}(\theta)$ is non-negative and finite.

The limit of the bargaining weight $\varphi$

$$
\lim _{\theta \rightarrow 0} \varphi=\lim _{\theta \rightarrow 0} \Upsilon^{\prime}(\theta) \frac{\theta}{\Upsilon(\theta)}
$$

can be rewritten as

$$
\lim _{\theta \rightarrow 0} \varphi=\lim _{\theta \rightarrow 0} \Upsilon^{\prime}(\theta) \lim _{\theta \rightarrow 0} \frac{\theta}{\Upsilon(\theta)}
$$

due to the finiteness of $\lim _{\theta \rightarrow 0} \Upsilon^{\prime}(\theta)$ if the limit $\lim _{\theta \rightarrow 0} \frac{\theta}{\Upsilon(\theta)}$ exists. By L'Hôpital's rule $\lim _{\theta \rightarrow 0} \frac{\theta}{\Upsilon(\theta)}=$ $\lim _{\theta \rightarrow 0} \frac{1}{\Upsilon^{\prime}(\theta)}$, which again must be finite since $\lim _{\theta \rightarrow 0} \Upsilon^{\prime}(\theta)$ is finite. Hence we can write

$$
\lim _{\theta \rightarrow 0} \varphi=\lim _{\theta \rightarrow 0} \Upsilon^{\prime}(\theta) \lim _{\theta \rightarrow 0} \frac{1}{\Upsilon^{\prime}(\theta)}=1
$$

Combining this expression with the definitions of $R^{I B}(21)$ and $R^{L}$ (18) we find that these two interest rates converge to $R^{D F}$. 
If furthermore $\Upsilon$ is asymptotically match efficient we have that $\lim _{\theta \rightarrow 0} \Gamma^{B}(\theta)=1$. To see this note that

$$
\Gamma^{B}(\theta)=\frac{\Upsilon\left(\Phi^{L}, \Phi^{B}\right)}{\Phi^{B}}=\Upsilon\left(\theta^{-1}, 1\right)
$$

where the last equality is due to constant returns to scale. Hence

$$
\lim _{\theta \rightarrow 0} \Gamma^{B}(\theta)=\lim _{\theta \rightarrow 0} \Upsilon\left(\theta^{-1}, 1\right)=\lim _{\theta^{-1} \rightarrow \infty} \Upsilon\left(\theta_{t}^{-1}, 1\right)=1
$$

where the last equality followed from the definition of asymptotic match efficiency. Combining the limits of $\varphi$ and $\Gamma^{B}$ with the definitions of $R^{L}(13)$ and $R^{D}(19)$ we find that these two interest rates also converge to $R^{D F}$.

\section{A.5 Proof of Proposition 6 (Equivalence of loan and bond programs)}

Consider a particular sequence of prices and quantities and exogenous processes $\left\{x_{t}^{*}\right\}_{t=0}^{\infty} \in X$, which constitutes an equilibrium. The sub-sequences $\left\{b_{t}^{G, C B *}\right\}_{t=0}^{\infty},\left\{N_{t}^{*}\right\}_{t=0}^{\infty},\left\{\omega_{t}^{B *}\right\}_{t=0}^{\infty},\left\{\Gamma_{t}^{L *}\right\}_{t=0}^{\infty}$, ... are elements of this set. Similarly, denote the initial conditions by $x_{0}^{*}$. Assume that in this particular equilibrium the central bank holds some government bonds $b_{t}^{G, C B *}>0$ for some $t$ but never holds any loans to banks through direct lending programs $B_{t}^{C B *}=0, \forall t \geq 0$. Note that, for later use, the ratio of lending and borrowing orders in this equilibrium is given by

$$
\Phi_{t}^{L *} / \Phi_{t}^{B *}=\frac{\left(N_{t}^{*}+D_{t}^{*}\right) F\left(\omega_{t}^{L *}\right)-\overbrace{\left(\bar{b}_{t}^{G *}-b_{t}^{G, C B *}\right)}^{b_{t}^{G *}},}{\left.(\phi-1)-D_{t}^{*}\right)\left[1-F\left(\omega_{t}^{B *}\right)\right]},
$$

Now consider an alternative sequences $\left\{x_{t}^{+}\right\}_{t=0}^{\infty}$, where all sub-sequences are the same as above with a few exceptions: in $x_{t}^{+}$the central bank never holds any government bond,

$$
b_{t}^{G, C B+}=0 \forall t \geq 0,
$$

but sometimes may extend loans to banks through direct lending programs

$$
B_{t}^{C B+} \geq 0 \text { for some } t
$$

Also allow $\Phi_{t}^{B+}, \Phi_{t}^{L+}$ and $b_{t}^{G+}$ to differ from their $*$-counterparts. We will now show (by construction) that a path for $B_{t}^{C B+}, b_{t}^{G, C B+}, \Phi_{t}^{B+}, b_{t}^{G+}$ and $\Phi_{t}^{L+}$ exists that, given the same initial conditions $x_{0}^{*}=x_{0}^{+}$, constitutes an equilibrium.

For $\left\{x_{t}^{+}\right\}_{t=0}^{\infty}$ to be an equilibrium, the equilibrium conditions explicitly stated in appendix B1 (augmented by $B_{t}^{C B}$ ) must hold together with certain implicit non-negativity constraints on 
certain variables. However, since most values in $\left\{x_{t}^{+}\right\}_{t=0}^{\infty}$ are equal to $\left\{x_{t}^{*}\right\}_{t=0}^{\infty}$, all those equilibrium conditions that only include values that are equal for $\left\{x_{t}^{+}\right\}_{t=0}^{\infty}$ and $\left\{x_{t}^{*}\right\}_{t=0}^{\infty}$ are obviously satisfied. There are only 8 equilibrium conditions, where the non-identical sequences $B_{t}^{C B+}, b_{t}^{G, C B+}, \Phi_{t}^{B+}$, $b_{t}^{G+}$ and $\Phi_{t}^{L+}$ show up. Replacing those +-sequences, which are identical to their $*$-counterparts, by the latter, these 8 conditions read: ${ }^{60}$

$$
\begin{aligned}
\Phi_{t}^{B+} & =\left(N_{t}^{*}(\phi-1)-D_{t}^{*}\right)\left[1-F\left(\omega_{t}^{B *}\right)\right]-B_{t}^{C B+} \\
\Phi_{t}^{L+} & =\left(N_{t}^{*}+D_{t}^{*}\right) F\left(\omega_{t}^{L *}\right)-b_{t}^{G+} \\
\Phi_{t}^{L+}\left(1-\Gamma_{t}^{L *}\right) & =B_{t}^{C B+}+\Phi_{t}^{B+}\left(1-\Gamma_{t}^{B *}\right) \\
N_{t}^{*} & =\varsigma\left[\begin{array}{c}
R_{t}^{A *} Q_{t-1}^{K *} \Omega_{t-1}^{*} K_{t-1}^{*}+\frac{R_{t-1}^{L *}}{1+\pi_{t}^{*}} \Phi_{t-1}^{L *}+\frac{R_{t}^{G *}}{1+\pi_{t}^{*}} b_{t-1}^{G+}-\frac{R_{t}^{D *}}{1+\pi_{t}^{*}} D_{t-1}^{*}-\frac{R_{t-1}^{B *}}{1+\pi_{t}^{*}} \Phi_{t-1}^{B *}-\frac{R_{t-1}^{B *}}{1+\pi_{t}^{*}} B_{t}^{C B+}
\end{array}\right] \\
\bar{b}_{t}^{G *} & =b_{t}^{G, C B+}+b_{t}^{G+} \\
\Gamma_{t}^{B *} & =\Upsilon\left(\frac{\Phi_{t}^{L+}}{\Phi_{t}^{B+}}, 1\right) \\
\Gamma_{t}^{L *} & =\Upsilon\left(1, \frac{\Phi_{t}^{B+}}{\Phi_{t}^{L+}}\right) \\
\varphi_{t}^{*} & =\frac{\partial \Gamma^{L *}\left(\Phi_{t}^{B+} / \Phi_{t}^{L+}+\right)}{\partial\left(\Phi_{t}^{B+} / \Phi_{t}^{L+}\right)} \frac{\Phi_{t}^{B+} / \Phi_{t}^{L+}}{\Gamma^{L *}\left(\Phi_{t}^{B+} / \Phi_{t}^{L+}\right)}
\end{aligned}
$$

Notice first that as $b_{t}^{G, C B+}=0$, equation (78) requires that $b_{t}^{G+}=\bar{b}_{t}^{G *}$. Furthermore, notice that equation (77), after subsituting for $\Phi_{t}^{B+}$ and $\Phi$ using (74) and (75) reads

$$
N_{t}^{*}=\varsigma\left[\begin{array}{c}
R_{t}^{A *} Q_{t-1}^{K *} \Omega_{t-1}^{*} K_{t-1}^{*}+\frac{R_{t-1}^{L *}}{1+\pi_{t}^{*}}\left[\left(N_{t}^{*}+D_{t}^{*}\right) F\left(\omega_{t}^{L *}\right)-b_{t}^{G+}\right]+\frac{R_{t}^{G *}}{1+\pi_{t}^{*}} b_{t-1}^{G+} \\
-\frac{R_{t}^{D *}}{1+\pi_{t}^{*}} D_{t-1}^{*}-\frac{R_{t-1}^{B *}}{1+\pi_{t}^{*}}\left[\left(N_{t}^{*}(\phi-1)-D_{t}^{*}\right)\left[1-F\left(\omega_{t}^{B *}\right)\right]-B_{t}^{C B+}\right]-\frac{R_{t-1}^{B *}}{1+\pi_{t}^{*}} B_{t}^{C B+}
\end{array}\right]
$$

${ }^{60}$ Note that $(77)$ can be derived by combining the law of motion of equity

$$
\frac{N_{t}}{\varsigma}=R_{t}^{A} \Omega_{t-1} Q_{t-1}^{K} K_{t-1}+\frac{R_{t-1}^{L}}{1+\pi_{t}} \Phi_{t-1}^{L}+\frac{R_{t}^{G}}{1+\pi_{t}} b_{t-1}^{G}-\frac{R_{t-1}^{D}}{1+\pi_{t}} D_{t-1}-\frac{R_{t-1}^{B}}{1+\pi_{t}} \Phi_{t-1}^{B}-\frac{R_{t-1}^{B}}{1+\pi_{t}} B_{t-1}^{C B},
$$

with equations (74) and (75) to get

$$
\frac{N_{t}}{\varsigma}=\left[\begin{array}{c}
R_{t}^{A *} Q_{t-1}^{K *} \Omega_{t-1}^{*} K_{t-1}^{*}-\frac{R_{t-1}^{B *}}{1+\pi_{t}^{*}}\left[\left[1-F\left(\omega_{t-1}^{B *}\right)\right]\left(N_{t-1}^{*}(\phi-1)-D_{t-1}^{*}\right)-B_{t}^{C B+}\right] \\
+\frac{R_{t-1}^{L *}}{1+\pi_{t}^{*}}\left(F\left(\omega_{t-1}^{L *}\right)\left(N_{t-1}^{*}+D_{t-1}^{*}\right)-b_{t-1}^{G+}\right)+\frac{R_{t}^{G *}}{1+\pi_{t}^{*}} b_{t-1}^{G+}-\frac{R_{t}^{D *}}{1+\pi_{t}^{*}} D_{t-1}^{*}-\frac{R_{t-1}^{B *}}{1+\pi_{t}^{*}} B_{t}^{C B+}
\end{array}\right]
$$

and the eliminating $B_{t}^{C B+}$. 
We can eliminate $B_{t}^{C B+}$ and rearrange to get

$$
N_{t}^{*}=\varsigma\left[\begin{array}{c}
R_{t}^{A *} Q_{t-1}^{K *} \Omega_{t-1}^{*} K_{t-1}^{*}+\frac{R_{t-1}^{L *}}{1+\pi_{t}^{*}}\left[\left(N_{t}^{*}+D_{t}^{*}\right) F\left(\omega_{t}^{L *}\right)\right]+\frac{R_{t}^{G *}-R_{t-1}^{L *}}{1+\pi_{t}^{*}} b_{t-1}^{G+} \\
-\frac{R_{t}^{D *}}{1+\pi_{t}^{*}} D_{t-1}^{*}-\frac{R_{t-1}^{B *}}{1+\pi_{t}^{*}}\left[\left(N_{t}^{*}(\phi-1)-D_{t}^{*}\right)\left[1-F\left(\omega_{t}^{B *}\right)\right]\right]
\end{array}\right]
$$

This condition satisfied for all $t>0$ since in equilibrium under perfect forsight the no-arbitrage condition (12) becomes $R_{t-1}^{L *}=R_{t}^{G *}$, so that all references to + -variables can be cancelled out. For $t=0$ equation (77) holds because $R_{t-1}^{L *}=R_{t-1}^{L+}$ and $b_{t-1}^{G+}=b_{t-1}^{G *}$ (since we start from the same initial conditions) and $R_{t}^{G+}=R_{t}^{G *}$ (by construction).

Next, we make the guess that $\Phi_{t}^{L+}$ and $\Phi_{t}^{B+}$ are such that

$$
\Phi_{t}^{L *} / \Phi_{t}^{B *}=\Phi_{t}^{L+} / \Phi_{t}^{B+}
$$

This immediatley implies that equations (79) - (81) are satisfied. Using equations $(74,75,78)$ to replace $\Phi_{t}^{L+}$ and $\Phi_{t}^{B+}$ and equation 73 to replace $\Phi_{t}^{L *} / \Phi_{t}^{B *}$ in (82) we get:

$$
\frac{\left(N_{t}^{*}+D_{t}^{*}\right) F\left(\omega_{t}^{L *}\right)-\left(\bar{b}_{t}^{G *}-b_{t}^{G, C B *}\right)}{\left(N_{t}^{*}(\phi-1)-D_{t}^{*}\right)\left[1-F\left(\omega_{t}^{B *}\right)\right]}=\frac{\left(N_{t}^{*}+D_{t}^{*}\right) F\left(\omega_{t}^{L *}\right)-\bar{b}_{t}^{G *}}{\left(N_{t}^{*}(\phi-1)-D_{t}^{*}\right)\left[1-F\left(\omega_{t}^{B *}\right)\right]-B_{t}^{C B+}} .
$$

After rearranging terms, we obtain:

$$
B_{t}^{C B+}=b_{t}^{G, C B *}\left(\frac{\left(N_{t}^{*}(\phi-1)-D_{t}^{*}\right)\left[1-F\left(\omega_{t}^{B *}\right)\right]}{\left(N_{t}^{*}+D_{t}^{*}\right) F\left(\omega_{t}^{L *}\right)-\bar{b}_{t}^{G *}+b_{t}^{G, C B *}}\right)=b_{t}^{G, C B *} \frac{\Phi_{t}^{B *}}{\Phi_{t}^{L *}} .
$$

Plugging (74) and (75) into (76) we get

$B_{t}^{C B+}+\left[\left(N_{t}^{*}(\phi-1)-D_{t}^{*}\right)\left[1-F\left(\omega_{t}^{B *}\right)\right]-B_{t}^{C B+}\right]\left(1-\Gamma_{t}^{B *}\right)=\left[\left(N_{t}^{*}+D_{t}^{*}\right) F\left(\omega_{t}^{L *}\right)-b_{t}^{G+}\right]\left(1-\Gamma_{t}^{L *}\right)$,

and then taking into account the value of $B_{t}^{C B+}$ in (83)

$b_{t}^{G, C B *} \frac{\Phi_{t}^{B *}}{\Phi_{t}^{L *}} \Gamma_{t}^{B *}+\left[\left(N_{t}^{*}(\phi-1)-D_{t}^{*}\right)\left[1-F\left(\omega_{t}^{B *}\right)\right]\right]\left(1-\Gamma_{t}^{B *}\right)=\left[\left(N_{t}^{*}+D_{t}^{*}\right) F\left(\omega_{t}^{L *}\right)-b_{t}^{G+}\right]\left(1-\Gamma_{t}^{L *}\right)$,

Using the fact that by interbank market clearing $\Gamma_{t}^{L *}=\frac{\Phi_{t}^{B *}}{\Phi_{t}^{L *}} \Gamma_{t}^{B *}$ we can write:

$b_{t}^{G, C B *} \Gamma_{t}^{L *}+\left[\left(N_{t}^{*}(\phi-1)-D_{t}^{*}\right)\left[1-F\left(\omega_{t}^{B *}\right)\right]\right]\left(1-\Gamma_{t}^{B *}\right)=\left[\left(N_{t}^{*}+D_{t}^{*}\right) F\left(\omega_{t}^{L *}\right)-\bar{b}_{t}^{G *}\right]\left(1-\Gamma_{t}^{L *}\right)$, 
Since the $*$-sequence constituted an equilibrium, the $*$-counterpart of equations (74-78) must hold. If we again plug the values of $\Phi_{t}^{L *}$ and $\Phi_{t}^{B *}$ in (the $*$-counterpart of) equations (74-75) into (the $*$-counterpart of) equation $(76)$ we get

$$
\begin{aligned}
\overbrace{B_{t}^{C B *}}^{=0}+b_{t}^{G, C B *}+\Phi_{t}^{B *}\left(1-\Gamma_{t}^{B *}\right) & =\Phi_{t}^{L *}\left(1-\Gamma_{t}^{L *}\right), \\
b_{t}^{G, C B *}+\left\{\left[N_{t}^{*}(\phi-1)+D_{t}^{*}\right]\left[1-F\left(\omega_{t}^{B *}\right)\right]-b_{t}^{G *}\right\}\left(1-\Gamma_{t}^{B *}\right) & =\left[\left(N_{t}^{*}+D_{t}^{*}\right) F\left(\omega_{t}^{L *}\right)-b_{t}^{G *}\right]\left(1-\Gamma_{t}^{L *}\right), \\
\Gamma_{t}^{L *} b_{t}^{G, C B *}+\left\{\left[N_{t}^{*}(\phi-1)+D_{t}^{*}\right]\left[1-F\left(\omega_{t}^{B *}\right)\right]-b_{t}^{G *}\right\}\left(1-\Gamma_{t}^{B *}\right) & =\left[\left(N_{t}^{*}+D_{t}^{*}\right) F\left(\omega_{t}^{L *}\right)-\bar{b}_{t}^{G *}\right]\left(1-\Gamma_{t}^{G(85)}\right)
\end{aligned}
$$

where in the last equation we have applied the market clearing condition (78). Since equations (84) and (85) are the same, we have shown that all of the 8 equations above hold for $\left\{x_{t}^{+}\right\}_{t=1}^{\infty}$. Hence, under the condition that the paths $\Phi_{t}^{B+}, b_{t}^{G+}$ and $\Phi_{t}^{L+}$ are feasible, i.e. non-negative, any equilibrium with bond purchases can be reproduced by an adequate path of lending to banks.Feasibility requires that $B_{t}^{C B+}, b_{t}^{G, C B+}, b_{t}^{G+}, \Phi_{t}^{B+}$ and $\Phi_{t}^{L+}$ are all non-negative. This condition holds for the former three sequences as $B_{t}^{C B+}=b_{t}^{G, C B *} \Gamma_{t}^{L *} \geq 0, b_{t}^{G, C B+}=0$ and $b_{t}^{G+}=\bar{b}_{t}^{G *}>0$, which again is an exogenous process. For the latter two this means that the following must hold:

$$
\begin{aligned}
\Phi_{t}^{L+} & =\left(N_{t}^{*}+D_{t}^{*}\right) F\left(\omega_{t}^{L *}\right)-\bar{b}_{t}^{G *} \geq 0 \\
\Phi_{t}^{B+} & =\left[N_{t}^{*}(\phi-1)-D_{t}^{*}\right]\left[1-F\left(\omega_{t}^{B *}\right)\right]-B_{t}^{C B+} \geq 0
\end{aligned}
$$

Substituting for $B_{t}^{C B+}$ in (83), the latter condition (87) reduces to

$$
\left[N_{t}^{*}(\phi-1)-D_{t}^{*}\right]\left[1-F\left(\omega_{t}^{B *}\right)\right]-b_{t}^{G, C B *\left(\frac{\left[N_{t}^{*}(\phi-1)-D_{t}^{*}\right]\left[1-F\left(\omega_{t}^{B *}\right)\right]}{\left(N_{t}^{*}+D_{t}^{*}\right) F\left(\omega_{t}^{L *}\right)-\bar{b}_{t}^{G *}+b_{t}^{G, C B *}}\right)} \begin{aligned}
\left(N_{t}^{*}+D_{t}^{*}\right) F\left(\omega_{t}^{L *}\right)-\bar{b}_{t}^{G *} & \geq 0
\end{aligned}
$$

which is identical to (86). So its sufficient to show that (86) holds.Using the $*$-counterpart of equation (76)

$$
b_{t}^{G, C B *}+\Phi_{t}^{B *}\left(1-\Gamma_{t}^{B *}\right)=\Phi_{t}^{L *}\left(1-\Gamma_{t}^{L *}\right)
$$

and using the fact that by interbank market clearing $\Phi_{t}^{B+} \Gamma_{t}^{B *}=\Phi_{t}^{L+} \Gamma_{t}^{L *}$ we obtain

$$
\Phi_{t}^{B *}=\Phi_{t}^{L *}-b_{t}^{G, C B *}
$$

Furthermore, using the $*$-counterpart of equation (75) and (78)

$$
\Phi_{t}^{B *}=\left(N_{t}^{*}+D_{t}^{*}\right) F\left(\omega_{t}^{L *}\right)-\bar{b}_{t}^{G *}
$$

Since $\Phi_{t}^{B *}$ forms part of an equilibrium it must be that $\Phi_{t}^{B *} \geq 0$. Hence $\Phi_{t}^{L+}>0$. (86) holds. Hence feasibility is always guaranteed. 
Finally, notice that this path satisfies the condition that $b_{t}^{C B+}=0$ if $b_{t}^{G, C B *}=0$ and $b_{t}^{G, C B *} \geq$ $b_{t}^{C B+}=b_{t}^{G, C B *} \Gamma_{t}^{L *}>0$ if $b_{t}^{G, C B *}>0$.

\section{B. Complete set of equations}

We display below the complete set of equations of the model. We define $p_{t}^{*} \equiv P_{t}^{*} / P_{t}$.

\section{B.1 Transitional dynamics}

- Households

$$
\begin{aligned}
1 & =\Lambda_{t, t+1} \frac{R_{t}^{L}}{1+\pi_{t+1}}, \\
W_{t} & =\frac{v^{\prime}\left(L_{t}\right)}{u^{\prime}\left(C_{t}\right)} \\
\Lambda_{t, t+1} & =\beta \frac{u^{\prime}\left(C_{t+1}\right)}{u^{\prime}\left(C_{t}\right)} \\
1 & =Q_{t}^{K}\left[1-S\left(\frac{I_{t}}{I_{t-1}}\right)-S^{\prime}\left(\frac{I_{t}}{I_{t-1}}\right) \frac{I_{t}}{I_{t-1}}\right]+\Lambda_{t, t+1} Q_{t+1}^{K} S^{\prime}\left(\frac{I_{t+1}}{I_{t}}\right)\left(\frac{I_{t+1}}{I_{t}}\right)^{2}, \\
K_{t} & =\left[1-S\left(\frac{I_{t}}{I_{t-1}}\right)\right] I_{t}+(1-\delta) \Omega_{t-1} K_{t-1} .
\end{aligned}
$$

- Firms

$$
\begin{aligned}
Y_{t} & =\frac{Z_{t}}{\Delta_{t}} L_{t}^{1-\alpha}\left(\Omega_{t-1} K_{t-1}\right)^{\alpha}, \\
1 & =\theta\left(1+\pi_{t}\right)^{\epsilon-1}+(1-\theta)\left(p_{t}^{*}\right)^{1-\epsilon}, \\
p_{t}^{*} & =\frac{\Xi_{t}^{1}}{\Xi_{t}^{2}} \\
\Xi_{t}^{1} & =\frac{\epsilon}{\epsilon-1} M_{t} Y_{t}+\theta \mathbb{E}_{t} \Lambda_{t, t+1}\left(1+\pi_{t+1}\right)^{\epsilon} \Xi_{t+1}^{1}, \\
\Xi_{t}^{2} & =Y_{t}+\theta \mathbb{E}_{t} \Lambda_{t, t+1}\left(1+\pi_{t+1}\right)^{\epsilon-1} \Xi_{t+1}^{2}, \\
\Delta_{t} & =(1-\theta)\left(p_{t}^{*}\right)^{-\epsilon}+\theta\left(1+\pi_{t}\right)^{\epsilon} \Delta_{t-1}, \\
R_{t}^{A} & =\frac{R_{t}^{k}+(1-\delta) Q_{t}^{K}}{Q_{t-1}^{K}}, \\
R_{t}^{k} & =\alpha M_{t} Z_{t}\left[\frac{(1-\alpha) M_{t} Z_{t}}{W_{t}}\right]^{(1-\alpha) / \alpha}, \\
L_{t} & =\left(\frac{(1-\alpha) Z_{t} M_{t}}{W_{t}}\right)^{1 / \alpha} \Omega_{t-1} K_{t-1} .
\end{aligned}
$$


- Banks

$$
\begin{aligned}
Q_{t}^{K} K_{t}= & \left\{N_{t} \phi\left[1-F\left(\omega_{t}^{B}\right)\right]+\left(N_{t}+D_{t}\right)\left[F\left(\omega_{t}^{B}\right)-F\left(\omega_{t}^{L}\right)\right]\right\} \\
N_{t}= & \varsigma\left[\begin{array}{c}
R_{t}^{A} Q_{t-1}^{K} \Omega_{t-1} K_{t-1}-\frac{R_{t-1}^{B}}{1+\pi_{t}} \Phi_{t-1}^{B}+ \\
\frac{R_{t-1}^{L}}{1+\pi_{t}} \Phi_{t-1}^{L}+\frac{R_{t}^{G}}{\left(1+\pi_{t}\right)} b_{t-1}^{G}-\frac{R_{t-1}^{D}}{\left(1+\pi_{t}\right)} D_{t-1}
\end{array}\right] \\
\omega_{t}^{B}= & \frac{R_{t}^{B}}{R_{t+1}^{A}\left(1+\pi_{t+1}\right)}, \\
\omega_{t}^{L}= & \frac{R_{t}^{L}}{R_{t+1}^{A}\left(1+\pi_{t+1}\right)}, \\
R_{t+1}^{G}= & R_{t}^{L} \cdot\left(1-F\left(\omega_{t}^{B}\right)\right) R_{t}^{B}+F\left(\omega_{t}^{L}\right) R_{t}^{L}+ \\
R_{t}^{D}= & \left(F\left(\omega_{t}^{B}\right)-F\left(\omega_{t}^{L}\right)\right)\left(R_{t+1}^{A}\left(1+\pi_{t+1}\right) \mathbb{E}\left[\omega_{t} \mid \omega_{t}^{B}>\omega_{t}>\omega_{t}^{L}\right]\right)
\end{aligned} .
$$

- Interbank market

$$
\begin{aligned}
\Phi_{t}^{B} & =\left(N_{t}(\phi-1)-D_{t}\right)\left[1-F\left(\omega_{t}^{B}\right)\right], \\
\Phi_{t}^{L} & =\left(N_{t}+D_{t}\right) F\left(\omega_{t}^{L}\right)-b_{t}^{G}, \\
\Gamma_{t}^{B} & =\Upsilon\left(\frac{\Phi_{t}^{L}}{\Phi_{t}^{B}}, 1\right) \\
\Gamma_{t}^{L} & =\Upsilon\left(1, \frac{\Phi_{t}^{B}}{\Phi_{t}^{L}}\right), \\
R_{t}^{B} & =\varphi_{t} \Gamma_{t}^{B} R_{t}^{D F}+\left[1-\varphi_{t} \Gamma_{t}^{B}\right] R_{t}^{L F}, \\
R_{t}^{L} & =\left(1-\varphi_{t}\right) \Gamma_{t}^{L} R_{t}^{L F}+\left(1-\left(1-\varphi_{t}\right) \Gamma_{t}^{L}\right) R_{t}^{D F}, \\
\varphi_{t} & =\frac{1}{\left(\Phi_{t}^{B} / \Phi_{t}^{L}\right)^{\lambda}+1}
\end{aligned}
$$

- Central bank

$$
\begin{aligned}
R_{t}^{L F} & =R_{t}^{D F}+\chi \\
R_{t}^{D F} & =\max \left\{\rho\left(R_{t-1}^{D F}\right)+(1-\rho)\left[\bar{R}+v\left(\pi_{t}-\bar{\pi}\right)\right], 1-\kappa\right\} \\
b_{t}^{G, C B}+\Phi_{t}^{B}\left(1-\Gamma_{t}^{B}\right) & =\Phi_{t}^{L}\left(1-\Gamma_{t}^{L}\right) \\
b_{t}^{G, C B} & =(1-\zeta) b_{t-1}^{G, C B}+\zeta \bar{b}^{G, C B}+n p_{t}+\zeta\left(b_{t-1}^{G, C B}-\bar{b}^{G, C B}\right) r i_{t},
\end{aligned}
$$

- Government

$$
\begin{aligned}
\bar{b} & =b_{t}^{G, C B}+b_{t}^{G}, \\
R_{t}^{G} & =\frac{\zeta+(1-\zeta) Q_{t}^{G}}{Q_{t-1}^{G}} .
\end{aligned}
$$


- Aggregate constraint

$$
\begin{aligned}
\Omega_{t} & \equiv \frac{\phi\left[1-F\left(\omega_{t}^{B}\right)\right] \mathbb{E}\left(\omega \mid \omega \geq \omega_{t}^{B}\right)}{\phi\left[1-F\left(\omega_{t}^{B}\right)\right]+\frac{N_{t}+D_{t}}{N_{t}}\left[F\left(\omega_{t}^{B}\right)-F\left(\omega_{t}^{L}\right)\right]}+\frac{\frac{N_{t}+D_{t}}{N_{t}}\left[F\left(\omega_{t}^{B}\right)-F\left(\omega_{t}^{L}\right)\right] \mathbb{E}\left(\omega \mid \omega_{t}^{L} \leq \omega<\omega_{t}^{B}\right)}{\phi\left[1-F\left(\omega_{t}^{B}\right)\right]+\frac{N_{t}+D_{t}}{N_{t}}\left[F\left(\omega_{t}^{B}\right)-F\left(\omega_{t}^{L}\right)\right]} \\
Y_{t} & =C_{t}+I_{t}
\end{aligned}
$$

There are 35 equations and 35 endogenous variables: $Y_{t}, Q_{t}^{K}, I_{t}, C_{t}, K_{t}, N_{t}, W_{t}, L_{t}, \Lambda_{t, t+1}, M_{t}$, $\pi_{t}, p_{t}^{*}, \Xi_{t}^{1}, \Xi_{t}^{2}, \Delta_{t}, R_{t}^{A}, R_{t}^{k}, R_{t}^{L}, R_{t}^{B}, R_{t}^{D F}, R_{t}^{L F}, R_{t}^{G}, R_{t}^{D}, \Gamma_{t}^{B}, \Gamma_{t}^{L}, \Phi_{t}^{L}, \Phi_{t}^{B}, \varphi_{t}, \omega_{t}^{B}, \omega_{t}^{L}, b_{t}^{G, C B}, b_{t}^{G}$, $D_{t}, \Omega_{t}, Q_{t}^{G}$.

\section{B.2 Steady-state with zero inflation}

- Households

$$
\begin{aligned}
R^{L} & =\frac{1}{\beta}, \\
\Lambda & =\beta, \\
W & =\frac{v^{\prime}(L)}{u^{\prime}(C)}, \\
Q & =1, \\
I & =K[1-(1-\delta) \Omega] .
\end{aligned}
$$

- Firms

$$
\begin{aligned}
Y_{t} & =(\Omega K)^{\alpha} L^{1-\alpha}, \\
\Delta & =1, \\
p^{*} & =1, \\
\Xi^{1} & =\frac{\epsilon}{(\epsilon-1)(1-\theta \beta)} M Y, \\
\Xi^{2} & =\frac{Y}{(1-\theta \beta)}, \\
M & =\frac{(\epsilon-1)}{\epsilon}, \\
R^{k} & =\alpha M Z\left[\frac{(1-\alpha)(\epsilon-1) Z}{W \epsilon}\right]^{(1-\alpha) / \alpha}, \\
R^{A} & =R^{k}+(1-\delta), \\
L & =\left(\frac{(1-\alpha) Z(\epsilon-1)}{W \epsilon}\right)^{1 / \alpha} \Omega K .
\end{aligned}
$$


- Banks

$$
\begin{aligned}
K & =\left\{N \phi\left[1-F\left(\omega^{B}\right)\right]+(N+D)\left[F\left(\omega^{B}\right)-F\left(\omega^{L}\right)\right]\right\}, \\
N_{t} & =\varsigma\left[\begin{array}{c}
R^{A} \Omega K-R^{B} \Phi^{B}+ \\
R^{L} \Phi^{L}+R^{G} b^{G}-R^{D} D
\end{array}\right], \\
\omega^{B} & =\frac{R^{B}}{R^{A}}, \\
\omega^{L} & =\frac{1}{\beta R^{A}}, \\
R^{G} & =R^{L}, \quad\left(1-F\left(\omega^{B}\right)\right) R^{B}+F\left(\omega^{L}\right) R^{L}+ \\
R_{t}^{D} & =\left(F\left(\omega^{B}\right)-F\left(\omega^{L}\right)\right)\left(R^{A}(1+\pi) \mathbb{E}\left[\omega \mid \omega^{B}>\omega>\omega^{L}\right]\right)
\end{aligned} .
$$

- Interbank market

$$
\begin{aligned}
\Phi^{B} & =(N(\phi-1)-D)\left(1-F\left(\omega^{B}\right)\right) \\
\Phi^{L} & =(N+D) F\left(\omega^{L}\right)-b^{G} \\
\Gamma^{B} & =\Upsilon\left(\frac{\Phi^{L}}{\Phi^{B}}, 1\right) \\
\Gamma^{L} & =\Upsilon\left(1, \frac{\Phi^{B}}{\Phi^{L}}\right) \\
R^{B} & =\bar{R}-\Gamma^{B} \varphi \chi \\
R^{L} & =\bar{R}-\left(1-(1-\varphi) \Gamma^{L}\right) \chi \\
\varphi & =\frac{1}{\left(\Phi^{B} / \Phi^{L}\right)^{\lambda}+1}
\end{aligned}
$$

- Central bank

$$
\begin{aligned}
R^{L F} & =\bar{R}, \\
R^{D F} & =\bar{R}-\chi, \\
b^{G, C B}+b^{C B}+\Phi^{B}\left(1-\Gamma^{B}\right) & =\Phi^{L}\left(1-\Gamma^{L}\right), \\
b^{G, C B} & =\bar{b}^{G, C B} .
\end{aligned}
$$

- Government

$$
\begin{aligned}
\bar{b} & =b^{G, C B}+b^{G} \\
Q^{G} & =\frac{\zeta}{\left(\frac{1}{\beta}+\zeta-1\right)} .
\end{aligned}
$$


- Aggregate constraint

$$
\begin{aligned}
& \Omega= \begin{array}{c}
\phi[1-F(\omega)] \mathbb{E}\left(\omega \mid \omega \geq \omega^{B}\right) \\
\phi\left[1-F\left(\omega^{B}\right)\right]+\left[F\left(\omega^{B}\right)-F\left(\omega^{L}\right)\right](1+D / N)
\end{array} \\
& \frac{\left[F\left(\omega^{B}\right)-F\left(\omega^{L}\right)\right] \mathbb{E}\left(\omega \mid \omega^{L} \leq \omega<\omega^{B}\right)(1+D / N)}{\phi\left[1-F\left(\omega^{B}\right)\right]+\left[F\left(\omega^{B}\right)-F\left(\omega^{L}\right)\right](1+D / N)} \\
& Y=C+I .
\end{aligned}
$$

\section{Additional figures}
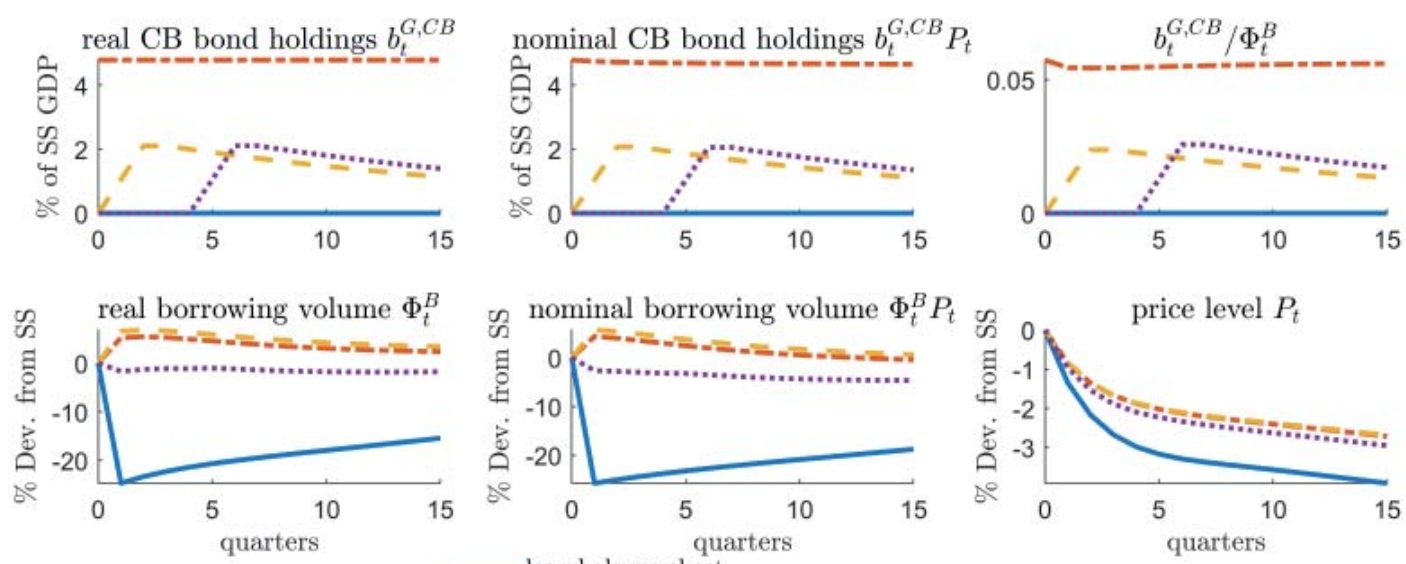

- lean balance sheet

- - lean balance sheet with temporary asset purchases

........ lean balance sheet with delayed temporary asset purchases

Figure 9: This figure shows the evolution of further variables in the experiments illustrated in figure 6. The purpose of this figure is to show that by controlling nominal bond holdings the central bank can implicitly control real bond holdings and the ratio $b_{t}^{G, C B} / \Phi_{t}^{B}$. In fact, movements in nominal bond holdings $b_{t}^{G, C B} P_{t}$ are translated almost proportionally into movements in $b_{t}^{G, C B} / \Phi_{t}^{B}$. Notice that for this ratio the price level plays no role. Hence any deviation from a proportional adjustement is due to movements in $\Phi_{t}^{B}$. However, for our calibration the movements of $\Phi_{t}^{B}$, which arise in general equilibrium, are relatively small. 


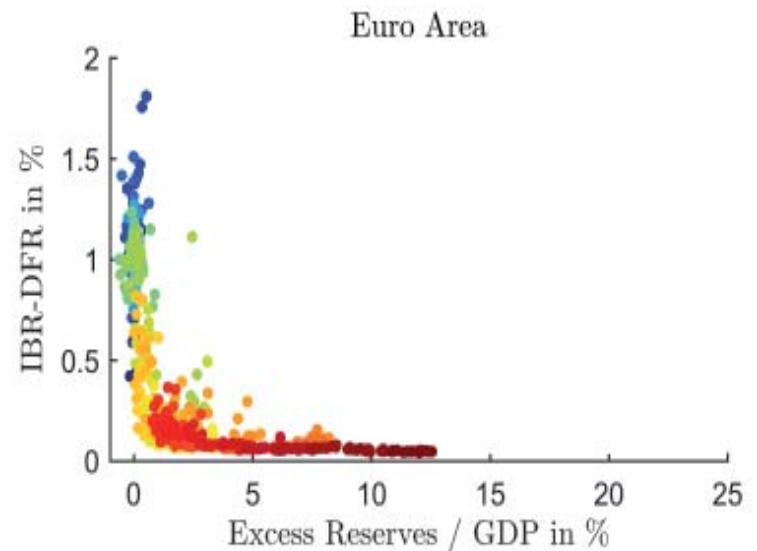

US

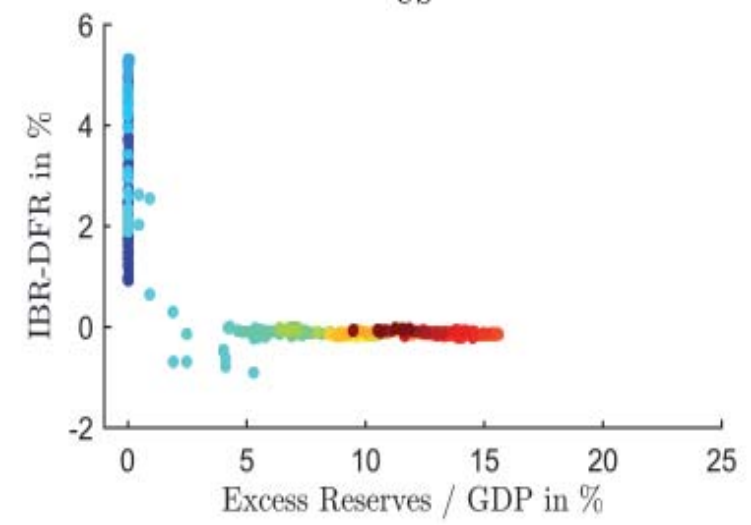

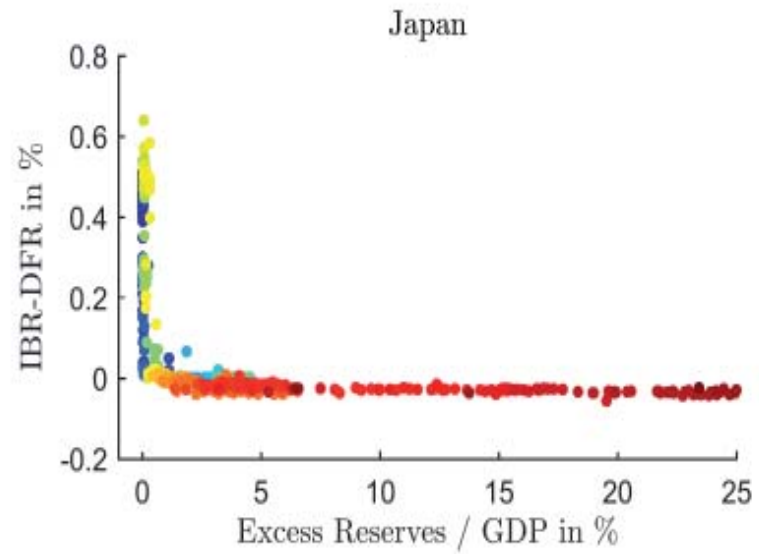

UK

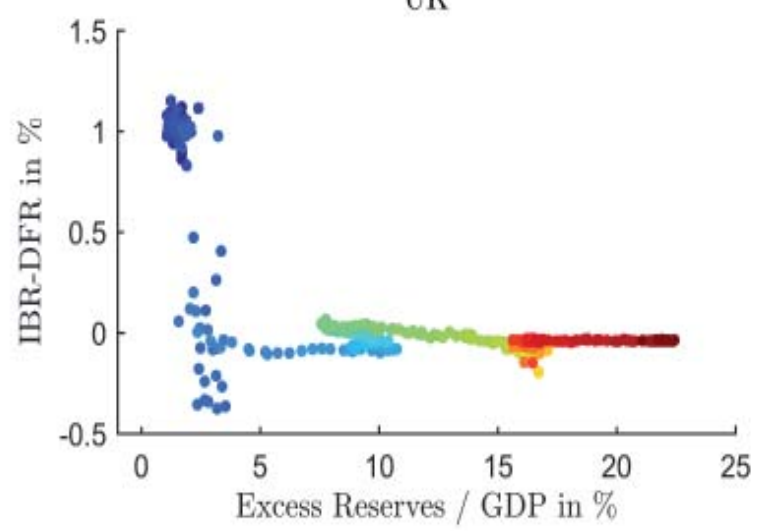

Figure 10: This figure shows the relationship between the interbank-deposit facility rate spread and the amount of excess reserves for 4 major currency areas. It documents that similar relationships between excess reserves and the interbank-DFR spread hold in the Eurozone, the US, Japan and the UK. The plot for Japan is cut at 25\% (2009) for better visual comparability. For the US we report the spread between the Fed funds rate and the interest rate on excess reserves. Note that the Fed did not pay any interest on excess reserves prior to 2008. We plot data since 1999. For Japan we show the spread between the Japan Uncollateralized Overnight rate and the interest on excess reserves, which was introduced only in 2008. We use data from 1997 untill 2016, when the BoJ changed its operational framework and introduced a 3 tier reserve remuneration system. This sample includes Japans first experiement with balance sheet expansion 2002-2006. The plot for Japan is cut at 25\% (2009) for better visual comparability. For the UK we report the spread between the SONIA and the interest rate on reserves (there is no reserve requirement). We plot data since the monetary policy framework change of 2006. The data is weekly and is taken from datastream. GDP is linearly interpolated based on quarterly data. Reserves for Japan before 2006 are interpolated based on monthly data. Colours indicate time from the beginning of each sample (blue) to the end (red). Notice that for all countries but the Euro zone the interbank-DFR spread did actually become slightly negative due to the fact that there are some agents in the respective money markets that do not have access to the deposit facility, a detail that we abstacted from in the model. 


\section{Data}

To derive the stylized balance sheet structure, which serves as a target in our calibration, we use public data from the ECB on the "aggregate balance sheet of the MFI sector". This data set documents the aggregate composition of the balance sheet of all monetary and financial institutions in the euro area at monthly frequency. Furthermore, we added data on reserves from the ECB's "daily liquidity conditions" dataset. We focus on post-euro pre-crisis data (1999-2007) and average the monthly data across time.

To derive our stylized balance sheet, we treat the different asset and liability classes as follows: On the asset side we abstract from $0.7 \%$ of reserves (most of which arerequired reserves). Claims on the private sector are the sum of loans and securities with private, non-MFI counterparties plus investment fund shares, equity, nonfinancial assets and remaining liabilities (for the latter 4 categories there is no information about counterparties). Claims on the government are loans and securities with the government counterparties. To calculate interbank claims we use loans and securities with the MFI non central bank counterparties. However this series includes intra-group positions. A series net of intra-group positions is available only from 2014, but not for our sample period. Therefore we adjust the series including intra-group positions by a factor reflecting the average share of non-intra-group claims from 2014 till 2018. On the liabilities side we abstract from $1.3 \%$ liabilities to the central bank, mainly MROs and from $10 \%$ of "remaining liabilities" which we can't clasify. As deposits we define the sum of deposits with counterparts other than MFIs, plus securities, which are not liabilities to other MFIs, according to information from the asset side. Equity corresponds to capital and reserves. The remaining types of liabilities should correspond to interbank liabilities, however, since they do not add up exactly to the same number as for the asset side, we disregard them. To arrive to the liabilities side of the balance sheet in the text, we set the interbank liabilities equal to interbank assets, and divide the rest of the liabilities side such as to match the ratio of equity to deposits, as defined above.

For figures 1 and 4, we combine the "daily liquidity conditions" dataset with quartely data on Euro area GDP and daily policy and EUREPO rates. All data are from the ECB. The data is aggregated at weekly frequency. GDP is interpolated for this purpose. 


\title{
BANCO DE ESPAÑA PUBLICATIONS
}

\author{
WORKING PAPERS
}

1801 OLYMPIA BOVER, LAURA HOSPIDO and ERNESTO VILLANUEVA: The impact of high school financial education on financial knowledge and choices: evidence from a randomized trial in Spain.

1802 IGNACIO HERNANDO, IRENE PABLOS, DANIEL SANTABÁRBARA and JAVIER VALLÉS: Private Saving. New CrossCountry Evidence Based on Bayesian Techniques.

1803 PABLO AGUILAR and JESÚS VÁZQUEZ: Term structure and real-time learning.

1804 MORITZ A. ROTH: International co-movements in recessions.

1805 ANGELA ABBATE and DOMINIK THALER: Monetary policy and the asset risk-taking channel.

1806 PABLO MARTÍN-ACEÑA: Money in Spain. New historical statistics. 1830-1998.

1807 GUILHERME BANDEIRA: Fiscal transfers in a monetary union with sovereign risk.

1808 MIGUEL GARCÍA-POSADA GÓMEZ: Credit constraints, firm investment and growth: evidence from survey data.

1809 LAURA ALFARO, MANUEL GARCÍA-SANTANA and ENRIQUE MORAL-BENITO: On the direct and indirect real effects of credit supply shocks.

1810 ROBERTO RAMOS and CARLOS SANZ: Backing the incumbent in difficult times: the electoral impact of wildfires.

1811 GABRIEL JIMÉNEZ, ENRIQUE MORAL-BENITO and RAQUEL VEGAS: Bank lending standards over the cycle: the role of firms' productivity and credit risk.

1812 JUAN S. MORA-SANGUINETTI and ROK SPRUK: Industry vs services: do enforcement institutions matter for specialization patterns? Disaggregated evidence from Spain.

1813 JAMES CLOYNE, CLODOMIRO FERREIRA and PAOLO SURICO: Monetary policy when households have debt: new evidence on the transmission mechanism

1814 DMITRI KIRPICHEV and ENRIQUE MORAL-BENITO: The costs of trade protectionism: evidence from Spanish firms and non-tariff measures.

1815 ISABEL ARGIMÓN, CLEMENS BONNER, RICARDO CORREA, PATTY DUIJM, JON FROST, JAKOB DE HAAN, LEO DE HAAN and VIKTORS STEBUNOVS: Financial institutions' business models and the global transmission of monetary policy.

1816 JOSE ASTURIAS, MANUEL GARCÍA-SANTANA and ROBERTO RAMOS: Competition and the welfare gains from transportation infrastructure: evidence from the Golden Quadrilateral of India.

1817 SANDRA GARCÍA-URIBE: Multidimensional media slant: complementarities in news reporting by US newspapers.

1818 PILAR CUADRADO, AITOR LACUESTA, MARÍA DE LOS LLANOS MATEA and F. JAVIER PALENCIA-GONZÁLEZ: Price strategies of independent and branded dealers in retail gas market. The case of a contract reform in Spain.

1819 ALBERTO FUERTES, RICARDO GIMENO and JOSÉ MANUEL MARQUÉS: Extraction of inflation expectations from financial instruments in Latin America.

1820 MARIO ALLOZA, PABLO BURRIEL and JAVIER J. PÉREZ: Fiscal policies in the euro area: revisiting the size of spillovers.

1821 MARTA MARTÍNEZ-MATUTE and ALBERTO URTASUN: Uncertainty, firm heterogeneity and labour adjustments. Evidence from European countries.

1822 GABRIELE FIORENTINI, ALESSANDRO GALESI, GABRIEL PÉREZ-QUIRÓS and ENRIQUE SENTANA: The rise and fall of the natural interest rate.

1823 ALBERTO MARTÍN, ENRIQUE MORAL-BENITO and TOM SCHMITZ: The financial transmission of housing bubbles: evidence from Spain.

1824 DOMINIK THALER: Sovereign default, domestic banks and exclusion from international capital markets.

1825 JORGE E. GALÁN and JAVIER MENCÍA: Empirical assessment of alternative structural methods for identifying cyclical systemic risk in Europe.

1826 ROBERTO BLANCO and NOELIA JIMÉNEZ: Credit allocation along the business cycle: evidence from the latest boom bust credit cycle in Spain.

1827 ISABEL ARGIMÓN: The relevance of currency-denomination for the cross-border effects of monetary policy.

1828 SANDRA GARCÍA-URIBE: The effects of tax changes on economic activity: a narrative approach to frequent anticipations.

1829 MATÍAS CABRERA, GERALD P. DWYER and MARÍA J. NIETO: The G-20 regulatory agenda and bank risk.

1830 JACOPO TIMINI and MARINA CONESA: Chinese exports and non-tariff measures: testing for heterogeneous effects at the product level.

1831 JAVIER ANDRÉS, JOSÉ E. BOSCÁ, JAVIER FERRI and CRISTINA FUENTES-ALBERO: Households' balance sheets and the effect of fiscal policy. 
1832 ÓSCAR ARCE, MIGUEL GARCÍA-POSADA, SERGIO MAYORDOMO and STEVEN ONGENA: Adapting lending policies when negative interest rates hit banks' profits.

1833 VICENTE SALAS, LUCIO SAN JUAN and JAVIER VALLÉS: Corporate cost and profit shares in the euro area and the US: the same story?

1834 MARTÍN GONZÁLEZ-EIRAS and CARLOS SANZ: Women's representation in politics: voter bias, party bias, and electoral systems.

1835 MÓNICA CORREA-LÓPEZ and BEATRIZ DE BLAS: Faraway, so close! Technology diffusion and firm heterogeneity in the medium term cycle of advanced economies.

1836 JACOPO TIMINI: The margins of trade: market entry and sector spillovers, the case of Italy (1862-1913).

1837 HENRIQUE S. BASSO and OMAR RACHEDI: The young, the old, and the government: demographics and fiscal multipliers.

1838 PAU ROLDÁN and SONIA GILBUKH: Firm dynamics and pricing under customer capital accumulation.

1839 GUILHERME BANDEIRA, JORDI CABALLÉ and EUGENIA VELLA: Should I stay or should I go? Austerity, unemployment and migration.

1840 ALESSIO MORO and OMAR RACHEDI: The changing structure of government consumption spending.

1841 GERGELY GANICS, ATSUSHI INOUE and BARBARA ROSSI: Confidence intervals for bias and size distortion in IV and local projections - IV models.

1842 MARÍA GIL, JAVIER J. PÉREZ, A. JESÚS SÁNCHEZ and ALBERTO URTASUN: Nowcasting private consumption: traditional indicators, uncertainty measures, credit cards and some internet data.

1843 MATÍAS LAMAS and JAVIER MENCÍA: What drives sovereign debt portfolios of banks in a crisis context?

1844 MIGUEL ALMUNIA, POL ANTRÀS, DAVID LÓPEZ-RODRÍGUEZ and EDUARDO MORALES: Venting out: exports during a domestic slump.

1845 LUCA FORNARO and FEDERICA ROMEI: The paradox of global thrift.

1846 JUAN S. MORA-SANGUINETTI and MARTA MARTÍNEZ-MATUTE: An economic analysis of court fees: evidence from the Spanish civil jurisdiction.

1847 MIKEL BEDAYO, ÁNGEL ESTRADA and JESÚS SAURINA: Bank capital, lending booms, and busts. Evidence from Spain in the last 150 years.

1848 DANIEL DEJUÁN and CORINNA GHIRELLI: Policy uncertainty and investment in Spain.

1849 CRISTINA BARCELÓ and ERNESTO VILLANUEVA: The risk of job loss, household formation and housing demand: evidence from differences in severance payments.

1850 FEDERICO TAGLIATI: Welfare effects of an in-kind transfer program: evidence from Mexico.

1851 ÓSCAR ARCE, GALO NUÑO, DOMINIK THALER and CARLOS THOMAS: A large central bank balance sheet? Floor vs corridor systems in a New Keynesian environment.

\begin{tabular}{|r|c|}
\hline BANCODE ESPANA & $\begin{array}{l}\text { Unidad de Servicios Auxiliares } \\
\text { Alcalá, 48 - 28014 Madrid } \\
\text { E-mail: publicaciones@bde.es } \\
\text { www.bde.es }\end{array}$ \\
\hline
\end{tabular}

